\title{
EMERGING FACTORS ASSOCIATED WITH THE DECLINE OF A GRAY FOX POPULATION AND MULTI-SCALE LAND COVER ASSOCIATIONS OF MESOPREDATORS IN THE CHICAGO METROPOLITAN AREA
}

\author{
A Thesis \\ Presented in Partial Fulfillment of the Requirements for \\ the Degree Master of Science in the \\ Graduate School of the Ohio State University
}

By

Alison N. Willingham, B.S.

$* * * * *$

The Ohio State University 2008

Master's Examination Committee:

Dr. Stanley D. Gehrt, Advisor

Dr. Robert J. Gates

Dr. Charles Goebel

Dr. Suzanne Prange

Approved by

Advisor

Graduate Program in Natural Resources 



\begin{abstract}
Statewide surveys of furbearers in Illinois indicate gray (Urocyon cinereoargenteus) and red (Vulpes vulpes) foxes have experienced substantial declines in relative abundance, whereas other species such as raccoons (Procyon lotor) and coyotes (Canis latrans) have exhibited dramatic increases during the same time period. The cause of the declines of gray and red foxes has not been identified, and the current status of gray foxes remains uncertain. Therefore, I conducted a large-scale predator survey and tracked radiocollared gray foxes from 2004 to 2007 in order to determine the distribution, survival, cause-specific mortality sources and land cover associations of gray foxes in an urbanized region of northeastern Illinois, and examined the relationships between the occurrence of gray fox and the presence other species of mesopredators, specifically coyotes and raccoons.
\end{abstract}

Although generalist mesopredators are common and can reach high densities in many urban areas their urban ecology is poorly understood due to their secretive nature and wariness of humans. Understanding how mesopredators utilize urbanized landscapes can be useful in the management and control of disease outbreaks, mitigation of nuisance wildlife issues, and gaining insight into how mesopredators shape wildlife communities in highly fragmented areas. I examined habitat associations of raccoons, opossums (Didelphis virginiana), domestic cats (Felis catus), coyotes, foxes (gray and red), and striped skunks (Mephitis mephitis) at multiple spatial scales in an urban environment. 
Gray fox occurrence was rare and widely dispersed, and survival estimates were similar to other studies. Gray fox occurrence was negatively associated with natural and semi-natural land cover types. Fox home range size increased with increasing urban development suggesting that foxes may be negatively influenced by urbanization. Gray fox occurrence was not associated with coyote or raccoon presence. However, spatial avoidance and mortality due to coyote predation was documented and disease was a major mortality source for foxes. The declining relative abundance of gray fox in Illinois is likely a result of a combination of factors.

Assessment of habitat associations indicated that urban mesopredators, particularly coyotes and foxes, perceived the landscape as relatively homogeneous and that urban mesopredators interacted with the environment at scales larger than that accommodated by remnant habitat patches. Coyote and fox presence was found to be associated with a high degree of urban development at large and intermediate spatial scales. However, at a small spatial scale fox presence was associated with high density urban land cover whereas coyote presence was associated with urban development with increased forest cover. Urban habitats can offer a diversity of prey items and anthropogenic resources and natural land cover could offer coyotes daytime resting opportunities in urban areas where they may not be as tolerated as smaller foxes. 
Raccoons and opossums were found to utilize moderately developed landscapes with interspersed natural and semi-natural land covers at a large spatial scale, which may facilitate dispersal movements. At intermediate and small spatial scales, both species were found to utilize areas that were moderately developed and included forested land cover. These results indicated that raccoons and opossums used natural areas in proximity to anthropogenic resources.

At a large spatial scale, skunk presence was associated with highly developed landscapes with interspersed natural and semi-natural land covers. This may indicate that skunks perceived the urban matrix as more homogeneous than raccoons or opossums. At an intermediate spatial scale skunks were associated with moderate levels of development and increased forest cover, which indicated that they might utilize natural land cover in proximity to human-dominated land cover. At the smallest spatial scale skunk presence was associated with forested land cover surrounded by a suburban matrix. Compared to raccoons and opossums, skunks may not be tolerated in close proximity to human development in urban areas.

Domestic cat presence was positively associated with increasingly urbanized and less diverse landscapes with decreased amounts of forest and urban open space at the largest spatial scale. At an intermediate spatial scale, cat presence was associated with a moderate degree of urban development characterized by increased forest cover, and at a small spatial scale cat presence was associated with a high degree of urbanization. Free- 
ranging domestic cats are often associated with human-dominated landscapes and likely utilize remnant natural habitat patches for hunting purposes, which may have implications for native predator and prey species existing in fragmented habitat patches in proximity to human development. 


\section{ACKNOWLEDGMENTS}

I would like to thank my funding sources, the Illinois Department of Natural Resources, and the Forest Preserve District of Cook County for their financial support. I would like to thank the Max McGraw Wildlife Foundation for the use of their trucks, housing facilities, and office space. I would like to thank the Max McGraw Wildlife Foundation, the Forest Preserve Districts of Cook County, Lake County and DuPage County, the McHenry County Conservation District, Fermi National Accelerator Laboratory, Homewood Izaak Walton Preserve, and several private landowners for allowing me access to their properties.

I would like to thank my advisor, Dr. Stanley Gehrt for providing me with guidance and an opportunity to work on a very interesting, and often challenging, graduate project. To my entire committee, Dr. Stanley Gehrt, Dr. Robert Gates, Dr. Charles Goebel, and Dr. Suzanne Prange, thank you for your editorial and statistical support. Thank you to Chris Anchor and Chuck Rizzo of the Forest Preserve District of Cook County for all of the hard work and time that you invested in my project.

I could not have completed my project without the help and support of my fellow graduate students, in particular Stephanie Hauver, Bill Graser and Ashley Buchanan, who often lent a sympathetic ear or words of advice. I would like to thank all of the research 
technicians at the Max McGraw Wildlife Foundation who helped with my work. I would also like to thank my family for their support and I apologize for any worry I might have caused by staying out all night trapping and tracking animals.

Lastly, I would like to thank Justin Brown who was a constant help and support throughout my graduate work. Thank you for sleeping in trucks with me, walking through the woods at ridiculous hours of the night to check traps, carrying heavy batteries, helping with radio telemetry, running scent stations....the list could go on and on. I truly could not have done it without you. 
VITA

September 2005 - December 2008 ....Graduate Research Assistant, The Ohio State University, Columbus, Ohio

March 2005 - September 2005 ..........Coyote Research Technician, The Ohio State University, Columbus, Ohio

September 2004 - February 2005 ......Raccoon Research Technician, The Ohio State University, Columbus, Ohio

March 2004 - September 2004 ..........Coyote Research Technician, The Ohio State University, Columbus, Ohio

March 2004 ....................................B.S. Biology, California State University Bakersfield, Bakersfield, California

August 2003 - January 2004 .............Botany Intern, USDA Forest Service, Porterville, CA

February 2003 - July 2003 ...............Field Biologist, California State University Bakersfield, Bakersfield, California

November 2002- February 2003 ........Environmental Consultant, Lawler and Associates Applied Geoscience, Bakersfield, California

\section{FIELDS OF STUDY}

Major Field: Natural Resources 
TABLE OF CONTENTS

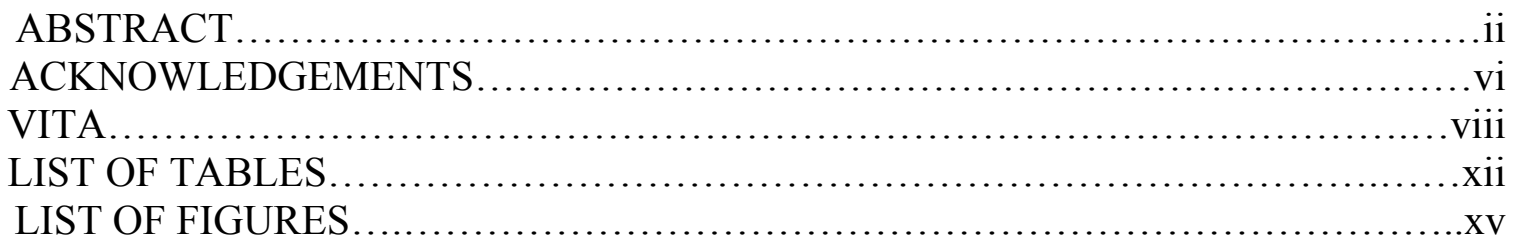

Chapter:

1 EMERGING FACTORS CONTRIBUTING TO A GRAY FOX POPULATION DECLINE IN ILLINOIS: DISTRIBUTION, SURVIVAL, LAND COVER ASSOCIATIONS, AND RELATIONSHIPS WITH SYMPATRIC

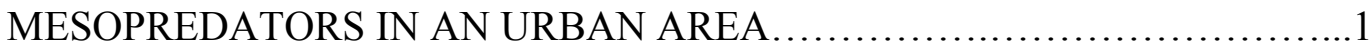

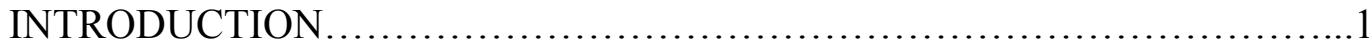

Effects of Urban Development..................................... 3

Intraguild Competition with Coyotes.....................................4

Interspecific Relationship with Raccoons........................... 8

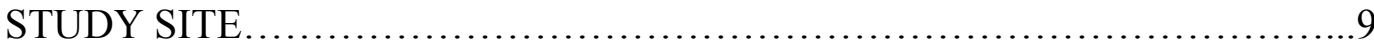

METHODS................................................................ 11

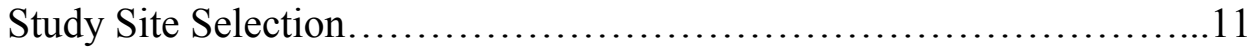

Field Surveys.....................................................

Trapping / Radio Telemetry........................................

Analysis......................................................... 15

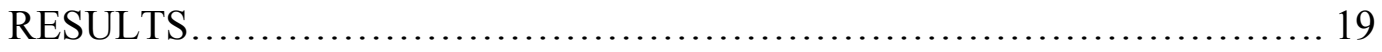

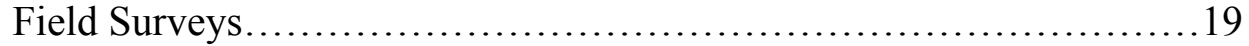

Trapping / Radio Telemetry ......................................20

Analysis....................................................... 20

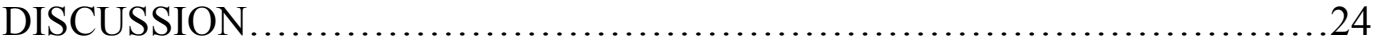

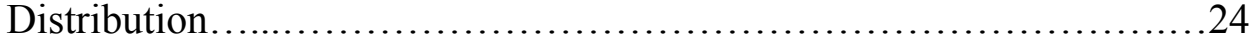

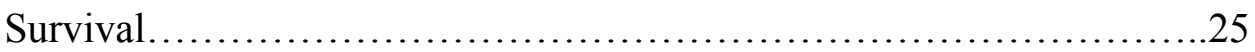

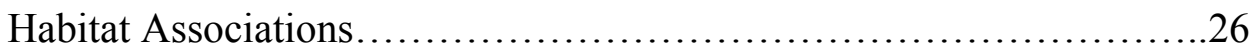

ix 
Intraguild Competition with Coyotes..............................27

Interspecific Interactions with Raccoons...........................29

Limitations on Inference......................................... 30

Recommendations................................................. 31

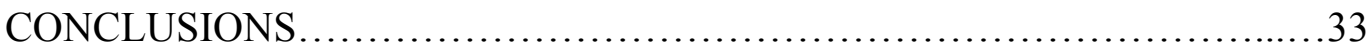

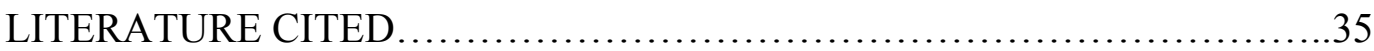

2 MULTI-SCALE LAND COVER ASSOCIATIONS OF MESOPREDATORS IN AN URBANIZED LANDSCAPE ....................................64

INTRODUCTION ...................................................64

Land Cover Associations of Urban Mammalian Mesopredators..........67

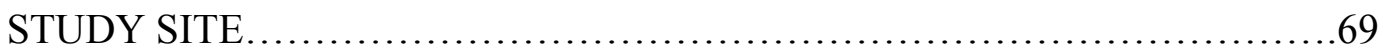

METHODS ......................................................... 70

Study Site Selection.......................................... 70

Field Surveys..................................................71

Multi-scale Landscape Characteristics................................. 73

Environmental Predictor Variables.................................. 75

Species Data....................................................... 79

Analysis of Species Occurrence and Landscape Data..................80

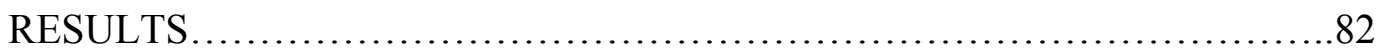

Field Surveys.................................................. 82

Analysis of Species Occurrence and Landscape Data..................83

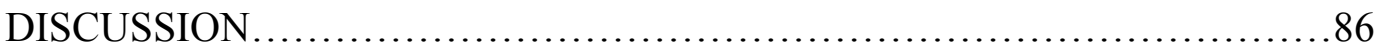

Land Cover Associations of Coyotes.................................... 86

Land Cover Associations of Foxes...................................8 89

Land Cover Associations of Raccoons and Opossums....................90

Land Cover Associations of Striped Skunks............................ 92

Land Cover Associations of Domestic Cats..............................994

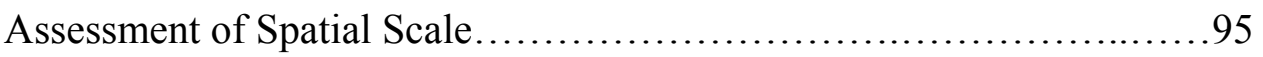

Limitation on Inference..........................................96

CONCLUSIONS........................................................... 98 


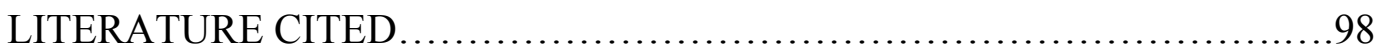

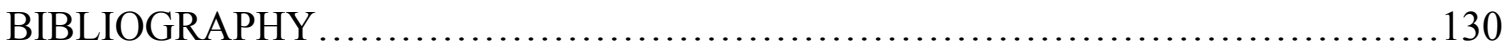

APPENDICES:

A. RESULTS OF SCENT STATION SURVEYS FROM 96 STUDY

SITES .............................................................141

B. RESULTS OF SCENT STATION SURVEYS FROM 72 UNIQUE LANDSCAPES COMPOSED OF THE STUDY SITE PLUS 1-KM BUFFER AROUND THE STUDY SITE ..............................145

C. RESULTS OF SCENT STATION SURVEYS FROM 21 UNIQUE LANDSCAPES COMPOSED OF THE STUDY SITE PLUS 5-KM BUFFER AROUND THE STUDY SITE 


\section{LIST OF TABLES}

Table:

1.1 Amount of publicly owned land held as preserves and populations for each county (Openlands Project 2006)....

1.2 Status of land cover in northeastern Illinois (Openlands Project 1999).

'Built up' includes already developed land, 'At Risk' includes land at risk of being developed in 10-30 years, 'Perm. Open Space' includes county forest preserves and 'Low Risk' includes land uses such as golf courses and cemeteries

1.3 Original and reclassified land cover values derived from the Illinois GAP data

1.4 Complete suite of untransformed covariables considered for logistic regression modeling of fox (gray fox [Urocyon cinereoargenteus] and red fox [Vulpes vulpes] combined) occurrence in northeastern Illinois from 2005-2007.

1.5 Transformed covariables used for logistic regression modeling of fox (gray fox [Urocyon cinereoargenteus] and red fox [Vulpes vulpes] combined) occurrence in northeastern Illinois from 2005-2007.

1.6 Capture information, home range estimates and status of collared gray (Urocyon cinereoargenteus) and red (Vulpes vulpes) foxes in northeastern Illinois from 2006-2007.

1.7 Percent habitat types in 95\% MCP home ranges of collared foxes. ** indicates the highest percentage for each respective home range. 'Med Urb'=Medium Density Urban, 'Urb Open'=Urban Open Space, 'High Urb'=High Density Urban, 'Low Urb'=Low Density Urban, 'Water'=Surface Water, 'Ag'=Agriculture, 'Barren'=Barren Exposed Land

1.8 Table 1.8. Model selection results for 37 models of fox occurrence (gray fox [Urocyon cinereoargenteus] and red fox [Vulpes vulpes] combined) in northeastern Illinois from 2005-2007. Models were ranked by $\mathrm{AIC}_{\mathrm{C}} . \Delta \mathrm{AIC}_{\mathrm{C}}$ 
is the difference in $\mathrm{AIC}_{\mathrm{C}}$ units from the highest ranking model. Number of parameters $(\mathrm{K})$, model $\mathrm{AIC}_{\mathrm{C}}$ weights $\left(\mathrm{w}_{\mathrm{i}}\right)$, and evidence ratios (evid.rat) are also shown. Coding and explanation of model parameters are shown in Table 1.5 .

1.9 Cumulative $\mathrm{AIC}_{\mathrm{C}}$ weight $\left(\Sigma \mathrm{w}_{\mathrm{i}}\right)$ of most common parameters in top ranked models $\left(\mathrm{w}_{\mathrm{i}}>0.04\right)$ for gray fox presence. Coding and explanation of model parameters are provided in Table 1.5

1.10 Covariate $\left(\beta_{\mathrm{i}}\right)$ and odds ratio $(\mathrm{OR})$ estimates under top ten logistic regression models $\left(\mathrm{AIC}_{\mathrm{C}}\right.$ weight $\left.\left[\mathrm{w}_{\mathrm{i}}\right]>0.04\right)$ for fox occurrence (gray fox [Urocyon cinereoargenteus] and red fox [Vulpes vulpes] combined) in northeastern Illinois from 2005-2007. Models were ranked by $\mathrm{AIC}_{\mathrm{C}} . \Delta \mathrm{AIC}_{\mathrm{C}}$ is the difference in $\mathrm{AIC}_{\mathrm{C}}$ units from the highest ranking model. Number of parameters $(\mathrm{K})$, model $\mathrm{AIC}_{\mathrm{C}}$ weights, standard errors of covariates $(\mathrm{SE})$, and $95 \%$ confidence intervals of covariates ( $\beta$ 95\% CI) and odds ratios (OR 95\% CI) are also shown. Coding and explanation of model parameters are shown in Table 1.5 .

1.11 Optimum number of surveys per site when sites are surveyed an equal number of times using estimates of occupancy and detectability. 'Occupancy $(\Psi)$ '= probability of a site being occupied, ' $p$ '= probability of detecting the species in site (MacKenzie and Royle 2005)....

2.1 Amount of publicly owned land held as preserves and populations for each county (Openlands Project 2006).

2.2 Status of land cover in northeastern Illinois (Openlands Project 1999).

'Built up' includes already developed land, 'At Risk' includes land at risk of being developed in 10-30 years, 'Perm. Open Space' includes county forest preserves and 'Low Risk' includes land uses such as golf courses and cemeteries

2.3 Original and reclassified land cover values derived from the Illinois GAP data 
2.4 Description of environmental predictor variables used in smallest (SS) spatial scale partial redundancy analysis to determine land cover associations of mammalian mesopredators in the Chicago metropolitan area from 2005-2007.

2.5 Description of environmental predictor variables used in intermediate (L1) spatial scale partial redundancy analysis to determine land cover associations of mammalian mesopredators in the Chicago metropolitan area from 2005-2007.

2.6 Description of all environmental predictor variables used in largest (L2) spatial scale partial redundancy analysis to determine land cover associations of mammalian mesopredators in the Chicago metropolitan area from 2005-2007. 'Land cover classes' indicates all land cover classes for which a respective metric was derived........................................................... 114

2.7 Results of data reduction step at largest (L2) spatial scale, in which environmental predictor variables were grouped according to correlation coefficients. 'Relationship' indicates the direction of the correlation relative to the representative variable. 'Description' indicates general characteristics of each group of variables

2.8 Description of final set of environmental predictor variables, after data reduction steps, used in largest (L2) spatial scale partial redundancy analysis to determine land cover associations of mammalian mesopredators in the Chicago metropolitan area from 2005-2007. 'Land cover classes' indicates all land cover classes for which a respective metric was derived

2.9 Correlation matrix from smallest (SS) spatial scale partial redundancy analysis for environmental predictor variables and ordination axes. Description and coding of environmental variables can be found in Table $2.5 \ldots \ldots \ldots \ldots \ldots \ldots \ldots . . . . .121$

2.10 Correlation matrix from intermediate (L1) spatial scale partial redundancy analysis for environmental predictor variables and ordination axes. Description and coding of environmental variables can be found in Table 2.6

2.11 Correlation matrix from largest (L2) spatial scale partial redundancy analysis for environmental predictor variables and ordination axes. Description and coding of environmental variables can be found in Table 2.8 . 


\section{LIST OF FIGURES}

Figure:

1.1 Illinois Archery Deer Hunter Survey results from 1992-2005. Data points represent the number of sightings (per 1000 hunting hours) of red (Vulpes vulpes) and gray (Urocyon cinereoargenteus) fox (Bluett 2006)

1.2 Land cover map of northeastern Illinois (Under Pressure Map, Openlands Project 1999).

1.3 Distribution of scent station surveys conducted from 2005-2007 in northeastern Illinois. Red dots indicate scent station placement across the landscape

1.4 Distribution of gray fox (Urocyon cinereoargenteus) from surveys conducted between 2005-2007 in the northeastern Illinois. Yellow stars indicate sites with confirmed gray fox presence.

1.5 Annual home ranges of fox ID 6 (purple) and fox ID 7 (red) in 2006 (A) and 2007 (B). Home ranges are placed over a modified version of the Illinois GAP land cover layer (Table 1.3) in order to determine the composition of each home range. The foxes primarily used the Thorn Creek Forest Preserve and surrounding areas in 2006 and moved to residential yards in Homewood, IL in 2007

1.62006 (dark blue) and 2007 (red) home range estimates of fox ID 5. Home ranges are placed over a modified version of the Illinois GAP land cover layer (Table 1.3) in order to determine the composition of each home range. The activity of this fox was completely encompassed by the boundary walls of an urban

cemetery

1.7 Solid line indicates the predicted probability of fox occurrence using modelaveraged parameter for 'Square root of Percent of Urban Wetland' from candidate set of logistic regression models ranked by $\mathrm{AIC}_{\mathrm{C}}$. The probability of 
fox occurrence was calculated holding all variables constant while allowing the square root of the percent of wetland to vary. Dashed lines indicate upper and lower 95\% confidence intervals. Open circles indicate original data points.

1.8 Solid line indicates the predicted probability of fox occurrence using modelaveraged parameter for 'Square root of Percent of Forest' from candidate set of models ranked by $\mathrm{AIC}_{\mathrm{C}}$. The probability of fox occurrence was calculated holding all variables constant while allowing the square root of the percent of forest to vary. Dashed lines indicate upper and lower 95\% confidence intervals. Open circles indicate original data points.

1.9 Solid line indicates the predicted probability of fox occurrence using modelaveraged parameter for 'Fourth root of Percent of Agriculture' from candidate set of models ranked by $\mathrm{AIC}_{\mathrm{C}}$. The probability of fox occurrence was calculated holding all variables constant while allowing the fourth root of the percent of agriculture to vary. Dashed lines indicate upper and lower $95 \%$ confidence intervals. Open circles indicate original data points.

1.10 Solid line indicates the predicted probability of fox occurrence using modelaveraged parameter for 'Square root of Percent of Urban Open Space' from candidate set of models ranked by $\mathrm{AIC}_{\mathrm{C}}$. The probability of fox occurrence was calculated holding all variables constant while allowing the square root of the percent of urban open space to vary. Dashed lines indicate upper and lower 95\% confidence intervals. Open circles indicate original data points.

2.1 Land cover map of northeastern Illinois (Under Pressure Map, Openlands Project 1999).

2.2 Example of three spatial scales used to assess land cover associations of mammalian mesopredators in the Chicago metropolitan area from 2005-2007. 'SS' indicates the smallest site-level scale, 'L1' indicated the intermediate landscape scale which consists of the study site plus a $1 \mathrm{~km}$ buffer, and 'L2' indicates the largest landscape scale which consists of the study site plus a 5 $\mathrm{km}$ buffer.

2.3 Distribution of scent station surveys conducted from 2005-2007 in northeastern Illinois. Red dots indicate scent station placement across the landscape. 
2.4 Ordination biplot of first and second axes of pRDA at smallest (SS) spatial scale describing association of mammalian mesopredators with environmental predictor variables in the Chicago metropolitan area from 2005-2007. Angles between respective species arrows and other species or environmental arrows indicate the correlation value. The length of arrows indicates the correlation strength with the ordination axes. Explanation of coding of environmental variables can be found in Table 2.5

2.5 Variance partitioning results of partial redundancy analysis at smallest (SS) spatial scale. Reported variance fractions are adjusted $R^{2}$ values

2.6 Ordination biplot of first and second axes of partial redundancy analysis at intermediate (L1) spatial scale describing the association of mammalian mesopredators with environmental predictor variables in the Chicago metropolitan area from 2005-2007. Angles between respective species arrows and other species or environmental arrows indicate the correlation value. The length of arrows indicates the correlation strength with the ordination axes. Explanation of coding of environmental variables can be found in Table 2.6

2.7 Results of variance partitioning procedure for partial redundancy analysis at intermediate (L1) spatial scale. Reported variance fractions are adjusted $R^{2}$ values

2.8 Ordination biplot of first and second axes of partial redundancy analysis at largest (L2) spatial scale describing association between mammalian mesopredators and environmental predictor variables in the Chicago metropolitan area from 2005-2007. Angles between respective species arrows and other species or environmental arrows indicate the correlation value. The length of arrows indicates the correlation strength with the ordination axes. Explanation of coding of environmental variables can be found in Table 2.8

2.9 Results of variance partitioning procedure for partial redundancy analysis at the largest (L2) spatial scale. Reported variance fractions are adjusted $R^{2}$ values 


\section{CHAPTER 1}

\section{EMERGING FACTORS CONTRIBUTING TO A GRAY FOX POPULATION DECLINE IN ILLINOIS: DISTRIBUTION, SURVIVAL, LAND COVER ASSOCIATIONS, AND RELATIONSHIPS WITH SYMPATRIC MESOPREDATORS IN AN URBAN AREA}

\section{INTRODUCTION}

The gray fox (Urocyon cinereoargenteus) is a furbearing species, which is widely distributed throughout North America and northern South America, from southern Canada to northern Venezuela and Colombia (Fritzell 1987, Fritzell and Haroldson 1982). The species is often associated with woodland and shrubland habitats (Cypher 2003). In the past 50 years, the range of the gray fox has expanded along the northern borders and into the Great Plains (Fritzell and Haroldson 1982), probably due to fire suppression practices and changes in land uses such as increased agriculture (Fritzell 1987). Despite its widespread distribution, gray fox ecology is poorly understood relative to many of its North American canid counterparts, most likely due to low economic value and high densities of gray fox throughout much of their range (Cypher 2003). 
Recent trends in the Illinois Archery Deer Hunter Survey, which is a relatively unbiased indicator of large-scale trends in abundance for species difficult to census, indicates that relative abundances of both gray and red foxes (Vulpes vulpes) have declined steadily $([\mathrm{r}=-0.84$ and $\mathrm{r}=-0.86$, respectively]; Figure 1.1; Bluett 2006). In contrast, coyotes (Canis latrans; $\mathrm{r}=0.71$ ), raccoons (Procyon lotor; 0.73 ) and bobcats (Lynx rufus; $\mathrm{r}=0.82$ ) have increased during the same time interval. The overall sighting index in 2005 was only 0.62 for gray fox, which was lower than indices for other secretive carnivores such as red fox (3.62), bobcats (3.69), and coyotes (32.01). The factors driving this apparent decline in gray fox abundance have not been conclusively identified, as little research has been conducted on gray foxes inhabiting the Midwest.

Although the Archery Deer Hunter Survey is a useful tool with which to determine long-term trends in wildlife populations over large spatial scales, it may be more applicable to rural and undeveloped regions, where most hunting activity occurs. The survey may offer little information regarding gray fox populations existing within large metropolitan areas where hunting is often prohibited. Much of the gray fox research conducted thus far has focused on rural and undeveloped natural areas with high gray fox densities but in the face of widespread urbanization and development, it is important to determine the status of this species within urbanized areas.

While causes for the current gray fox population decline remain unknown, it has occurred steadily with increased urbanization and concurrently with increasing coyote and raccoon populations (Bluett 2006), which suggests that any one of these factors may have contributed to the decline. The gray fox, a species commonly associated with deciduous woodlands, may be negatively affected by changes in habitat that occur with 
urbanization, or increasing coyote and raccoon populations may be increasing pressure on gray foxes through interspecific competition. Although there is little research relating to competition between raccoons and foxes, coyotes have been documented to kill gray foxes, likely relating to the reduction of competition for resources. Dense populations of sympatric mesopredators such as raccoons and coyotes may act as vectors for disease, which could suppress the gray fox population. Any of these factors could affect gray fox survival, recruitment and/or the ability to find mates. It is the purpose of this study to determine the distribution and status of gray foxes in an urbanized region of northeastern Illinois and explore the ecological factors that may be contributing to their population decline.

Effects of Urban Development

Studies have shown urban development to have varied effects on gray fox populations. Gray foxes in New Mexico avoided high density subdivisions, suggesting that high density development might pose a higher risk for gray foxes (Harrison 1997). Road kill surveys in California suggested that carnivores were more likely to be found in rural than urban areas (Caro et al. 2000). Urban development may be a 'low quality habitat' and, in the case of gray foxes in New Mexico, there may be an upper limit to the amount of development that can be tolerated (Harrison 1997).

Conversely, gray foxes are known to utilize urbanized areas (Riley 2006), possibly as a means to avoid competitive interactions with coyotes (Gosselink et al. 2003). Small forested patches in urbanized landscapes may provide high quality habitat for foxes, whose home ranges and energetic demands are small enough to be 
accommodated by smaller tracts of land (Rosenblatt et al. 1999). Compared to gray foxes living in undeveloped areas, those occupying developed areas are heavier and consume a more diverse diet including higher amounts of mammalian and avian prey items (Harrison 1997, Cypher and Frost 1999). Moreover, urban red foxes have been found to act as a source population for rural red foxes (Gosselink et al. 2007). The availability of anthropogenic resources (e.g. denning sites, food) may benefit wildlife in urban areas (Fedriani et al. 2001), although anthropogenic food resources may have a negative impact on urban fox populations by encouraging coyote use (Cypher and Spencer 1998).

Despite evidence supporting the idea that urbanized areas benefit gray fox populations, there may be inherent costs associated with the use of human-dominated landscapes. In New Mexico, the shape of gray fox home ranges in urbanized areas were more complex than those in undeveloped areas, which may result in decreased foraging efficiency due to increased travel time (Harrison 1997). Furthermore, wildlife populations inhabiting urban areas may be characterized by higher incidents of mortality attributed to human-related causes such as traffic collisions (Riley 2006).

\section{Intraguild Competition with Coyotes}

Coyote populations throughout North America are expanding, perhaps originally due to the extirpation of wolves (Smith et al. 2003) and most recently due to increases in agricultural land use (Patterson and Messier 2001). Agricultural fields may support greater densities of prey species such as deer, rabbits and mice, as well as provide abundant seasonal food in the form of crops. Patterson and Messier (2001) found a positive correlation between coyote and prey abundance, suggesting that these areas may 
serve as high quality habitat for this behaviorally plastic carnivore. In Illinois, approximately $81 \%$ of the land is used for agricultural practices with $50 \%$ of that consisting of row crops (Rosenblatt et al. 1999). This shift in land use may be providing an abundant food source supporting increasing coyote populations. Most recently, coyotes have moved into urban areas (Gompper 2002), likely in response to the diversity and abundance of prey items and anthropogenic resources (Fedriani et al. 2001, Morey et al. 2007).

A gradient of intraguild competition has been reported between coyotes and gray foxes, as well as between coyotes and other species of fox. Some studies suggest that gray foxes may be well equipped to coexist with coyotes, primarily due to their omnivorous food habits, evasive tree-climbing behavior and seclusive nature (Sheldon 1949, Cypher 1993). Chamberlain and Leopold (2005) found that coyotes did not limit the distribution of gray foxes, as several were found living entirely within coyote home ranges; although foxes did avoid the core use areas of these territories. Gray foxes in California were found to use space in a way that was more influenced by resource distribution than by coyote distribution (Neale and Sacks 2001).

Other studies have documented negative relationships between coyotes and foxes (Sargeant et al. 1987, Crooks and Soule 1999, Fedriani et al. 2000). In one study, 92\% of all gray fox mortalities were attributed to larger predators, with $67 \%$ of those mortalities caused by coyotes (Farias et al. 2005). A kit fox (Vulpes macrotis) study determined that coyote predation accounted for $75.8 \pm 7.7 \%$ of mortality (Cypher and Spencer 1998). 
Fox mortalities in these studies most likely represent interference competition (a majority of carcasses in both cases were not consumed) and may be a mechanism by which coyotes reduce exploitative competition (Cypher and Spencer 1998, Farias et al. 2005).

The larger body size of the coyote may enable it to spatially exclude foxes from certain areas (Crooks and Soule 1999), and its energetic demands exceed that of the smaller foxes, requiring coyotes to maintain larger territories on higher quality patches of habitat (Crooks 2002). Coyote home ranges in North Dakota included large secluded patches of natural habitat, whereas red foxes used territories close to roads and humanuse areas with more cropland (Sargeant et al. 1987). An Illinois study reported that coyotes used cover-rich woodlands in rural areas that were distant from human activity, whereas red foxes selected rural residential areas, abandoned farmsteads and urban grasslands while strongly avoiding woodlands (Gosselink et al. 2003). Foxes may avoid negative interactions with coyotes by residing closer to humans, and coyotes may select areas far from human activity to avoid hostile interactions (Gosselink et al. 2003).

Spatial segregation may also be a result of resource partitioning, as foxes are able to exploit habitats of poorer quality due to lower energetic demands (Voigt and Earle 1983) and lower spatial requirements (Harrison et al. 1989). The higher energetic and spatial requirements of coyotes demand larger home ranges, often reaching sizes 3-7 times those of foxes (Voigt and Earle 1983, Sargeant et al. 1987, Harrison et al. 1989). Gray foxes in California exhibited patterns of spatial segregation with coyotes and a majority of gray fox mortalities occurred in the outer limits of their home ranges, where the probability of encountering a neighboring coyote increased (Farias et al. 2005). Similarly, red foxes have been found to occupy smaller territories adjacent to and 
between larger coyote home ranges, exhibiting spatial avoidance of competitive interactions (Voigt and Earle 1983, Sargeant et al. 1987, Harrison et al 1989). If interspecific territoriality is a driving force behind coyote and fox distributions, larger coyote territories may limit the number of foxes that can inhabit an area (Voigt and Earle 1983). As coyote numbers increase and home ranges are established, foxes are likely to adjust their territory boundaries in order to avoid competitive interactions with coyotes (Sargeant et al. 1987).

High dietary overlap may contribute to the complexity of canid interactions. The flexible foraging habits of canids in particular can lead to dietary overlap between species and complicated trophic interactions (Cypher 2003, Lavin et al. 2003). Although North American canids fill similar dietary niches, diets of coyotes and red foxes tend to be more similar than the diet of gray foxes, suggesting that competition for resources may be greatest between coyotes and red foxes (Cypher 1993). In southern Illinois both coyotes and red foxes consumed a greater proportion of rabbits than other food items, whereas gray foxes consumed more fruit (Cypher 1993). In California, however, both coyotes and gray foxes consumed fruit at high frequencies and gray foxes actually had a more narrow dietary breadth during summer and autumn than coyotes (Neale and Sacks 2001).

Competitive interactions are not restricted to those involving foxes and coyotes, as many studies have documented the occurrence of competition between sympatric species of foxes. The red fox is a species with a widespread distribution, which in many cases overlaps that of the gray fox. Similar food habits and body sizes may result in competitive interactions occurring between these two species. Gray foxes, however, are more omnivorous than red foxes (Hockman and Chapman 1983). The variation in diet 
could alleviate competition for resources and allow these species to coexist across much of their shared range. It has been suggested that gray foxes may have a competitive advantage over red foxes in regions where resources are scarce (Hockman and Chapman 1983). In Illinois, however, it is unlikely that competition with the red fox plays a significant role in the gray fox population decline, as the relative abundance of red fox is also declining (Figure 1.1).

Interspecific Relationship with Raccoons

High raccoon densities (Riley et al. 1998, Prange et al. 2003, Schubert 1998) can contribute to the spread of disease throughout wildlife communities in urban areas. Raccoons are known carriers of canine distemper virus (CDV; Hoff et al. 1974), which is highly fatal in gray foxes. A major source of gray fox mortality includes outbreaks of disease such as CDV (Nicholson and Hill 1984, Fritzell 1987, Davidson et al. 1992), after which gray fox populations may take several years to recover (Chamberlain and Leopold 2000). Gray foxes using urban zones in California exhibited higher canine parvovirus seroprevalence, exposure to canine adenovirus and leptospirosis and experienced an outbreak of canine distemper virus (Riley et al. 2004). In urban areas where a resource such as den sites might be scarce or patchily distributed, gray foxes and raccoons may live in close proximity to one another, facilitating the spread of disease.

My objectives were fourfold: (i) using presence data determine the distribution of mesopredators in northeastern Illinois, with a special emphasis on gray foxes, (ii) using telemetry data, estimate annual survival and determine cause-specific mortality sources for gray foxes in an urbanized area, (iii) using presence data and radio telemetry data, 
assess land cover associations and home range composition of gray foxes in order to determine the relationship between urbanization and gray fox presence, and (iv) using presence data, examine the relationship between the presence of gray foxes and other mesopredator species, most specifically coyotes and raccoons.

I predicted that: (i) the low relative abundance of gray fox may indicate negative effects of urban development, (ii) the low relative abundance of gray fox may indicate negative effects of intraguild competition with coyotes, and (iii) the low relative abundance of gray fox may indicate negative effects of interspecific interactions with raccoons. Lastly, using information from this study I provide recommendations for sampling designs for gray foxes in urban areas.

\section{STUDY SITE}

Northeastern Illinois is home to Chicago, the third largest metropolitan region in the United States. The Chicago metropolitan area spans six counties and encompasses approximately 887,838 hectares. Collectively these six counties are home to a population of 8.4 million people, a third of which are living within the Chicago city limits (Openlands Project 2006). My study focused on Cook County, which is the second most populated county in the country, DuPage, Lake and McHenry counties, accounting for greater than 613,995 ha, and $85 \%$ of the total population of the Chicago metropolitan area (Openlands Project 2006). Urbanization and urban sprawl are apparent forces shaping the landscape around Chicago (Figure 1.2). 
Following urban land cover, agriculture is the second most dominant land cover. Approximately $17 \%$ of the total area of the four counties is used for the production of crops, cattle and pigs (Illinois Agricultural Statistics Supplement 2004). Natural land managed by forest preserve and conservation districts is the third largest land cover and makes up approximately $9 \%$ of the total area of the four counties (Table 1.1; Openlands Project 2006).

Most (52\%; Table 1.2) of the land cover in northeastern Illinois has been classified as 'built up', which includes urbanized and developed areas. Approximately $19 \%$ of the land cover has been classified as 'at risk' (Table 1.2), which includes those areas under pressure to be developed within the next 10 to 30 years. Approximately $11 \%$ of the area is held as permanent open space (Table 1.2), which includes county holdings and the remainder is classified as 'low risk' (Table 1.2) including cemeteries, golf courses, private land and large tracts of government-owned land.

Major ecological communities within the six counties comprising the Chicago region include prairies, savannas, woodlands, and wetlands such as marshes, shrub swamps, sedge meadows, fens and bogs (Sullivan 2000). The region has an average annual rainfall of $91 \mathrm{~cm}$ per year and average summer and winter temperatures of $21.7^{\circ} \mathrm{C}$ and $-3.9^{\circ} \mathrm{C}$, respectively (National Weather Service 2006). 


\section{METHODS}

Study Site Selection

ArcView 3.3 (Environmental Systems Research Institute, Redlands, California) was used to divide the entire study area into 64 grid cells, each encompassing approximately 9,400ha. From the 64 grid cells, 32 were selected in a multi-step approach. Cells were first selected based upon priority levels, where a high priority cell was one with either reported historic gray fox activity or a recent gray fox sighting. This subset was selected in order to obtain a minimum number of sites with gray fox presence. Of the 32 cells selected, 20 fell into this category. The 12 remaining cells were chosen by simple random selection. A multi-step approach was then used to select study sites within each of the 32 selected cells. Study site selection was primarily limited to publicly owned forest preserves, golf courses and cemeteries, which represented natural and seminatural green space within the urban matrix. Public property was selected because of difficulties associated with gaining access to private property. Within each high priority cell, I selected a forest preserve near the occurrence of gray fox activity and then randomly selected forest preserves until approximately $10 \%$ of the collective area of the cell had been selected. I then randomly selected 1 golf course and 1 cemetery in each cell. Study site selection in cells that were not classified as high priority occurred in much the same way, although in these cases there were no sites with reported gray fox activity. 


\section{Field Surveys}

I used sand scent stations and camera scent stations in order to document the presence of mesopredators. Scent stations were operated from October through December in 2004, June through September in 2005, January through September in 2006, and March through September in 2007. I placed two scent stations per 120 hectares of area at study sites, based upon the average annual home range of gray foxes in southern Illinois (Follman 1973). The stations were spread opportunistically throughout the sites to avoid human disturbance.

Methods for operating sand track stations were adapted from Linhart and Knowlton (1975) and Roughton and Sweeny (1982). Sites were sampled using $1 \mathrm{~m}^{2}$ track stations baited with an attractant (e.g. gland lure, fatty acid disc). The substrate was a 1:32 mixture of masonry sand and mineral oil (Sargeant et al. 1998). The stations were checked every other day, at which time they were smoothed and rebaited, until a minimum of four operative station-nights were accumulated. All identifiable tracks were documented and later recorded in a database as a presence for each respective species detected at the station.

Infrared cameras were used to monitor scent stations in secure locations. Two types of cameras were used including infrared video systems and infrared digital trail cameras. The infrared video systems included an infrared video lens, a $17 \mathrm{~m}$ video power cable, a deep cycle marine battery, and a time-lapse VCR housed in a waterproof case. The infrared video lens was placed approximately $1.5 \mathrm{~m}$ above the ground on a nearby tree and aimed at an attractant (e.g. gland lure, fatty acid disc). The remaining equipment 
was placed approximately $10 \mathrm{~m}$ away from the scent station and covered with local debris. The substrate of camera scent stations was typically left natural although camera equipment was placed at a small subset of sand scent stations in order to assess bias associated with either method. The video systems were allowed to run for two to three nights at which time the battery was replaced and the attractant was refreshed. Scent stations equipped with infrared video systems were typically operated until four to six station-nights were accumulated. I reviewed the tapes that were generated by these systems, and documented species visitation at the station, time of visit, duration of visit, and both inter- and intraspecific interactions.

Several models of infrared digital trail cameras were used including: Leaf River IR-3BU (Leaf River, Taylorsville, MS), Bushnell Trail Scout (Bushnell, Overland Park, KS), Cuddeback NoFlash (Cuddeback, Park Falls, WI), and Moultrie Game Spy I40 (Moultrie, Alabaster, AL). All trail cameras consisted of self-contained units, which were placed approximately $0.3 \mathrm{~m}$ above the ground on a nearby tree and aimed at an attractant (e.g. gland lure, fatty acid disc). Since these systems could run for an extended period of time without battery replacement, infrared trail cameras were allowed to run undisturbed for approximately three to seven days before refreshing the attractant. All species that were documented were recorded as a presence in the database.

Trapping/Radio Telemetry

When gray fox presence was detected, 1.5 Victor soft-catch leg hold traps (Woodstream Corp., Lititz, PA; current manufacturer Oneida Victor Inc., Euclid, OH) were used to capture the animal. Traps were run intermittently during all seasons and 
years of the study, dependent upon the detection of gray fox activity. Traps were opened at dusk and checked at 3-hr intervals throughout the night to ensure that foxes were not left in the trap for extended periods of time, which lessened the chance of trap injuries and death due to coyotes. Foxes were not anesthetized to minimize handling time. However, muzzles and feet were bound to eliminate escape or injury to the handlers. Foxes were placed in a large pillowcase to reduce stress to the animal.

Upon capture, foxes were fitted with 100g VHF radio collars (Advance Telemetry Systems, Inc., Isanti, MN.), and ear-tagged with size 3 Jiffy tags (National Band and Tag Co., Newport, KY.). Sex was determined and age class was estimated (adult, yearling, kit) using tooth wear and body size. Weight was determined to the nearest $0.1 \mathrm{~kg}$ and standard measurements were collected including lengths of ear, foot pad, foot, tail, and total body, and a blood sample was collected for serology. All animals were handled and processed following protocols approved by the Animal Care and Use Committee at the Ohio State University under permit number 2003R0061.

Locations of individual foxes were obtained using a truck-mounted, directional yagi antenna. Three compass bearings were collected for each location and triangulated using Locate II (Nams 1990). Data collection occurred at hourly intervals primarily during crepuscular time periods, which encompassed the interval from sunset until 1-hr after sunset or from 1-hr before sunrise until sunrise, and nighttime tracking sessions which spanned from 1-hr after sunset until 1-hr prior to sunrise. A subset of telemetry locations occurred at 15 -min intervals. Hourly locations were used to calculate annual home ranges for foxes with $>30$ locations for a given year. Survival estimates were derived from monthly detection records for each animal. 
Analysis

Survival/Mortality--Annual survival of radiocollared foxes was estimated using a known fate model in program MARK (White and Burnham 1999) with a staggered entry design (Pollock et al. 1989). Survival probabilities across sampling intervals, sex, and age classes were held equal due to the limited number of foxes included in the analysis. Two annual survival estimates were calculated. The first estimate was a 'best case scenario' in which two foxes that presumably slipped their collars were censored and one fox with a malfunctioning collar was presumed alive until the end of the study. The second estimate was a 'worst case scenario' in which the two foxes that presumably slipped their collars were considered dead and the fox with the malfunctioning collar was censored. Necropsies were conducted on dead foxes in order to determine cause-specific mortality sources.

Home range description--I used hourly locations to calculate 95\% Minimum Convex Polygons (95\% MCPs) for foxes with > 30 locations in any given year. The 95\% MCPs were created using the Home Range Extension in ArcView 3.3. MCPs yield more accurate estimates of home ranges in urban environments compared to kernel methods, which tend to yield disjunct home range 'bubbles'. Home range polygons were combined with a modified version of the Illinois GAP land cover (Illinois Natural History Survey, Champaign, Illinois), in which original values were collapsed into nine land cover types (Table 1.3) in order to determine the proportion of each land cover within fox home ranges. Due to the small number of foxes in my study $(n=7)$, I was unable to conduct a typical resource selection analysis, and was restricted to descriptive measures. 
In addition to descriptive measures, I used linear regression to evaluate the relationship between fox home range size and the amount of urban development within home ranges. I used ArcView 3.3 to determine the size of 95\% MCP home range estimates and the percent of 5 land cover classifications within home ranges including: forest, agriculture, wetland, urban open space, and urban development. The classification 'urban development' represented high, medium, and low density urban development combined.

\section{Habitat Associations and Assessment of Relationships with Coyotes and}

Raccoons-- In total, 96 study sites were sampled during the study (Appendix A). On occasion, scent stations were placed in a residential yard or commercial area where a logical study site boundary could not be delineated. In such cases an artificial study site boundary was created from a circular 120-ha buffer centered on the survey station, which reflected the annual home range size of gray foxes in southern Illinois (Follman 1973).

For this investigation I merged the area within a 1-km buffer around a study site with the study site itself to incorporate elements of the external matrix, which may influence fox occurrence. In order to mitigate the effects of spatial autocorrelation, any buffered sites that had $>30 \%$ overlap were merged, which resulted in 72 unique study sites (Appendix B). ArcView 3.3 was used to intersect the Illinois GAP data with digitized study site polygons yielding individual land cover clips for each of the 72 study sites. The land cover clips were converted to raster format with a resolution of $30 \mathrm{~m} \mathrm{x}$ $30 \mathrm{~m}$ corresponding to the resolution of the original Illinois GAP coverage. 
Individual survey stations within study sites were not considered to be independent so detections were collapsed, yielding a single detection (1) or non-detection (0) value for respective study sites (Appendix B). Gray and red fox detections were combined into one category due to low detection rates for both species and difficulties associated with discriminating between the two species from degraded sand track stations. The 2 species are likely exploiting similar resources in this urbanized environment, and results of the Illinois Archery Deer Hunter Survey (Bluett 2006) indicate that the relative abundance of both gray and red foxes are declining, so it is unlikely that these species are competing for resources. This approach assumes equal detectability of gray and red foxes.

Using FRAGSTATS 3.3 (University of Massachusetts, Amherst, MA) I derived environmental variables that quantified the land cover composition of individual study sites. The percentages of 8 different land cover types were used (Table 1.4): forest (PER_FOR), agriculture (PER_AG), wetland (PER_WET), surface water (PER_WAT), urban open space (PER_URBOP), low density urban (PER_LOW), medium density urban (PER_MED), and high density urban (PER_HIGH). In order to assess the relationship between gray fox presence and the presence of coyotes and raccoons, I added two binary variables that coded for coyote and raccoon presence within a study site (COYOTE, RACCOON; Table 1.4). Lastly, I included the total area, measured in ha, (TA_HA; Table 1.4) and the number of station nights operated at a site to account for differences in sampling effort between sites (no_stations: Table 1.4). 
I applied log, square root, cube root and fourth root transformations to environmental variables to meet the assumptions of normality (Shapiro-Wilks; $p>0.05$ ). Due to the limited number of fox detections, I screened predictor variables in order to facilitate a more concise model-building procedure. I used univariate logistic regression models to eliminate predictor variables with $\mathrm{p}$-values $>0.4$. This preliminary step resulted in the elimination of $\log \_$TA_HA $(p=0.98)$, cube_PER_WAT $(p=0.90)$, and RACCOON $(p=0.815)$. In total, nine predictor variables were used to assess patterns in gray fox occurrence (Table 1.5).

I predicted that there would be a negative association between the presence of gray fox and predictor variables related to anthropogenic land cover types (e.g. fourth_PER_AG, sqrt_PER_URBOP, sqrt_PER_LOW, sqrt_PER_MED, cube_PER_HIGH), and a positive relationship with predictor variables indicating natural land cover types (e.g. sqrt_PER_FOR, sqrt_PER_WET). I predicted that gray fox presence would be negatively associated with coyote presence (COYOTE). The predictor for the presence of raccoons (RACCOON) was eliminated in a preliminary data reduction step, which likely reflected the ubiquitous nature of this species.

I used R (R Development Core Team 2008) for goodness of fit testing, fitting logistic regression models, model assessment and model averaging. I explored the global model to assess the goodness of fit and examined residual plots. The global model fit the data well (Hosmer-Lemeshow; $\left.\mathrm{X}_{8}^{2}=10.79, \mathrm{p}=0.214\right)$. The dispersion parameter of the global model was 1.43 and pseudo $R^{2}$ value was 0.62 . These measures indicated that the global model adequately fit the data. 
I developed a set of candidate models based on a priori hypotheses, using variables of interest. I used Akaike's Information Criterion with small sample size correction $\left(\mathrm{AIC}_{\mathrm{C}}\right)$ to rank models (Burnham and Anderson 2002). Within top models ( $\mathrm{w}_{\mathrm{i}}$ $>0.04)$, I examined parameter estimates and cumulative $\operatorname{AIC}_{C}$ weights $\left(\Sigma w_{i}\right)$ of the most commonly occurring parameter estimates. To account for uncertainty in any one model, I used model averaging over all candidate models to weight parameter estimates by $\mathrm{AIC}_{\mathrm{C}}$ weights (Burnham and Anderson 2002). Model averaged estimates were used to examine trends in the probability of fox occurrence based on the most common parameters in the top models.

\section{RESULTS}

Field Surveys

I surveyed 96 sites within the study area, which resulted in 668 stations (Figure 1.3) that were monitored for 2,746 station nights (Appendix A). Detections of mesopredators (Appendix A) at the study sites included: raccoons (86\%), opossums (Didelphis virginiana; 65\%), coyotes (47\%), domestic cats (Felis catus; 36\%), foxes (red and gray combined; 25\%), and striped skunks (Mephitis mephitis; 18\%). Gray fox presence was confirmed at $8 \%$ of the sites, which were widely dispersed throughout the Chicago metropolitan area (Figure 1.4). 


\section{Trapping/Radio Telemetry}

I captured and radiocollared nine foxes ( 7 gray foxes, 2 red foxes), 4 of which were males and 5 were females (Table 1.6). Six were adults at the time they were collared and three were yearlings. An adequate number of locations were collected to create at least one annual home range for 7 of the 9 collared animals (Table 1.6).

In total, 10 annual home ranges were calculated (Table 1.6) which included multiple annual home ranges for 3 of the collared animals due to the low number of collared foxes in my study.

Analysis

Survival/Mortality-- Six of the collared foxes died, or were presumed to have died, during the study. Of these 6 mortalities, $33 \%(n=2)$ was attributed to CDV, $17 \%$ $(\mathrm{n}=1)$ to vehicular impact, $17 \%(\mathrm{n}=1)$ to coyote predation, $17 \%(\mathrm{n}=1)$ to project related factors and $17 \%(n=1)$ due to an unknown cause.

The 'best case scenario' annual survival estimate, when two missing fates were right-censored and one missing fate was presumed alive, was $0.62(\mathrm{SE}=0.15)$. Alternatively, the 'worst case scenario' annual survival estimate, when two missing fates were coded as mortalities and one missing fate was right censored, was $0.49(\mathrm{SE}=0.14)$. Fox ID 4 was actively tracked until a mortality signal was followed to a large brush pile. As the brush pile was much too large to dismantle, it is unknown whether this 
fox died or slipped its collar. Fox ID 6 was believed to have slipped his collar off under the porch of a single-family house. Fox ID 7 was still alive, however, the battery on her collar failed after approximately a year and a half. Fox ID 12 was a young animal that slipped her collar off before any data points were collected.

Fox ID 5 died from injuries incurred during a coyote attack. Within a few weeks, 2 of his 3 kits were found dead from injuries consistent with a coyote attack. Fox ID 8 slipped its lower jaw into the collar after being released and died from related factors. Fox ID 9 died from canine distemper (CDV) and was found under the porch of a singlefamily home. Fox ID 13 died after being hit by a car. Interestingly, histology reports showed that this fox was also infected with CDV. Fox ID 14 died as a result of a vehicular impact. Fox ID 6 and fox ID 7 comprised a mated pair, and produced litters in 2006, 2007 and 2008. Although the litter from 2006 was never found, 3 kits were confirmed in both their 2007 and 2008 litters. Fox ID 5 produced a litter of at least 3 kits in 2007 and fox ID 9 produced a litter of at least 4 kits in 2007. Fox ID 14 raised a litter of 3 kits in 2008 with no apparent help from a male fox.

Home range description-- At least one yearly home range was calculated for seven of the collared foxes (Table 1.6). A home range for fox ID 8 was not calculated because, despite a sufficient number of locations, it is difficult to determine how long the animal was impaired and the calculated home range would likely not represent its natural home range. Home range sizes were quite variable, ranging from 21 ha to 720 ha. (Table 1.6). However, the home range of fox ID 14 is likely inflated, as this fox seemed to be making long-range dispersal movements. Censoring this animal, the average home range size for this study was $165.3 \pm 102.0$ ha (mean $\pm \mathrm{SD})$. Linear regression using univariate 
models revealed that fox home range size was positively related to the amount of urban development (high, medium and low density urban combined; $R^{2}=53.5, \mathrm{~F}_{1,7}=8.07, \mathrm{p}=$ $0.025)$ and negatively related to the amount of urban open space $\left(R^{2}=64.9, \mathrm{~F}_{2,6}=5.55, \mathrm{p}\right.$ $=0.043)$.

Of the 10 annual home ranges, four were composed of a greater percentage of medium density urban than any other land cover type (Table 1.7). Three home ranges contained a greater percentage of forest, which represented a natural land cover classification (Table 1.7). One of these home ranges belonged to a red fox (Fox ID 4) which primarily used a private hunting preserve and the other two belonged to two gray foxes (Fox ID 6 and Fox ID 7), which in 2006 used a county forest preserve but in 2007 moved approximately $4 \mathrm{~km}$ west and took up residence under a single family home in an urbanized area. The home ranges of Fox ID 6 and Fox ID 7 overlapped almost completely in respective years (Figure 1.5). Two home ranges were composed of a greater amount of urban open space, however, these were home ranges from one animal for two consecutive years (Fox ID 5; Figure 1.6). This animal's movements were entirely confined within a cemetery on the south side of Chicago. He shared the cemetery with an adult female, and in 2006 they produced a litter of at least three kits. Interestingly, the home range in 2007 was reduced to only a portion of the cemetery (Fig. 1.6), which coincided with the appearance of coyotes in the cemetery (coyotes were not seen in 2006). In total, $50 \%$ of the calculated home ranges contained a greater amount of high or medium density urban land cover than any other habitat type (Table 1.7). 


\section{Habitat Associations and Assessment of Relationship with Coyotes and}

Raccoons-- Model selection resulted in ten top models $\left(\mathrm{w}_{\mathrm{i}}>0.04\right)$, in which four predictor variables appeared repeatedly: sqrt_PER_WET, sqrt_PER_FOR, fourth_PER_AG and sqrt_PER_URBOP (Table 1.8). These four covariates had the highest cumulative $\mathrm{AIC}_{\mathrm{C}}$ weights $\left(\Sigma \mathrm{w}_{\mathrm{i}}\right)$ totaling $0.66,0.61,0.33$ and 0.27 , respectively (Table 1.9). Furthermore, $\Sigma \mathrm{w}_{\mathrm{i}}$ for the combination of sqrt_PER_FOR and sqrt_PER_WET totaled 0.48 (Table 1.9).

Examination of odds ratios for beta estimates of sqrt_PER_WET, sqrt_PER_FOR, fourth_PER_AG AND sqrt_PER_URBOP revealed negative relationships between all covariables and fox occurrence (Table 1.10), and model-averaged predictions of the probability of fox occurrence for all four covariables showed decreasing probability of fox occurrence with increasing wetland cover (Figure 1.7), forest cover (Figure 1.8), agricultural cover (Figure 1.9), and urban open space cover (Figure 1.10). Although the presence of coyote appeared in only one of the top models $\left(\mathrm{w}_{\mathrm{i}}=0.08\right.$; Table 1.8$)$, investigation of the odds ratio for COYOTE revealed a positive relationship between fox occurrence and coyote presence (Table 1.10). The binary variable representing raccoon presence (RACCOON) was highly insignificant in a univariate logistic regression model $(\mathrm{p}=0.815)$ 


\section{DISCUSSION}

\section{Distribution}

Large-scale survey efforts indicated that gray fox activity was relatively rare throughout the Chicago metropolitan area and that the distribution of sites in which gray foxes occurred were widely dispersed across the region. In total, gray fox activity was confirmed at only $8 \%$ of study sites. It is possible that this may even be an overestimation of gray fox occupancy because gray fox reports from the public aided us in identifying many sites with gray fox activity (see CONCLUSIONS). Although these results are from a small portion of Illinois, these findings support statewide survey findings pointing to low relative abundance of gray fox in Illinois.

Of the 96 sites surveyed, approximately 23 sites were selected due to historic gray fox activity. Of these sites, $39 \%$ had a fox detection, however only 1 (4\%) was confirmed to have gray fox activity. This decline in gray fox occurrence is consistent with reported trends from the statewide archery survey. Additionally, 23 sites were surveyed in response to reports of gray fox sightings. Of these, fox activity was detected at $56.5 \%$, and $26 \%$ had confirmed gray fox activity. These results suggest that public outreach programs may be useful in future gray fox studies. 
Survival

The annual survival estimates ('best case': 0.62; 'worst case': 0.49) for foxes in northeastern Illinois were similar to those reported for other studies. Adult gray foxes inhabiting a natural area near Los Angeles, California, had an annual survival of 0.58 , (Farias et al. 2005). Survival for adult foxes in natural areas of southern Georgia (Wood 1958) and South Carolina (Weston and Brisbin 2003) were 0.5, and 0.69, respectively.

Disease was the major mortality source for foxes in the current study, followed by coyote attack, and vehicular impact. Disease has been implicated as a major source of mortality for gray foxes (Hoff et al. 1974, Nicholson and Hill 1984). Mortality associated with coyotes is also prevalent (Fedriani et al. 2000, Weston and Brisbin 2003, Farias et al. 2005). Mortality due to vehicular impact is less common but nonetheless is a contributing mortality factor (Weston and Brisbin 2003). The influence of disease as a mortality source may be underestimated as two uncollared gray foxes that were euthanized by animal control officers were also infected with CDV, and a collared gray fox that died from CDV was gravid with six fetuses, of which three were infected with the virus. 


\section{Habitat Associations}

The composition of fox home ranges in the Chicagoland area suggested that gray foxes were utilizing urbanized habitats. The probability of fox occurrence decreased with increasing natural land covers (forest and wetland) and with certain types of altered land covers (agriculture and urban open space). My study also indicated that the home range size of foxes was positively associated with the amount of urban land cover.

Gray foxes used urbanized habitats in California (Crooks 2002, Riley 2004, Riley 2006) and New Mexico (Harrison 1997), although the use of these areas resulted in increased home range shape complexity (Harrison 1997). Other fox species used urban and residential areas as part of their home ranges including red foxes in Illinois (Gosselink et al. 2003, Lavin et al. 2003, Gosselink et al. 2007), and kit foxes in California (Cypher 1999).

Foxes may benefit from the use of urban development, as those utilizing such areas are generally heavier than foxes in exurban areas (Harrison 1997, Cypher and Frost 1999). Increased home range sizes of foxes in urban settings suggested that one consequence of using urbanized areas might be the navigation of a large and complex home range in which foraging efficiency is reduced (Harrison 1997). Foxes may be forced to use urbanized habitats in response to increasing coyote numbers in natural areas (Gosselink et al. 2003), decreased raccoon numbers in dense urban cores (Graser 2008), or simply due to loss of suitable habitat. Although urban development may not act as an inhospitable matrix to foxes, indirect effects of inhabiting such a landscape may be influencing the recent population decline. 
Intraguild Competition with Coyotes

In my study I documented qualitative evidence of competitive exclusion and intraguild predation between coyotes and foxes. In 2006 fox ID 5 and an unmarked adult gray fox utilized the entire grounds of an urban cemetery and denned under headstones in the southern portion of the cemetery. During this time period no coyotes were known to consistently use the cemetery grounds. Early in 2007 a group of coyotes moved in to the cemetery and began using dens in the southern section of the cemetery. Following their arrival, fox ID 5 and the unmarked gray fox shifted to den sites in the northern section of the cemetery including a tree cavity and maintenance garages. Fox ID 5 was then found dead in June 2007 with injuries consistent with a coyote attack, and within a month two gray fox kits were found dead with similar injuries.

Intraguild competition can play a major role in structuring wildlife communities (Crooks and Soule 1999, Smith et al. 2003). In the absence of large carnivores such as wolves, coyotes have assumed the role of top predator throughout much of North America and more recently in urban and suburban landscapes (Gompper 2002, Grinder 2001). The coyote is able to competitively exclude smaller mesopredators, particularly those utilizing similar resources, such as foxes (Voigt and Earle 1983, Cypher 1993, Fedriani et al. 2000, Nelson et al. 2007). Foxes may make use of urbanized areas to avoid competitive interactions with coyotes (Gosselink et al. 2003). Conversely, coexistence between coyotes and foxes has been documented in California (Neale and Sacks 2001) and Mississippi (Chamberlain and Leopold 2005). In California, coyotes and gray foxes exhibited high dietary overlap, although coyotes utilized ungulate prey more often than did gray foxes (Neale and Sacks 2001). This study did not use telemetry, 
and any exclusion that occurred at a fine scale might not have been detected. In Mississippi, gray fox home ranges overlapped those of coyotes although there was some evidence of exclusion within core areas of home ranges (Chamberlain and Leopold 2005).

Negative interactions between gray foxes and coyotes are likely contributing to the population decline in Illinois. Results of predator surveys, which indicated no relationship between coyote and fox presence, were likely an artifact of the course-scale sampling design. The mortality due to coyote predation likely represented interference competition as a means to reduce exploitative competition (Cypher and Spencer 1998, Farias et al. 2005) as gray fox carcasses were not consumed.

My results may have been confounded by the need to combine red and gray fox detections into one general 'fox' category. An assumption of my analysis was that gray and red foxes had similar relationships with coyotes. It has been suggested that gray foxes may be better adapted to coexist with coyotes than red foxes due to their treeclimbing capabilities as well as an increased dietary breadth (Cypher 1993). However, telemetry data from foxes in my study site does not suggest such a trend. In fact, during my study the only fox killed by a coyote was a gray fox. 
Interspecific Relationship with Raccoons

Results of my study suggested that the presence of raccoons was not related to the probability of fox occurrence. This finding is most likely an artifact of the ubiquitous nature of raccoons in my study site (Graser 2008). Of the 21 sites with fox detections, 19 of those had raccoon presence as well. Foxes in the study area likely live in close proximity to raccoons due to the wide distribution and high densities of raccoons throughout the landscape.

Raccoons are carriers of many diseases, most notably CDV (Gehrt, unpublished data). Canine distemper virus does not cause cyclic die-offs in high density raccoon populations (Gehrt, unpublished data) and although CDV was found to be less prevalent in raccoon populations existing in heavily developed urban cores (Graser 2008), it is nonetheless consistently present in the population. The indirect influence of interspecific interactions with raccoons may have a large impact on apparently declining populations of gray foxes through disease transmission. Living among a large host reservoir, there may be no respite from the disease.

The effect of CDV on gray fox survival may be underestimated as within my study area two uncollared adult gray fox mortalities and the mortality of a collared fox that was gravid with 6 fetuses were attributed to CDV. Of these fetuses, three were infected with the disease. Raccoon density was not measured during my study but might have influenced disease transmission or detectability of foxes. The large number of raccoons in my study site may have led to an underestimation of fox occurrence. Raccoons were attracted to the scent stations, which were often found completely covered in raccoon tracks. 


\section{Limitations on Inference}

Assumptions of predator surveys were that all species would be detected if they were present, and all species would be detected with equal probability. Due to the secretive nature of mesopredators, it is difficult to assess the reliability of this assumption. It is likely that some species go undetected even when present at a site (i.e. probability of detection is less than 1). These discrepancies may be attributed to behavioral differences between species. When viewing videos from camera stations raccoons were often observed spending extended periods of time at stations whereas coyotes were more wary. Methods have been developed to accommodate detectability that is less than 1 , and should be used when ever possible. The original goal of this study was to utilize an occupancy modeling technique (see Recommendations; MacKenzie et al. 2006) to model factors affecting fox detection as well as occupancy, however, the resulting data did not support such an analysis (see Recommendations).

Informational fliers soliciting gray fox sightings were distributed to county forest preserve districts for posting in kiosks at preserves. These postings generated reports of fox sightings not only within forest preserves but also in urban areas. Of the 24 study sites that had fox (gray fox and red fox combined) activity, $46 \%$ of those were sampled due to a gray fox report. Of the study sites where a fox was reported and documented, $73 \%$ were located in residential yards ranging from low to high density urban development. In total, these sites comprised approximately one-third of all sites with fox activity, which may have resulted in an overestimation of the importance of urban land cover relating to the presence of foxes. 
Sampling design and logistical issues that arose from working in an urbanized environment could have influenced the results of the study. I was largely limited to sampling publicly owned property because of the amount of time and resources that would have been needed to gain access to privately owned land. Many of the sites that were surveyed were used for recreational activities (i.e. picnicking, bike riding, running) and as a result received varied amounts of human traffic. Within sites, stations were placed opportunistically in order to minimize the chance of vandalism or theft. A negative association with natural land cover could be attributed to decreased detectability of survey stations, or the amount of human activity at urban forest preserves.

\section{Recommendations}

It is unlikely that wildlife surveys will yield complete accuracy, particularly when surveying for elusive or rare species. Standard survey techniques may not detect the presence of a given species at a study site although the species may actually be present. There is a powerful method of estimating and modeling both occupancy and detectability of a species that incorporates this element of uncertainty into the estimates and allows for the incorporation of individual covariables (MacKenzie et al. 2006). It was the purpose of my study to utilize this occupancy modeling technique to model gray fox occupancy and detectability. However, a combination of factors including study design, survey effort, and low occupancy of foxes resulted in the failure of this analysis.

I operated scent stations within known gray fox home ranges in order to estimate gray fox detectability and allocate survey effort (MacKenzie and Royle 2005). I determined gray fox home range size and placed 2 scent stations for every 120 ha of area 
in order to standardize sampling efforts. Scent stations were equipped with infrared video cameras and operated for at least 4 station nights. These efforts resulted in the operation of 5 scent stations at 3 study sites. I detected gray fox presence at $80 \%$ of the scent stations and all of the detections occurred within 2 nights of station operation. These results indicated that the probability of detecting a gray fox, given that one was present, was high.

Using conservative estimates of gray fox detectability $(p=0.7$; Table 1.11) and occupancy $(\Psi=0.1$; Table 1.11), one can determine the optimum number of repeat surveys at a site to be 2 (Table 1.11). In the current study, this was the minimum number of repeat surveys at a study site. By solving for ' $U$ ' in Equation 1 the optimum number of sites to survey can be estimated:

$$
\begin{aligned}
& \text { Eq 1) } \operatorname{var}(\Psi)=\Psi / U\left[(1-\Psi)+\left(\left(1-p^{*}\right) /\left(p^{*}-K p(1-p)^{K-1}\right)\right]\right. \\
& \text { Eq 2) } p^{*}=1-(1-p)^{K}
\end{aligned}
$$

Where var $(\Psi)$ is the desired variance for psi, $\Psi$ is the occupancy estimation used in Table $1.11, \mathrm{U}$ is the optimum number of sites, $\mathrm{p}$ is the estimated detectability value used in Table 1.11 and $\mathrm{K}$ is the number of repeat surveys from Table 1.11. In the current study, to achieve a SE of $0.05\left(\operatorname{var}(\Psi)=0.05^{2}\right)$, the optimum number of sites to survey would be 44 , with 2 repeat surveys at each site. I surveyed 96 sites with a minimum of 2 repeat surveys at each site but did not have enough data to run the analysis.

Although fox detectability was high when stations were placed within fox home ranges, the design of my landscape monitoring may have decreased my ability to detect gray foxes. I primarily placed scent stations in publicly owned forest preserves, golf courses and cemeteries. However, according to statistical conclusions, fox presence is 
negatively associated with natural land cover (forest). Assuming the sampling design reduced the detectability of foxes by half, the minimum number of sites that should have been surveyed increased dramatically. When using estimations of detectability $(p=0.3$;

Table 1.11), and occupancy ( $\Psi=0.1$; Table 1.11), the optimum number of repeat surveys at a site would be 5 . Solving for ' $U$ ' in equation 1 with $S E=0.05,166$ study sites should have been surveyed 5 times each. I suggest that future surveys for gray foxes should incorporate the detectability and occupancy rates in relation to sampling scheme to effectively use this analysis.

\section{CONCLUSIONS}

Foxes in my study were positively associated with urban development and negatively associated with natural land covers. Urban development may offer some degree of refuge from intraguild competition with coyotes, and provide an abundance of anthropogenic resources. Contrary to findings for other species existing in urban areas (Gardner 1982, Kaufmann 1982, Barratt 1997, Prange and Gehrt 2007), fox home range size increased as the amount of urban development increased. This suggests that there may be an indirect negative influence on foxes using urban areas.

Negative interspecific interactions between foxes and coyotes were documented including spatial avoidance and mortality. Intraguild competition with coyotes is likely a factor driving the gray fox population decline. Coyotes are abundant in my study site and are capable of competitively excluding the smaller foxes. This most likely represents a mechanism by which coyotes reduce competition for resources. 
Interspecific interactions with raccoons are likely influencing the population decline through disease transmission. A dense raccoon population in my study area represented a host reservoir for CDV, which was a major mortality source for radiocollared foxes. Disease transmission could be further facilitated by a limited number of den sites in urban areas and clumped food resources (i.e. garbage cans).

It is difficult to disentangle the effects of each of the factors that were examined during my study. It is likely that the gray fox population decline is a result of many factors working in conjunction. For example, urbanization results in a loss of habitat, which in turn may increase competition for resources between both foxes and coyotes and foxes and raccoons. Limited resources may bring all of these species in close proximity to one another increasing the opportunity for the spread of disease and also the chance of competitive interactions.

Fox population trends may be driven by factors not measured during this study, or factors occurring at a finer scale than could be detected by survey efforts. Fox presence may be affected by the structure of the forest or by the core use areas of coyote home ranges. Kit survival was not monitored during my study but may be low in urban areas due to such factors as disease, navigation of roads, or increased coyote numbers. Given their sparse distribution across the landscape gray foxes may not be able to find mates during dispersal activities or following the loss of a mate. Future investigation of these factors as well as serological analyses and telemetry analysis of sympatric foxes and coyotes would be of great value in determining causes driving the decline of gray foxes in the Chicago metropolitan area. 


\section{LITERATURE CITED}

Bluett, R. 2006. 2005 Illinois Archery Deer Hunter Survey. Wildlife Diversity Program Note 06-4. Illinois Department of Natural Resources, Springfield, Illinois, USA.

Burnham, K. P., and D. R. Anderson. 2002. Model Selection and Multimodel Inference: A Practical Information-Theoretic Approach. Second edition. Springer, New York, New York, USA.

Caro, T. M., J. A. Shargel, and C. J. Stoner. 2000. Frequency of medium-sized mammal road kills in an agricultural landscape in California. American Midland Naturalist 144: 362-369.

Chamberlain, M. J., and B. D. Leopold. 2005. Overlap and space use among bobcats (Lynx rufus), coyotes (Canis latrans) and gray foxes (Urocyon cinereoargenteus). American Midland Naturalist 153: 171-179.

Chamberlain, M. J., and B. D. Leopold. 2000. Spatial use patterns, seasonal habitat selection, and interactions among adult gray foxes in Mississippi. Journal of Wildlife Management 64: 742-751.

Crooks, K. R. 2002. Relative sensitivities of mammalian carnivores to habitat fragmentation. Conservation Biology 16: 488-502.

Crooks, K. R., and M. E. Soule. 1999. Mesopredator release and avifaunal extinctions in a fragmented system. Nature 400: 563-566.

Cypher, B. L. 2003. Foxes. Chapter in Wild Mammals of North America, G. Feldhamer, B. Thompson, and J. Chapman, eds. Pp. 511-546. Second edition. John Hopkins University Press, Baltimore, Maryland, USA.

Cypher, B. L. 1993. Food item use by three sympatric canids in southern Illinois. Transactions of the Illinois State Academy of Science 86: 139-144.

Cypher, B. L., and N. Frost. 1999. Condition of San Joaquin kit foxes in urban and exurban habitats. Journal of Wildlife Management 63: 930-938. 
Cypher, B. L., and K. A. Spencer. 1998. Competitive interactions between coyotes and San Joaquin kit foxes. Journal of Mammalogy 79: 204-214.

Davidson, W. R., V. F. Nettles, L. E. Hayes, E. W. Howerth, and C. E. Couvillion. 1992. Diseases diagnosed in gray foxes (Urocyon cinereoargenteus) from the southeastern United States. Journal of Wildlife Diseases 28: 28-33.

Farias, V., T. K. Fuller, R. K.Wayne, and R. M. Sauvajot. 2005. Survival and causespecific mortality of gray foxes (Urocyon cinereoargenteus) in southern California. Journal of Zoology, London 266: 249-254.

Fedriani, J. M., T. K. Fuller, and R. M. Sauvajot. 2001. Does availability of anthropogenic food enhance densities of omnivorous mammals? An example with coyotes in southern California. Ecography 24: 325-331.

Fedriani, J. M., T. K. Fuller, R. M. Sauvajot, and E. C. York. 2000. Competition and intraguild predation among three sympatric carnivores. Oecologia 125: 258-270.

Follman, E. H. 1973. Comparative ecology and behavior of red and gray foxes. Ph.D. dissertation. Southern Illinois University, Carbondale, Illinois, USA.

Fritzell, E. K. 1987. Gray Fox and Island Gray Fox. Chapter in Wild Furbearer Mangement and Conservation in North America, M. Novak, J. A. Baker, M. E. Obbard, and B. Malloch, eds. Pp. 408-420. Ministry of Natural Resources, Concord, Ontario, Canada.

Fritzell, E. K., and K. J. Haroldson. 1982. Urocyon cinereoargenteus. Mammalian Species 189: 1-8.

Gompper, M. E. 2002. Top carnivores in the suburbs? Ecological and conservation issues raised by colonization of northeastern North America by coyotes. BioScience 52: 185-189.

Gosselink, T. E., T. R. Van Deelen, R. E. Warner, and P. C. Mankin. 2007. Survival and cause-specific mortality of red foxes in agricultural and urban areas of Illinois. Journal of Wildlife Management 71: 1862-1873.

Gosselink, T. E., T. R. Van Deelen, R. E. Warner, and M. G. Joselyn. 2003. Temporal habitat partitioning and spatial use of coyotes and red foxes in east-central Illinois. Journal of Wildlife Management 67: 90-103.

Graser, W. H. 2008. Density, demographic patterns, population structure and pathogen exposure of raccoons in the Chicago metropolitan area. M. S. thesis. The Ohio State University, Columbus, Ohio, USA. 
Grinder, M. I., and P. R. Krausman. 2001. Home range, habitat use, and nocturnal activity of coyotes in an urban environment. Journal of Wildlife Management 65: 887-889.

Harrison, R. L. 1997. A comparison of gray fox ecology between residential and undeveloped rural landscapes. Journal of Wildlife Management 61: 112-122.

Harrison, D. J., J. A. Bissonette, and J. A. Sherburne. 1989. Spatial relationships between coyotes and red foxes in eastern Maine. Journal of Wildlife Management 53: 181-185.

Hockman, J. G., and J. A. Chapman. 1983. Comparative feeding habits of red foxes (Vulpes vulpes) and gray foxes (Urocyon cinereoargenteus) in Maryland. American Midland Naturalist 110: 276-285.

Hoff, G. L., W. J. Bigler, S. J. Proctor, and L. P. Stallings. 1974. Epizootic of canine distemper virus infection among urban raccoons and gray foxes. Journal of Wildlife Diseases 10: 423-428.

Illinois Agricultural Statistics Supplement. 2004. Illinois county statistics. Illinois Dept. of Agriculture and National Agriculture Statistics Service. 2 Oct. 2006. URL http://www.agstats.state.il.us/ctyest/.

Lavin, S. R., T. R. Van Deelen, P. W. Brown, R. E. Warner, and S. H. Ambrose. 2003. Prey use by red foxes (Vulpes vulpes) in urban and rural areas of Illinois. Canadian Journal of Zoology 81: 1070-1082.

Linhart, S. B., and F. F. Knowlton. 1975. Determining the relative abundance of coyotes by scent station lines. Wildlife Society Bulletin 3: 119-124.

MacKenzie, D. I., J. D. Nichols, J. A. Royle, K. H. Pollock, L. L. Bailey, and J. E. Hines. 2006. Occupancy Estimation and Modeling: Inferring Patterns and Dynamics of Species Occurrence. Elsevier Inc., San Diego, California, USA.

MacKenzie, D. I., and J. A. Royle. 2005. Designing occupancy studies: general advice and allocating survey effort. Journal of Applied Ecology 42: 1105-1114.

Morey, P. S., E. M. Gese, and S. D. Gehrt. 2007. Spatial and temporal variation in the diet of coyotes in the Chicago metropolitan area. American Midland Naturalist 158: $147-161$.

National Weather Service. 2006. Weather forecast office: Chicago, IL. National Oceanic and Atmospheric Administration. 2 Oct. 2006. URL http://www.crh.noaa.gov/lot/. 
Nams, V. O. 1990. Locate II User's Guide. Pacer, Truro, Nova Scotia.

Neale, C. C., and B. N. Sacks. 2001. Food habits and space use of gray foxes in relation to sympatric coyotes and bobcats. Canadian Journal of Zoology 79: 1794-1800.

Nelson, J. L., B. L. Cypher, C. D. Bjurlin, and S. Creel. 2007. Effects of habitat on competition between kit foxes and coyotes. Journal of Wildlife Management 71: $1467-1475$.

Nicholson, W. S., and E. P. Hill. 1984. Mortality in gray foxes from east-central Alabama. Journal of Wildlife Management 48: 1429-1432.

Openlands Project. 2006. Forest preserve and conservation districts in northeastern Illinois: meeting the challenges of the $21^{\text {st }}$ century. Openlands Project, Chicago, Illinois, USA.

Openlands Project. 1999. Under pressure: land consumption in the Chicago region, 1998-2028. Openlands Project, Chicago Illinois, USA.

Patterson, B. R., and F. Messier. 2001. Social organization and space use of coyotes in eastern Canada relative to prey distribution and abundance. Journal of Mammalogy 82: 463-477.

Pollock, K. H., S. R. Winterstein, C. M. Bunck, and P. D. Curtis. 1989. Survival analysis in telemetry studies: the staggered entry design. Journal of Wildlife Management 53: 7-15.

Prange, S., S. D. Gehrt, and E. P. Wiggers. 2003. Demographic factors contributing to high raccoon densities in urban landscapes. Journal of Wildlife Management 67: 324-333.

R Development Core Team. 2008. R: A language and environment for statistical computing. R Foundation for Statistical Computing, Vienna, Austria, URL http://www.R-project.org.

Riley, S. P. D. 2006. Spatial ecology of bobcats and gray foxes in urban and rural zones of a national park. Journal of Wildlife Management 70: 1425-1435.

Riley, S. P. D., J. Foley, and B. Chomel. 2004. Exposure to feline and canine pathogens in bobcats and gray foxes in urban and rural zones of a national park in California. Journal of Wildlife Diseases 40: 11-22.

Riley, S. P. D., J. Hadidian, and D. A. Manski. 1998. Population density, survival, and rabies in raccoons in an urban national park. Canadian Journal of Zoology 76: 1153-1164. 
Rosenblatt, D. L., E. J. Heske, S. L. Nelson, D. M. Barber, M. A. Miller, and B. McAllister. 1999. Forest fragments in east-central Illinois: islands or habitat patches for mammals? American Midland Naturalist 141: 115-123.

Roughton, R. D., and M. W. Sweeny. 1982. Refinements in scent-station methodology for assessing trends in carnivore populations. Journal of Wildlife Management 46: 217-229.

Sargent, G. A., D. H. Johnson, and W. E. Berg. 1998. Interpreting carnivore scent station surveys. Journal of Wildlife Management 62: 1235-1245.

Sargeant, A. B., S. H. Allen, and J. O. Hastings. 1987. Spatial relations between sympatric coyotes and red foxes in North Dakota. Journal of Wildlife Management 51: 285-293.

Schubert, C. A., I. K. Barker, R. C. Rosatte, C. D. MacInnes, and T. D. Nudds. 1998. Effect of canine distemper on an urban raccoon population: and experiment. Ecological Applications 8: 379-387.

Sheldon, W. G. 1949. Reproductive behavior of foxes in New York State. Journal of Mammalogy 30: 236-246.

Smith, W. S., R. O. Peterson, and D. B. Houston. 2003. Yellowstone after wolves. BioScience 53: 330-340.

Sullivan, J. 2000. An atlas of biodiversity. Chicago Region Biodiversity Council: 64 .

Voigt, D. R., and B. D. Earle. 1983. Avoidance of coyotes by red fox families. Journal of Wildlife Management 47: 852-857.

Weston, J. L., and I. L. Brisbin. 2003. Demographics of a protected population of gray foxes (Urocyon cinereoargenteus) in South Carolina. Journal of Mammalogy 84: 996-1005.

White, G. C., and K. P. Burnham. 1999. Program MARK: survival estimation from populations of marked animals. Bird Study 46 Supplement: 120-138.

Wood, J. E. 1958. Age structure and productivity of a gray fox population. Journal of Mammalogy 39: 74-86. 


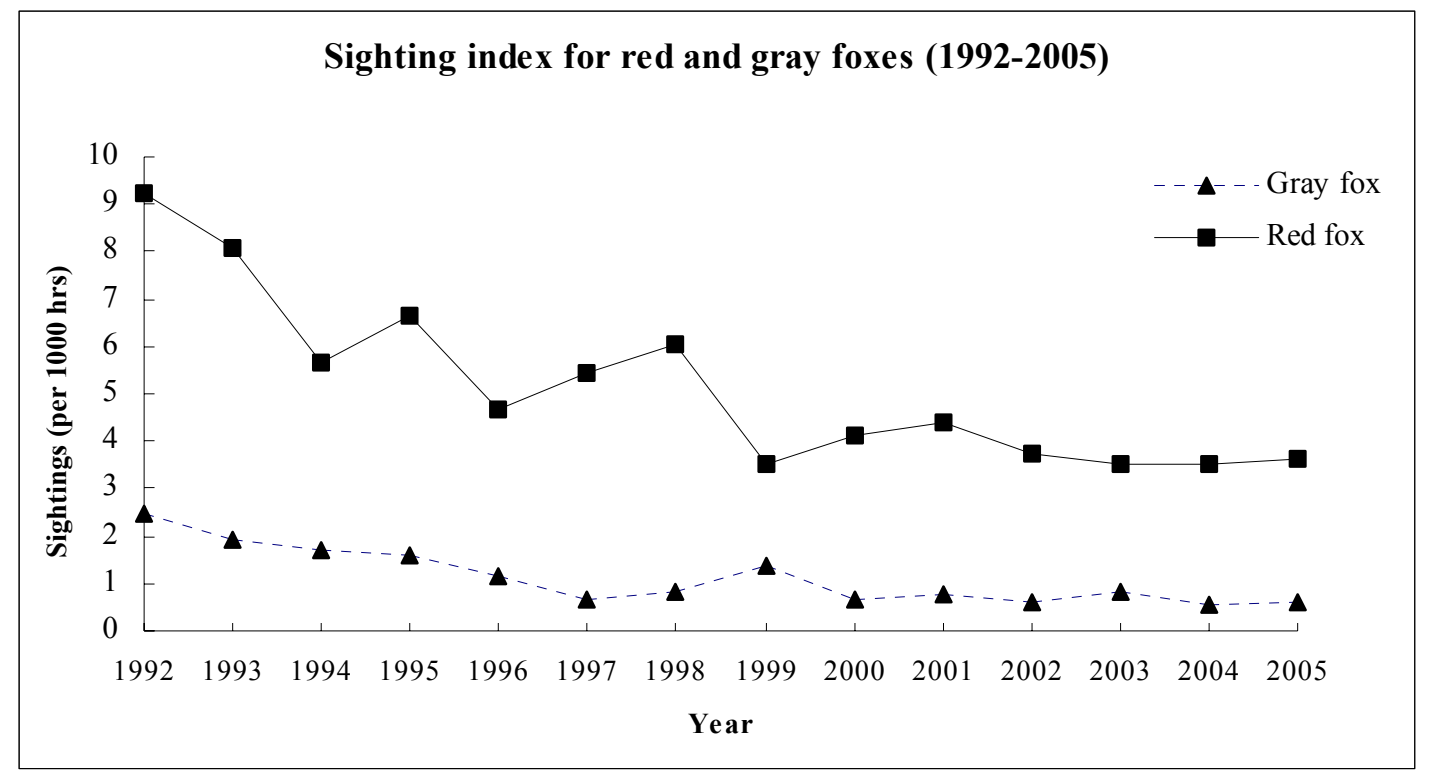

Figure 1.1. Illinois Archery Deer Hunter Survey results from 1992-2005. Data points represent the number of sightings (per 1000 hunting hours) of red (Vulpes vulpes) and gray (Urocyon cinereoargenteus) fox (Bluett 2006). 


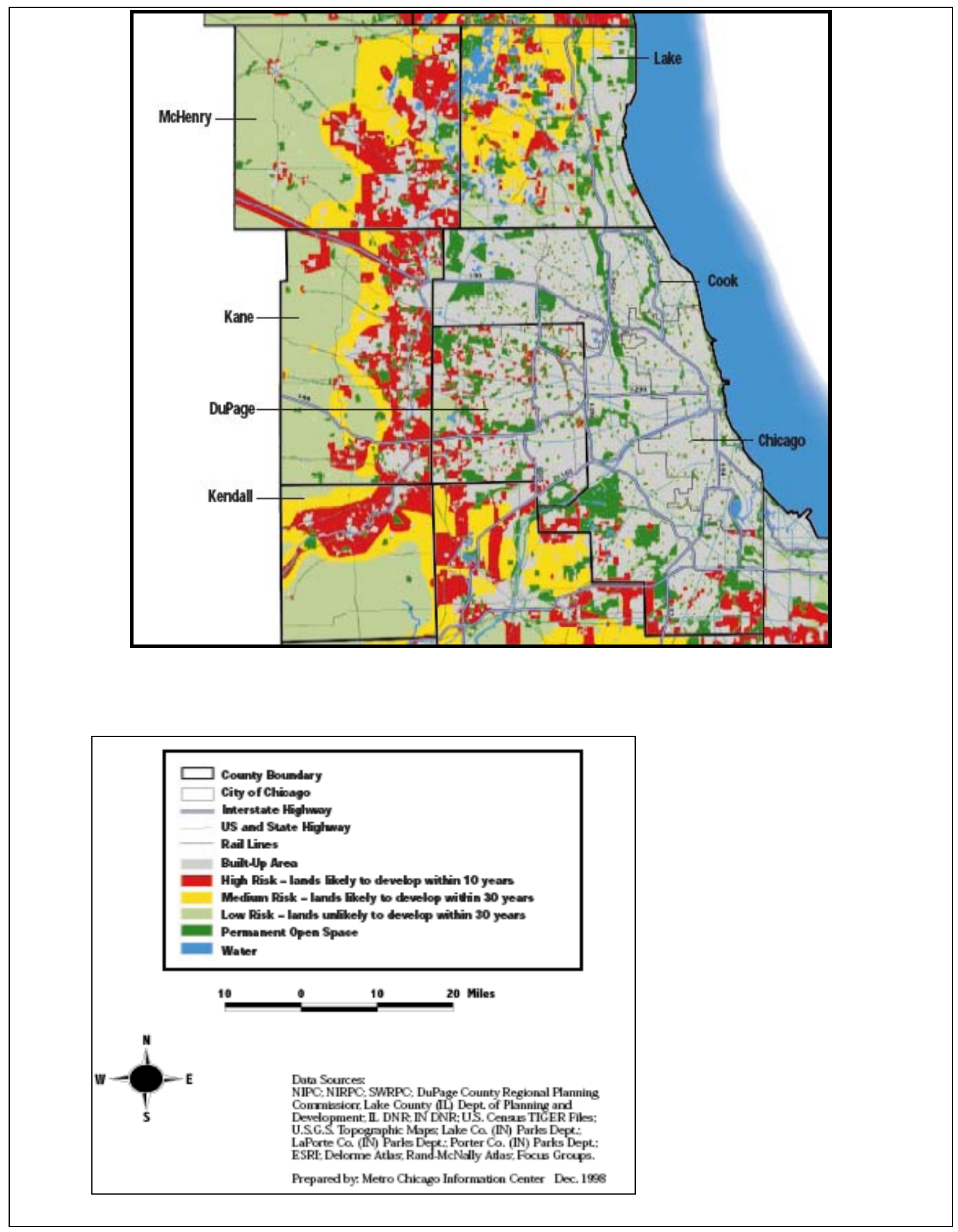

Figure 1.2. Land cover map of northeastern Illinois (Under Pressure Map, Openlands Project 1999). 


\begin{tabular}{lccccc}
\hline & & & & & \\
County & population & total area (ha) & preserved land (ha.) & \% of county & $\begin{array}{l}\text { 1000 residents } \\
\text { 1000 }\end{array}$ \\
\hline Cook & 5303683 & 246796.8 & 27641.2 & 11.2 & 13 \\
DuPage & 929113 & 86982.7 & 10003.0 & 11.5 & 27 \\
Lake & 702682 & 121357.1 & 10194.0 & 8.4 & 36 \\
McHenry & 303990 & 158858.9 & 8101.8 & 5.1 & 66 \\
Totals & 7239468 & 613995.5 & 55940 & 9 & \\
\hline
\end{tabular}

Table 1.1. Amount of publicly owned land held as preserves and populations for each county (Openlands Project 2006).

\begin{tabular}{lcccc}
\hline County & \% Built Up & \% At Risk & \% Perm. Open Space & \% Low Risk \\
\hline Cook & 78.3 & 4.8 & 14.5 & 1.2 \\
DuPage & 67.3 & 12.0 & 14.7 & 5.3 \\
Lake & 39.6 & 32.6 & 11.66 & 11.5 \\
McHenry & 13.7 & 35.9 & 3.52 & 45.7 \\
\hline
\end{tabular}

Table 1.2. Status of land cover in northeastern Illinois (Openlands Project 1999). 'Built up' includes already developed land, 'At Risk' includes land at risk of being developed in 10-30 years, 'Perm. Open Space' includes county forest preserves and 'Low Risk' includes land uses such as golf courses and cemeteries. 


\begin{tabular}{|c|c|}
\hline Collapsed Classification & Original Illinois GAP Classification \\
\hline \multirow[t]{7}{*}{ Agriculture } & Corn \\
\hline & Soybeans \\
\hline & Winter Wheat \\
\hline & Other Small Grains and Hay \\
\hline & Winter Wheat/Soybeans \\
\hline & Other Agriculture \\
\hline & Rural Grassland \\
\hline \multirow[t]{8}{*}{ Forest } & Dry Upland \\
\hline & Dry-Mesic Upland \\
\hline & Mesic Upland \\
\hline & Partial Canopy/Savannah Upland \\
\hline & Coniferous \\
\hline & Mesic Floodplain Forest \\
\hline & Wet-Mesic Floodplain Forest \\
\hline & Wet Floodplain Forest \\
\hline Urban Open Space & Urban Open Space \\
\hline High Density Urban & High Density Urban Land \\
\hline Medium Density Urban & Medium Density Urban Land \\
\hline Low Density Urban & Low Density Urban \\
\hline \multirow[t]{5}{*}{ Wetland } & Shallow Marsh/Wet Meadow \\
\hline & Deep Marsh \\
\hline & Seasonally/Temporarily Flooded \\
\hline & Swamp \\
\hline & Shallow Water \\
\hline Surface Water & Surface Water \\
\hline Barren/Exposed Land & Barren and Exposed Land \\
\hline
\end{tabular}

Table 1.3. Original and reclassified land cover values derived from the Illinois GAP data. 


\begin{tabular}{|c|c|c|c|c|c|c|}
\hline VAR & Name & Description & Units & Mean \pm SD & Range & Application \\
\hline no_stns & $\begin{array}{l}\text { Number of } \\
\text { survey stations }\end{array}$ & $\begin{array}{l}\text { Total number of survey stations operated within } \\
\text { respective landscapes. }\end{array}$ & count & $9.28 \pm 10.78$ & $1-52$ & $\begin{array}{l}\text { Covariable used to } \\
\text { adjust for differences } \\
\text { in survey effort. }\end{array}$ \\
\hline PER_AG & $\begin{array}{l}\text { Percent } \\
\text { agriculture }\end{array}$ & $\begin{array}{l}\text { Percent of agriculture land cover within respective } \\
\text { landscapes. }\end{array}$ & $\%$ & $14.21 \pm 21.71$ & $0-75.58$ & $\begin{array}{l}\text { Landscape } \\
\text { composition }\end{array}$ \\
\hline PER_FOR & Percent forest & Percent of forest land cover within respective landscapes. & $\%$ & $22.42 \pm 13.24$ & $0-57.11$ & $\begin{array}{l}\text { Landscape } \\
\text { composition }\end{array}$ \\
\hline PER_HIGH & $\begin{array}{l}\text { Percent high } \\
\text { density urban } \\
\text { development }\end{array}$ & $\begin{array}{l}\text { Percent of high density urban land cover within respective } \\
\text { landscapes. }\end{array}$ & $\%$ & $8.72 \pm 11$ & $0-59.64$ & $\begin{array}{l}\text { Landscape } \\
\text { composition }\end{array}$ \\
\hline PER_LOW & $\begin{array}{l}\text { Percent low } \\
\text { density urban } \\
\text { development }\end{array}$ & $\begin{array}{l}\text { Percent of low density urban land cover within respective } \\
\text { landscapes. }\end{array}$ & $\%$ & $6.244 \pm 5.476$ & $0.1-22.71$ & $\begin{array}{l}\text { Landscape } \\
\text { composition }\end{array}$ \\
\hline PER_MED & $\begin{array}{l}\text { Percent medium } \\
\text { density urban } \\
\text { development }\end{array}$ & $\begin{array}{l}\text { Percent of medium density urban land cover within } \\
\text { respective L1 landscapes. }\end{array}$ & $\%$ & $22.16 \pm 15.5$ & $0-66.16$ & $\begin{array}{l}\text { Landscape } \\
\text { composition }\end{array}$ \\
\hline PER_URBOP & $\begin{array}{l}\text { Percent urban } \\
\text { open space }\end{array}$ & $\begin{array}{l}\text { Percent of urban open space land cover within respective } \\
\text { L1 landscapes. }\end{array}$ & $\%$ & $21.39 \pm 13.73$ & $0-55.25$ & $\begin{array}{l}\text { Landscape } \\
\text { composition }\end{array}$ \\
\hline PER_WATER & $\begin{array}{l}\text { Percent surface } \\
\text { water }\end{array}$ & $\begin{array}{l}\text { Percent of surface water land cover within respective L1 } \\
\text { landscapes. }\end{array}$ & $\%$ & $2.739 \pm 2.907$ & $0.07-17.14$ & $\begin{array}{l}\text { Landscape } \\
\text { composition }\end{array}$ \\
\hline PER_WET & Percent wetland & $\begin{array}{l}\text { Percent of wetland land cover within respective L1 } \\
\text { landscapes. }\end{array}$ & $\%$ & $1.686 \pm 1.849$ & $0-11.04$ & $\begin{array}{l}\text { Landscape } \\
\text { composition }\end{array}$ \\
\hline TA_HA & $\begin{array}{l}\text { Total area } \\
\text { measured in } \\
\text { hectares }\end{array}$ & Total area of L1 landscape. & hectares & $1611 \pm 1340$ & $390-7913$ & $\begin{array}{l}\text { Covariable used to } \\
\text { adjust for differences } \\
\text { in survey effort. }\end{array}$ \\
\hline COYOTE & Coyote & Binary variable; codes for coyote presence & none & - & - & $\begin{array}{l}\text { Assess fox presence } \\
\text { in relation to coyotes }\end{array}$ \\
\hline RACCOON & Raccoon & Binary variable; codes for raccoon presence & none & - & - & $\begin{array}{l}\text { Assess fox presence } \\
\text { in relation to } \\
\text { raccoons }\end{array}$ \\
\hline
\end{tabular}

Table 1.4. Complete suite of untransformed covariables considered for logistic regression modeling of fox (gray fox [Urocyon cinereoargenteus] and red fox [Vulpes vulpes] combined) occurrence in northeastern Illinois from 2005-2007. 


\begin{tabular}{|c|c|c|c|c|c|}
\hline VAR & Name & Description & Mean \pm SD & Range & Application \\
\hline log_no_stns & $\begin{array}{l}\text { Number of survey } \\
\text { stations }\end{array}$ & $\begin{array}{l}\text { Log transformation of total number of survey stations } \\
\text { operated within respective landscapes. }\end{array}$ & $0.721 \pm 0.4719$ & $0-1.716$ & $\begin{array}{l}\text { Covariable used to adjust for } \\
\text { differences in survey effort. }\end{array}$ \\
\hline fourth_PER_AG & Percent agriculture & $\begin{array}{l}\text { Fourth root transformation of agriculture land cover within } \\
\text { respective landscapes. }\end{array}$ & $1.394 \pm 0.867$ & $0-2.95$ & Landscape composition \\
\hline sqrt_PER_FOR & Percent forest & $\begin{array}{l}\text { Square root transformation of percent of forest land cover } \\
\text { within respective landscapes. }\end{array}$ & $4.455 \pm 1.616$ & $0-7.56$ & Landscape composition \\
\hline cube_PER_HIGH & $\begin{array}{l}\text { Percent high density } \\
\text { urban }\end{array}$ & $\begin{array}{l}\text { Cube root transformation of percent of high density urban } \\
\text { land cover within respective landscapes. }\end{array}$ & $1.7358 \pm 0.7842$ & $0-3.85$ & Landscape composition \\
\hline sqrt_PER_LOW & $\begin{array}{l}\text { Percent low density } \\
\text { urban }\end{array}$ & $\begin{array}{l}\text { Square root transformation of percent of low density urban } \\
\text { land cover within respective landscapes. }\end{array}$ & $2.276 \pm 1.039$ & $0.31-4.77$ & Landscape composition \\
\hline sqrt_PER_MED & $\begin{array}{l}\text { Percent medium } \\
\text { density urban }\end{array}$ & $\begin{array}{l}\text { Square root transformation of percent of medium density } \\
\text { urban land cover within respective landscapes. }\end{array}$ & $4.337 \pm 1.844$ & $0-8.13$ & Landscape composition \\
\hline sqrt_PER_URBOP & $\begin{array}{l}\text { Percent urban open } \\
\text { space }\end{array}$ & $\begin{array}{l}\text { Square root transformation of percent of urban open space } \\
\text { land cover within respective landscapes. }\end{array}$ & $4.32 \pm 1.663$ & $0-7.43$ & Landscape composition \\
\hline sqrt_PER_WET & Percent wetland & $\begin{array}{l}\text { Square root transformation of percent of wetland land cover } \\
\text { within respective landscapes. }\end{array}$ & $1.1275 \pm 0.6493$ & $0-3.32$ & Landscape composition \\
\hline COYOTE & Coyote presence & Binary variable; codes for coyote presence & - & - & $\begin{array}{l}\text { Assess fox occurrence in } \\
\text { relation to coyote presence }\end{array}$ \\
\hline
\end{tabular}

Table 1.5. Transformed covariables used for logistic regression modeling of fox (gray fox [Urocyon cinereoargenteus] and red fox [Vulpes vulpes] combined) occurrence in northeastern Illinois from 2005-2007. 


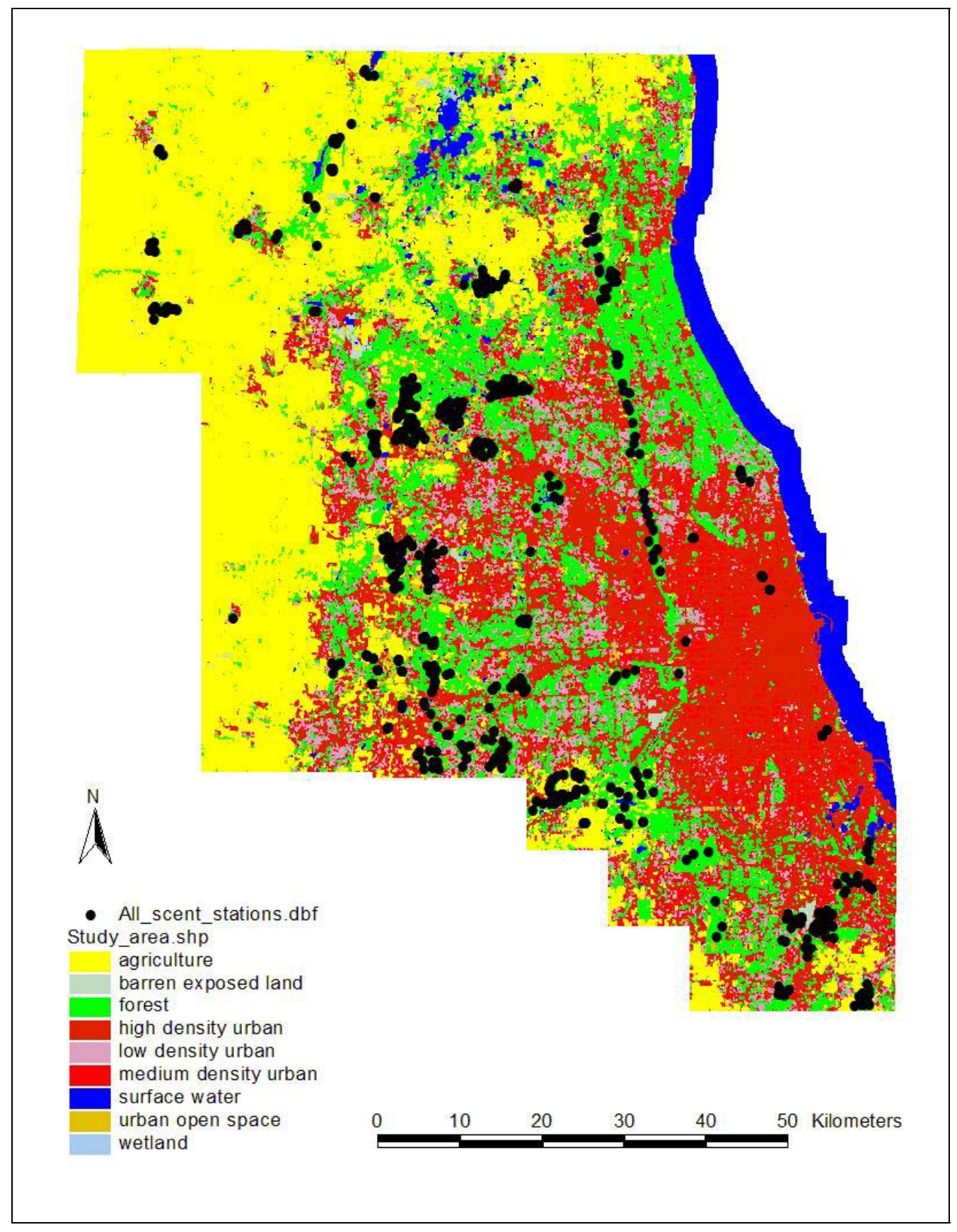

Figure 1.3. Distribution of scent station surveys conducted from 2005-2007 in northeastern Illinois. Black dots indicate scent station placement across the landscape. 


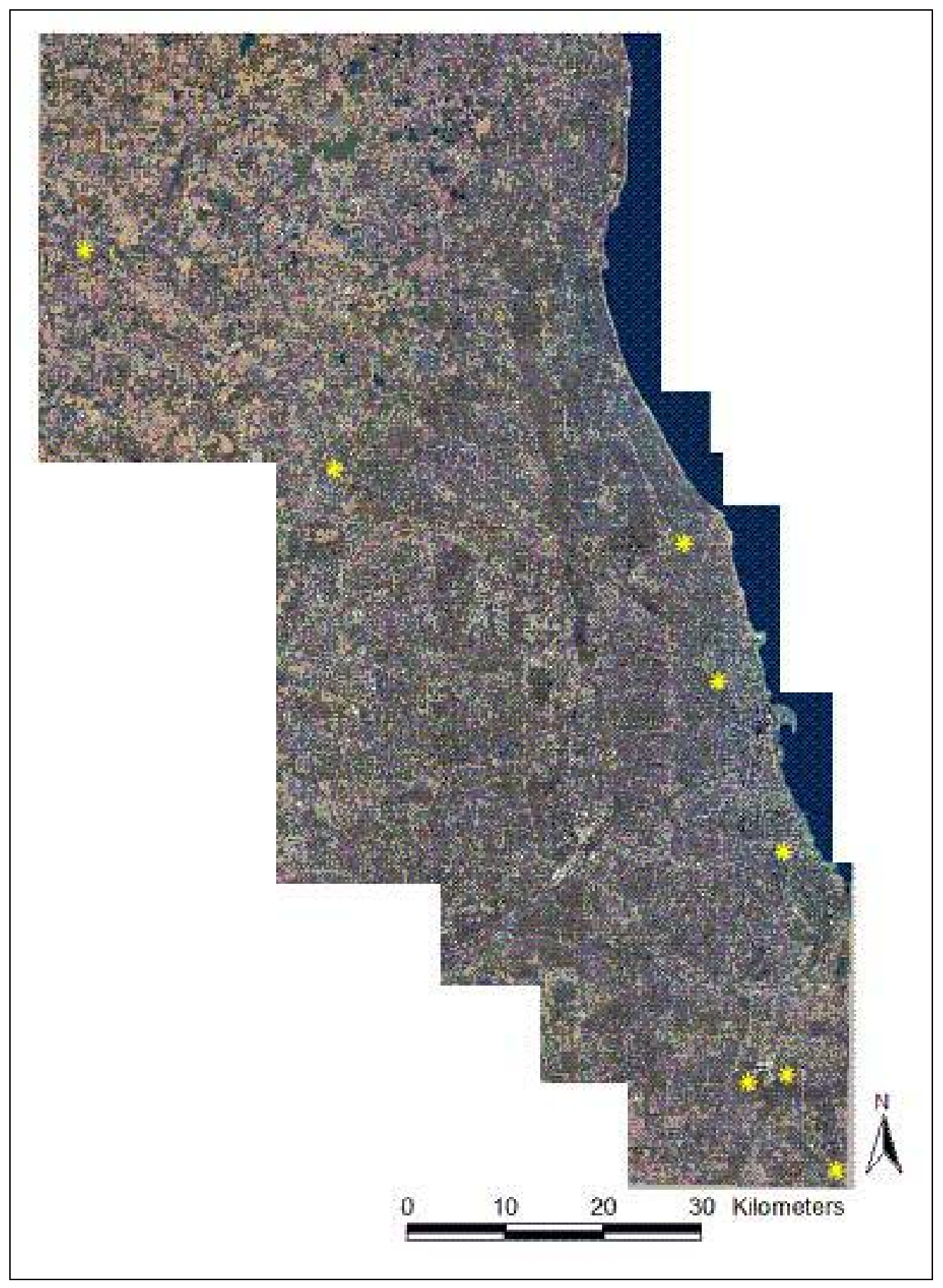

Figure 1.4. Distribution of gray fox (Urocyon cinereoargenteus) from surveys conducted between 2005-2007 in the northeastern Illinois. Yellow stars indicate sites with confirmed gray fox presence. 


\begin{tabular}{|c|c|c|c|c|c|c|c|c|c|}
\hline $\begin{array}{l}\text { Fox } \\
\text { ID }\end{array}$ & Study Site & Species & Capture date & Sex & Age & $\begin{array}{l}2006 \text { home rang } \\
\text { (\# locations) }\end{array}$ & $\begin{array}{l}2007 \text { home rans } \\
\text { (\# locations) }\end{array}$ & $\begin{array}{l}2008 \text { home rang } \\
\text { (\# locations) }\end{array}$ & Status \\
\hline 4 & $\begin{array}{l}\text { Max McGraw } \\
\text { Wildlife } \\
\text { Foundation }\end{array}$ & red fox & $1 / 5 / 2006$ & $\mathrm{M}$ & adult & $-(6)$ & $224(81)$ & $-(10)$ & presumed dead $(2 / 2008)$ \\
\hline 5 & $\begin{array}{l}\text { Oak Woods } \\
\text { Cemetery }\end{array}$ & gray fox & $5 / 16 / 2006$ & M & adult & $57(128)$ & $21(37)$ & - & $\begin{array}{l}\text { dead (killed by coyote; } \\
6 / 8 / 2007 \text { ) }\end{array}$ \\
\hline 6 & $\begin{array}{l}\text { Thorn Creek F.P. } \\
\text { Homewood }\end{array}$ & / gray fox & $6 / 8 / 2006$ & $\mathrm{M}$ & adult & $47(180)$ & $189(137)$ & $-(10)$ & $\begin{array}{l}\text { presumed slipped collar } \\
(3 / 2008)\end{array}$ \\
\hline 7 & $\begin{array}{l}\text { Thorn Creek F.P. } \\
\text { Homewood }\end{array}$ & / gray fox & $7 / 29 / 2006$ & $\mathrm{~F}$ & adult & $150(59)$ & $252(138)$ & $-(7)$ & collar dead $(2 / 2008)$ \\
\hline 8 & Skokie & gray fox & $8 / 23 / 2006$ & $\mathrm{~F}$ & yearling & $-(49)$ & - & 一 & dead (project related; 9/2006) \\
\hline 9 & Skokie & gray fox & $11 / 23 / 2006$ & $\mathrm{M}$ & adult & $-(11)$ & $249(178)$ & $-(15)$ & dead (distemper; 3/12/2008) \\
\hline 12 & Homewood & gray fox & $7 / 21 / 2007$ & $\mathrm{~F}$ & yearling & - & - & - & slipped collar $(7 / 2007)$ \\
\hline 13 & Skokie & gray fox & $9 / 13 / 2007$ & $\mathrm{~F}$ & yearling & - & $299(52)$ & $-(11)$ & $\begin{array}{l}\text { dead (road kill-likely related } \\
\text { to distemper; 3/6/2008) }\end{array}$ \\
\hline 14 & Poplar Creek F.P. & red fox & $11 / 29 / 2007$ & $\mathrm{~F}$ & adult & - & $-(11)$ & $720(62)$ & dead (road kill; 6/28/2008) \\
\hline
\end{tabular}

Table 1.6. Capture information, home range estimates and status of collared gray (Urocyon cinereoargenteus) and red (Vulpes vulpes) foxes in northeastern Illinois from 2006-2007. 


\begin{tabular}{lccccccccc}
\hline FOXID_YEAR & Med Urb & Forest & Urb Open & High Urb & Low Urb & Water & Wetland & Ag & Barren \\
\hline ID4_2007 & 3.58 & $63.60^{* *}$ & 22.51 & 0.31 & 1.01 & 6.46 & 1.71 & 0.83 \\
\hline ID5_2006 & 9.63 & 16.21 & $49.94 * *$ & 0.30 & 3.97 & 6.43 & 13.10 & 0.00 \\
ID5_2007 & 9.51 & 6.47 & $53.99 * *$ & 0.00 & 5.28 & 9.79 & 14.87 & 0.08 \\
\hline ID6_2006 & 13.57 & $67.86^{* *}$ & 9.81 & 0.25 & 3.58 & 3.59 & 0.00 & 1.35 & 0.00 \\
ID6_2007 & 29.35 & 14.18 & 16.40 & $30.92^{* *}$ & 3.39 & 3.18 & 1.19 & 0.00 & 1.41 \\
\hline ID7_2006 & 9.90 & $75.53 * *$ & 6.68 & 0.57 & 3.28 & 1.77 & 0.12 & 0.42 \\
ID7_2007 & $30.58^{* *}$ & 16.57 & 13.75 & 24.99 & 9.49 & 3.40 & 1.04 & 0.00 \\
\hline ID9_2007 & $53.75^{* *}$ & 4.03 & 3.27 & 3.18 & 35.76 & 0.00 & 0.00 & 0.18 \\
\hline ID13_2007 & $46.67 * *$ & 6.73 & 3.53 & 2.75 & 40.32 & 0.00 & 0.00 & 0.00 \\
\hline ID14_2008 & $59.83^{* *}$ & 2.31 & 4.66 & 14.71 & 15.98 & 2.37 & 0.14 & 0.00 \\
\hline
\end{tabular}

Table 1.7. Percent habitat types in $95 \% \mathrm{MCP}$ home ranges of collared foxes. ${ }^{* *}$ indicates the highest percentage for each respective home range. 'Med Urb'=Medium Density Urban, 'Urb Open'=Urban Open Space, 'High Urb'=High Density Urban, 'Low Urb'=Low Density Urban, 'Water'=Surface Water, 'Ag'=Agriculture, 'Barren' $=$ Barren Exposed Land. 


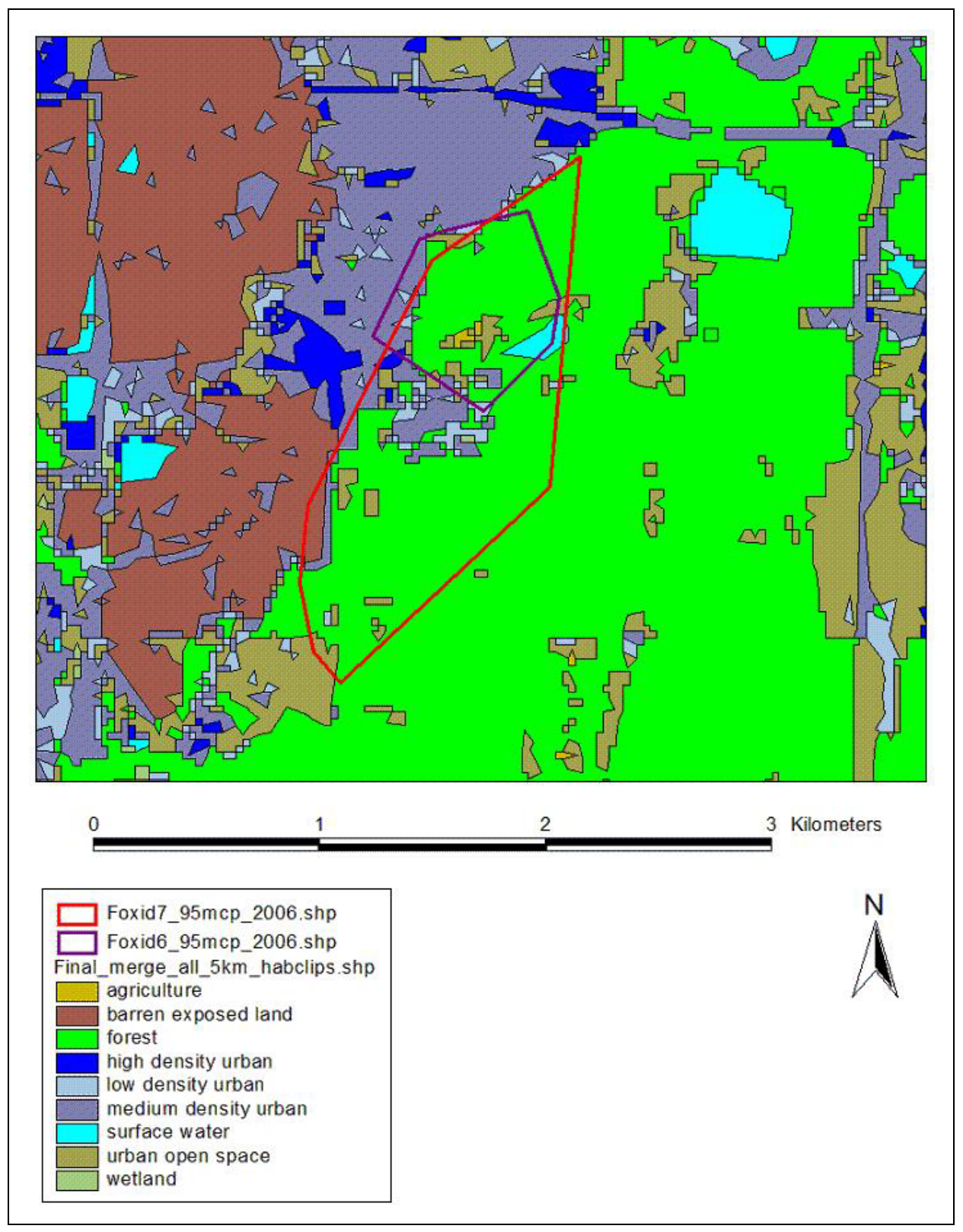

A

Figure 1.5. Annual home ranges of fox ID 6 (purple) and fox ID 7 (red) in 2006 (A) and 2007 (B). Home ranges are placed over a modified version of the Illinois GAP land cover layer (Table 1.3) in order to determine the composition of each home range. The foxes primarily used the Thorn Creek Forest Preserve and surrounding areas in 2006 and moved to residential yards in Homewood, IL in 2007.

Figure 1.5 continued... 
Figure 1.5 (continued)...

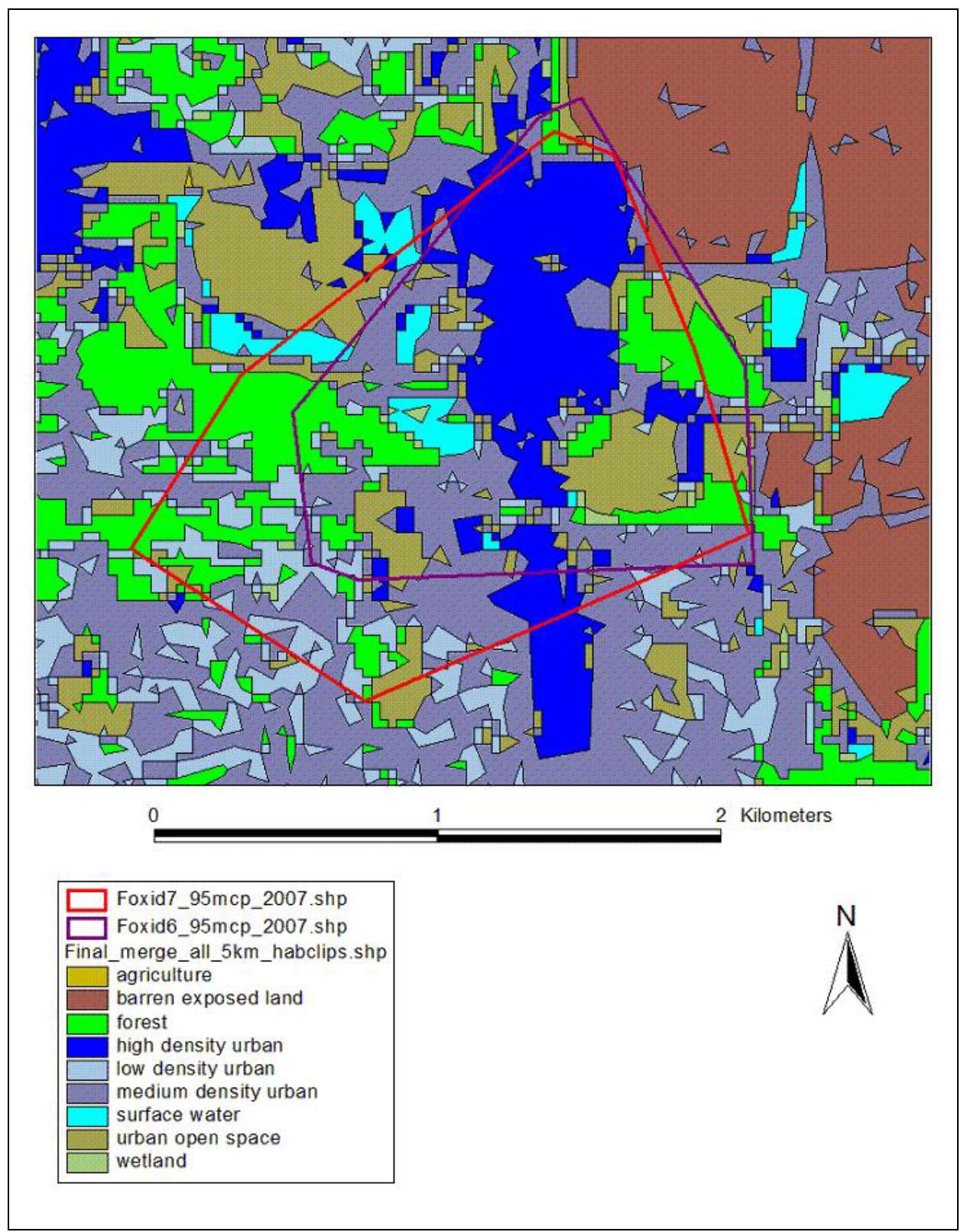

B 


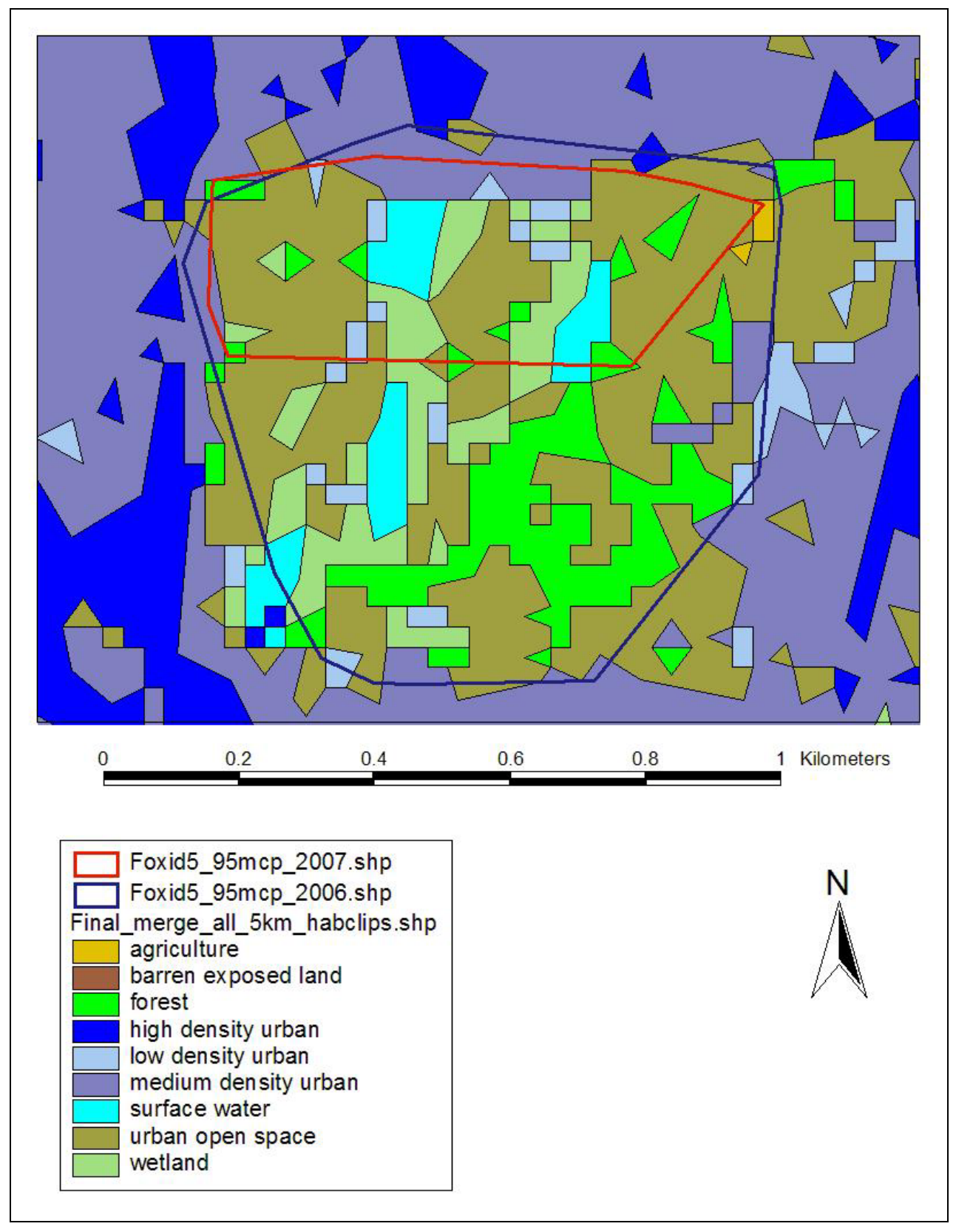

Figure 1.6. 2006 (dark blue) and 2007 (red) home range estimates of fox ID 5. Home ranges are placed over a modified version of the Illinois GAP land cover layer (Table 1.3) in order to determine the composition of each home range. The activity of this fox was completely encompassed by the boundary walls of an urban cemetery. 


\begin{tabular}{|c|c|c|c|c|c|c|}
\hline Models & $\mathrm{K}$ & AIC & $\mathrm{AIC}_{\mathrm{C}}$ & $\triangle \mathrm{AICC}$ & $\mathrm{w}_{\mathrm{i}}$ & evid.rat \\
\hline sqrt_PER_FOR + sqrt_PER_WET + log_no_stns & 4 & 74.42 & 75.01 & 0.00 & 0.23 & 1.00 \\
\hline sqrt_PER_FOR + sqrt_PER_WET + fourth_PER_AG + log_no_stns & 5 & 75.85 & 76.76 & 1.74 & 0.10 & 2.39 \\
\hline sqrt_PER_FOR + sqrt_PER_WET + COYOTE + log_no_stns & 5 & 76.15 & 77.06 & 2.04 & 0.08 & 2.78 \\
\hline fourth_PER_AG + sqrt_PER_WET + log_no_stns & 4 & 76.83 & 77.43 & 2.41 & 0.07 & 3.35 \\
\hline $\begin{array}{l}\text { sqrt_PER_FOR }+ \text { sqrt_PER_WET }+ \text { sqrt_PER_URBOP }+ \text { fourth_PER_AG }+ \\
\text { log_no_stns }\end{array}$ & 6 & 76.18 & 77.48 & 2.46 & 0.07 & 3.42 \\
\hline sqrt_PER_WET + sqrt_PER_URBOP + log_no_stns & 4 & 76.91 & 77.50 & 2.49 & 0.07 & 3.47 \\
\hline sqrt_PER_FOR + sqrt_PER_URBOP + fourth_PER_AG + log_no_stns & 5 & 77.28 & 78.19 & 3.17 & 0.05 & 4.89 \\
\hline fourth_PER_AG + sqrt_PER_WET + sqrt_PER_URBOP + log_no_stns & 5 & 77.41 & 78.32 & 3.31 & 0.04 & 5.22 \\
\hline sqrt_PER_LOW + sqrt_PER_FOR + log_no_stns & 4 & 77.84 & 78.44 & 3.42 & 0.04 & 5.54 \\
\hline sqrt_PER_FOR + sqrt_PER_URBOP + log_no_stns & 4 & 77.86 & 78.46 & 3.44 & 0.04 & 5.59 \\
\hline sqrt_PER_FOR + log_no_stns & 3 & 78.67 & 79.02 & 4.01 & 0.03 & 7.41 \\
\hline sqrt_PER_FOR + fourth_PER_AG + log_no_stns & 4 & 78.46 & 79.05 & 4.04 & 0.03 & 7.53 \\
\hline sqrt_PER_MED + sqrt_PER_FOR + log_no_stns & 4 & 79.44 & 80.04 & 5.02 & 0.02 & 12.33 \\
\hline fourth_PER_AG + sqrt_PER_URBOP + log_no_stns & 4 & 79.68 & 80.27 & 5.26 & 0.02 & 13.86 \\
\hline sqrt_PER_MED + log_no_stns & 3 & 80.51 & 80.86 & 5.84 & 0.01 & 18.59 \\
\hline COYOTE + sqrt_PER_FOR + log_no_stns & 4 & 80.65 & 81.25 & 6.23 & 0.01 & 22.54 \\
\hline sqrt_PER_LOW + sqrt_PER_URBOP + fourth_PER_AG $+\log$ no_stns & 5 & 80.43 & 81.34 & 6.32 & 0.01 & 23.60 \\
\hline sqrt_PER_FOR + fourth_PER_AG + COYOTE + log_no_stns & 5 & 80.45 & 81.36 & 6.35 & 0.01 & 23.91 \\
\hline $\begin{array}{l}\text { COYOTE + sqrt_PER_FOR }+ \text { fourth_PER_AG }+ \text { sqrt_PER_WET }+ \\
\text { sqrt_PER_LOW }+ \text { sqrt_PER_MED }+ \text { cube_PER_HIGH }+ \text { sqrt_PER_URBOP }+ \\
\text { log_no_stns }\end{array}$ & 10 & 78.10 & 81.71 & 6.70 & 0.01 & 28.44 \\
\hline cube_PER_HIGH + log_no_stns & 3 & 81.52 & 81.88 & 6.86 & 0.01 & 30.92 \\
\hline sqrt_PER_LOW + sqrt_PER_URBOP + log_no_stns & 4 & 81.35 & 81.94 & 6.93 & 0.01 & 31.94 \\
\hline
\end{tabular}

Table 1.8. Model selection results for 37 models of fox occurrence (gray fox [Urocyon cinereoargenteus] and red fox [Vulpes vulpes] combined) in northeastern Illinois from 2005-2007. Models were ranked by $\mathrm{AIC}_{\mathrm{C}} . \Delta \mathrm{AIC}_{\mathrm{C}}$ is the difference in $\mathrm{AIC}_{\mathrm{C}}$ units from the highest ranking model. Number of parameters $(\mathrm{K})$, model $\mathrm{AIC}_{\mathrm{C}}$ weights $\left(\mathrm{w}_{\mathrm{i}}\right)$, and evidence ratios (evid.rat) are also shown. Coding and explanation of model parameters are shown in Table 1.5.

Table 1.8 continued... 
Table 1.8 (continued)...

\begin{tabular}{|c|c|c|c|c|c|c|}
\hline Models & $\mathrm{K}$ & AIC & $\mathrm{AIC}_{\mathrm{C}}$ & $\triangle \mathrm{AICC}$ & $\mathrm{w}_{\mathrm{i}}$ & evid.rat \\
\hline $\begin{array}{l}\text { sqrt_PER_FOR + cube_PER_HIGH + sqrt_PER_MED + sqrt_PER_LOW + } \\
\text { log_no_stns }\end{array}$ & 6 & 80.98 & 82.27 & 7.25 & 0.01 & 37.60 \\
\hline $\begin{array}{l}\text { cube_PER_HIGH + sqrt_PER_MED + sqrt_PER_LOW + sqrt_PER_URBOP + } \\
\text { log_no_stns }\end{array}$ & 6 & 81.16 & 82.45 & 7.44 & 0.01 & 41.24 \\
\hline sqrt_PER_URBOP + log_no_stns & 3 & 82.41 & 82.77 & 7.75 & 0.00 & 48.21 \\
\hline cube_PER_HIGH + sqrt_PER_MED + log_no_stns & 4 & 82.20 & 82.80 & 7.79 & 0.00 & 49.09 \\
\hline log_no_stns & 2 & 82.90 & 83.08 & 8.06 & 0.00 & 56.33 \\
\hline $\begin{array}{l}\text { fourth_PER_AG + sqrt_PER_URBOP + sqrt_PER_LOW + sqrt_PER_MED + } \\
\text { log_no_stns }\end{array}$ & 6 & 81.97 & 83.26 & 8.25 & 0.00 & 61.76 \\
\hline sqrt_PER_LOW + log_no_stns & 3 & 83.21 & 83.56 & 8.54 & 0.00 & 71.68 \\
\hline fourth_PER_AG + COYOTE + log_no_stns & 4 & 82.99 & 83.59 & 8.57 & 0.00 & 72.66 \\
\hline cube_PER_HIGH + sqrt_PER_MED + sqrt_PER_LOW + log_no_stns & 5 & 83.03 & 83.94 & 8.92 & 0.00 & 86.53 \\
\hline COYOTE + log_no_stns & 3 & 84.67 & 85.03 & 10.01 & 0.00 & 149.24 \\
\hline 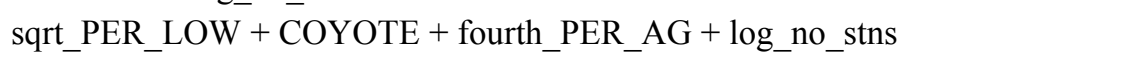 & 5 & 84.52 & 85.43 & 10.41 & 0.00 & 182.45 \\
\hline sqrt_PER_WET & 2 & 88.32 & 88.49 & 13.48 & 0.00 & 843.57 \\
\hline 1 & 1 & 88.92 & 88.98 & 13.97 & 0.00 & 1078.21 \\
\hline fourth_PER_AG & 2 & 89.24 & 89.41 & 14.40 & 0.00 & 1338.39 \\
\hline
\end{tabular}




\begin{tabular}{lc}
\hline Model Parameter & $\Sigma \mathrm{W}_{\mathrm{i}}$ \\
\hline$\beta_{\text {sqr_PER_WET }}$ & 0.66 \\
$\beta_{\text {sqr__PER_FOR }}$ & 0.61 \\
$\beta_{\text {sqrt_PER_FOR }}+\beta_{\text {sqrt_PER_WET }}$ & 0.48 \\
$\beta_{\text {fourth_PER_AG }}$ & 0.33 \\
$\beta_{\text {sqrt_URBOP }}$ & 0.27 \\
\hline
\end{tabular}

Table 1.9. Cumulative $\mathrm{AIC}_{\mathrm{C}}$ weight $\left(\Sigma \mathrm{w}_{\mathrm{i}}\right)$ of most common parameters in top ranked models $\left(\mathrm{w}_{\mathrm{i}}>0.04\right)$ for gray fox presence. Coding and explanation of model parameters are provided in Table 1.5. 


\begin{tabular}{|c|c|c|c|c|c|c|c|c|c|c|c|c|c|}
\hline \multirow[b]{2}{*}{ Model } & \multirow[b]{2}{*}{$\mathrm{K}$} & \multirow[b]{2}{*}{$\mathrm{AIC}_{\mathrm{C}}$} & \multirow[b]{2}{*}{$\Delta \mathrm{AIC}_{\mathrm{C}}$} & \multirow[b]{2}{*}{$\mathrm{w}_{\mathrm{i}}$} & \multirow[b]{2}{*}{$\beta \mathrm{i}$} & & & \multirow[b]{2}{*}{ SE } & \multicolumn{2}{|c|}{$\beta 95 \% \mathrm{CI}$} & \multirow[b]{2}{*}{ OR } & \multicolumn{2}{|c|}{ OR $95 \% \mathrm{CI}$} \\
\hline & & & & & & & & & Lower & Upper & & Lower & Upper \\
\hline \multirow{3}{*}{$\begin{array}{l}\text { sqrt_PER_FOR + sqrt_PER_WET + } \\
\text { log_no_stns }\end{array}$} & 4 & 75.01 & 0 & 0.23 & intercept & $=$ & -0.26 & 0.92 & -2.07 & 1.54 & & & \\
\hline & & & & & sqrt_PER_FOR & $=$ & -0.37 & 0.21 & -0.79 & 0.04 & 0.69 & 0.45 & 1.04 \\
\hline & & & & & sqrt_PER_WET & $=$ & -1.49 & 0.68 & -2.82 & -0.16 & 0.23 & 0.06 & 0.85 \\
\hline \multirow{4}{*}{$\begin{array}{l}\text { sqrt_PER_FOR + sqrt_PER_WET + } \\
\text { fourth_PER_AG }+ \text { log_no_stns }\end{array}$} & 5 & 76.76 & 1.74 & 0.1 & intercept & $=$ & -0.12 & 0.96 & -2.00 & 1.76 & & & \\
\hline & & & & & sqrt_PER_FOR & $=$ & -0.35 & 0.21 & -0.77 & 0.06 & 0.70 & 0.46 & 1.07 \\
\hline & & & & & sqrt_PER_WET & $=$ & -1.37 & 0.70 & -2.75 & 0.01 & 0.25 & 0.06 & 1.01 \\
\hline & & & & & fourth_PER_AG & $=$ & -0.31 & 0.41 & -1.12 & 0.50 & 0.74 & 0.33 & 1.65 \\
\hline \multirow{4}{*}{$\begin{array}{l}\text { sqrt_PER_FOR + sqrt_PER_WET + } \\
\text { COYYYTE + log_no_stns }\end{array}$} & 5 & 77.06 & 2.04 & 0.08 & intercept & $=$ & -0.30 & 0.93 & -2.12 & 1.52 & & & \\
\hline & & & & & sqrt_PER_FOR & $=$ & -0.36 & 0.21 & -0.78 & 0.06 & 0.70 & 0.46 & 1.06 \\
\hline & & & & & sqrt_PER_WET & $=$ & -1.53 & 0.69 & -2.88 & -0.19 & 0.22 & 0.06 & 0.83 \\
\hline & & & & & COYOTE & $=$ & 0.43 & 0.82 & -1.19 & 2.04 & 1.54 & 0.30 & 7.73 \\
\hline \multirow{3}{*}{$\begin{array}{l}\text { fourth_PER_AG }+ \text { sqrt_PER_WET }+ \\
\text { log_no_stns }\end{array}$} & 4 & 77.43 & 2.41 & 0.07 & intercept & $=$ & -1.14 & 0.73 & -2.57 & 0.30 & & & \\
\hline & & & & & fourth_PER_AG & $=$ & -0.39 & 0.40 & -1.18 & 0.39 & 0.67 & 0.31 & 1.48 \\
\hline & & & & & sqrt PER WET & $=$ & -1.61 & 0.72 & -3.02 & -0.20 & 0.20 & 0.05 & 0.82 \\
\hline
\end{tabular}

Table 1.10. Covariate $\left(\beta_{\mathrm{i}}\right)$ and odds ratio $(\mathrm{OR})$ estimates under top ten logistic regression models $\left(\mathrm{AIC} \mathrm{C}_{\mathrm{C}}\right.$ weight $\left.\left[\mathrm{w}_{\mathrm{i}}\right]>0.04\right)$ for fox occurrence (gray fox [Urocyon cinereoargenteus] and red fox [Vulpes vulpes] combined) in northeastern Illinois from 2005-2007. Models were ranked by $\mathrm{AIC}_{\mathrm{C}} . \Delta \mathrm{AIC}_{\mathrm{C}}$ is the difference in $\mathrm{AIC}_{\mathrm{C}}$ units from the highest ranking model. Number of parameters $(\mathrm{K})$, model $\mathrm{AIC}_{\mathrm{C}}$ weights, standard errors of covariates $(\mathrm{SE})$, and $95 \%$ confidence intervals of covariates $(\beta 95 \% \mathrm{CI})$ and odds ratios (OR 95\% CI) are also shown. Coding and explanation of model parameters are shown in Table 1.5.

Table 1.10 continued... 
Table 1.10 (continued)...

\begin{tabular}{|c|c|c|c|c|c|c|c|c|c|c|c|c|c|}
\hline \multirow[b]{2}{*}{ Model } & \multirow[b]{2}{*}{$\mathrm{K}$} & \multirow[b]{2}{*}{$\mathrm{AIC}_{\mathrm{C}}$} & \multirow[b]{2}{*}{$\Delta \mathrm{AIC}_{\mathrm{C}}$} & \multirow[b]{2}{*}{$\mathrm{w}_{\mathrm{i}}$} & \multirow[b]{2}{*}{$\beta \mathrm{i}$} & & & \multirow[b]{2}{*}{ SE } & \multicolumn{2}{|c|}{$\beta 95 \% \mathrm{CI}$} & \multirow[b]{2}{*}{ OR } & \multicolumn{2}{|c|}{$95 \% \mathrm{CI}$} \\
\hline & & & & & & & & & Lower & Upper & & Lower & Upper \\
\hline \multirow{5}{*}{$\begin{array}{l}\text { sqrt_PER_FOR + sqrt_PER_WET + } \\
\text { sqrt_PER_URBOP + fourth_PER_AG } \\
+\log _{\text {_no_stns }}\end{array}$} & 6 & 77.48 & 2.46 & 0.07 & intercept & $=$ & 0.82 & 1.29 & -1.70 & 3.35 & & & \\
\hline & & & & & sqrt_PER_FOR & $=$ & -0.39 & 0.23 & -0.84 & 0.06 & 0.68 & 0.43 & 1.06 \\
\hline & & & & & sqrt_PER_WET & $=$ & -1.14 & 0.70 & -2.52 & 0.24 & 0.32 & 0.08 & 1.27 \\
\hline & & & & & sqrt_PER_URBOP & $=$ & -0.26 & 0.21 & -0.67 & 0.14 & 0.77 & 0.51 & 1.15 \\
\hline & & & & & fourth_PER_AG & $=$ & -0.41 & 0.42 & -1.24 & 0.42 & 0.66 & 0.29 & 1.52 \\
\hline \multirow{3}{*}{$\begin{array}{l}\text { sqrt_PER_WET + sqrt_PER_URBOP + } \\
\text { log_no_stns }\end{array}$} & 4 & 77.5 & 2.49 & 0.07 & intercept & $=$ & -0.82 & 0.89 & -2.57 & 0.92 & & & \\
\hline & & & & & sqrt_PER_WET & $=$ & -1.63 & 0.70 & -3.00 & -0.27 & 0.20 & 0.05 & 0.76 \\
\hline & & & & & sqrt_PER_URBOP & $=$ & -0.18 & 0.19 & -0.56 & 0.19 & 0.83 & 0.57 & 1.21 \\
\hline \multirow{4}{*}{$\begin{array}{l}\text { sqrt_PER_FOR + sqrt_PER_URBOP + } \\
\text { fourth_PER_AG + log_no_stns }\end{array}$} & 5 & 78.19 & 3.17 & 0.05 & intercept & $=$ & 0.87 & 1.22 & -1.52 & 3.27 & & & \\
\hline & & & & & sqrt_PER_FOR & $=$ & -0.44 & 0.22 & -0.87 & 0.00 & 0.65 & 0.42 & 1.00 \\
\hline & & & & & sqrt_PER_URBOP & $=$ & -0.34 & 0.20 & -0.73 & 0.04 & 0.71 & 0.48 & 1.05 \\
\hline & & & & & fourth_PER_AG & $=$ & -0.61 & 0.40 & -1.39 & 0.17 & 0.54 & 0.25 & 1.18 \\
\hline \multirow{4}{*}{$\begin{array}{l}\text { fourth_PER_AG + sqrt_PER_WET + } \\
\text { sqrt_PER_URBOP + log_no_stns }\end{array}$} & 5 & 78.32 & 3.31 & 0.04 & intercept & $=$ & -0.41 & 0.96 & -2.30 & 1.47 & & & \\
\hline & & & & & fourth_PER_AG & $=$ & -0.49 & 0.41 & -1.29 & 0.31 & 0.61 & 0.27 & 1.37 \\
\hline & & & & & sqrt_PER_WET & $=$ & -1.36 & 0.73 & -2.80 & 0.07 & 0.26 & 0.06 & 1.07 \\
\hline & & & & & sqrt_PER_URBOP & $=$ & -0.24 & 0.20 & -0.63 & 0.16 & 0.79 & 0.53 & 1.17 \\
\hline
\end{tabular}

Table 1.10 continued... 
Table 1.10 (continued)...

\begin{tabular}{|c|c|c|c|c|c|c|c|c|c|c|c|c|c|}
\hline \multirow[b]{2}{*}{ Model } & \multirow[b]{2}{*}{$\mathrm{K}$} & \multirow[b]{2}{*}{$\mathrm{AIC}_{\mathrm{C}}$} & \multirow[b]{2}{*}{$\Delta \mathrm{AIC}_{\mathrm{C}}$} & \multirow[b]{2}{*}{$\mathrm{w}_{\mathrm{i}}$} & \multirow[b]{2}{*}{$\beta \mathrm{i}$} & & & \multirow[b]{2}{*}{ SE } & \multicolumn{2}{|c|}{$\beta 95 \% \mathrm{CI}$} & \multirow[b]{2}{*}{ OR } & \multicolumn{2}{|c|}{$95 \% \mathrm{CI}$} \\
\hline & & & & & & & & & Lower & Upper & & Lower & Upper \\
\hline \multirow[t]{3}{*}{$\begin{array}{l}\text { sqrt_PER_LOW + sqrt_PER_FOR + } \\
\text { log_no_stns }\end{array}$} & 4 & 78.44 & 3.42 & 0.04 & intercept & $=$ & -1.75 & 1.07 & -3.85 & 0.34 & & & \\
\hline & & & & & sqrt_PER_LOW & $=$ & 0.50 & 0.31 & -0.10 & 1.10 & 1.65 & 0.91 & 3.00 \\
\hline & & & & & sqrt_PER_FOR & $=$ & -0.56 & 0.22 & -0.99 & -0.13 & 0.57 & 0.37 & 0.88 \\
\hline \multirow{3}{*}{$\begin{array}{l}\text { sqrt_PER_FOR + sqrt_PER_URBOP + } \\
\text { log_no_stns }\end{array}$} & 4 & 78.46 & 3.44 & 0.04 & intercept & $=$ & 0.36 & 1.09 & -1.78 & 2.50 & & & \\
\hline & & & & & sqrt_PER_FOR & $=$ & -0.50 & 0.21 & -0.92 & -0.09 & 0.61 & 0.40 & 0.92 \\
\hline & & & & & sqrt PER URBOP & $=$ & -0.30 & 0.18 & -0.66 & 0.06 & 0.74 & 0.52 & 1.06 \\
\hline
\end{tabular}




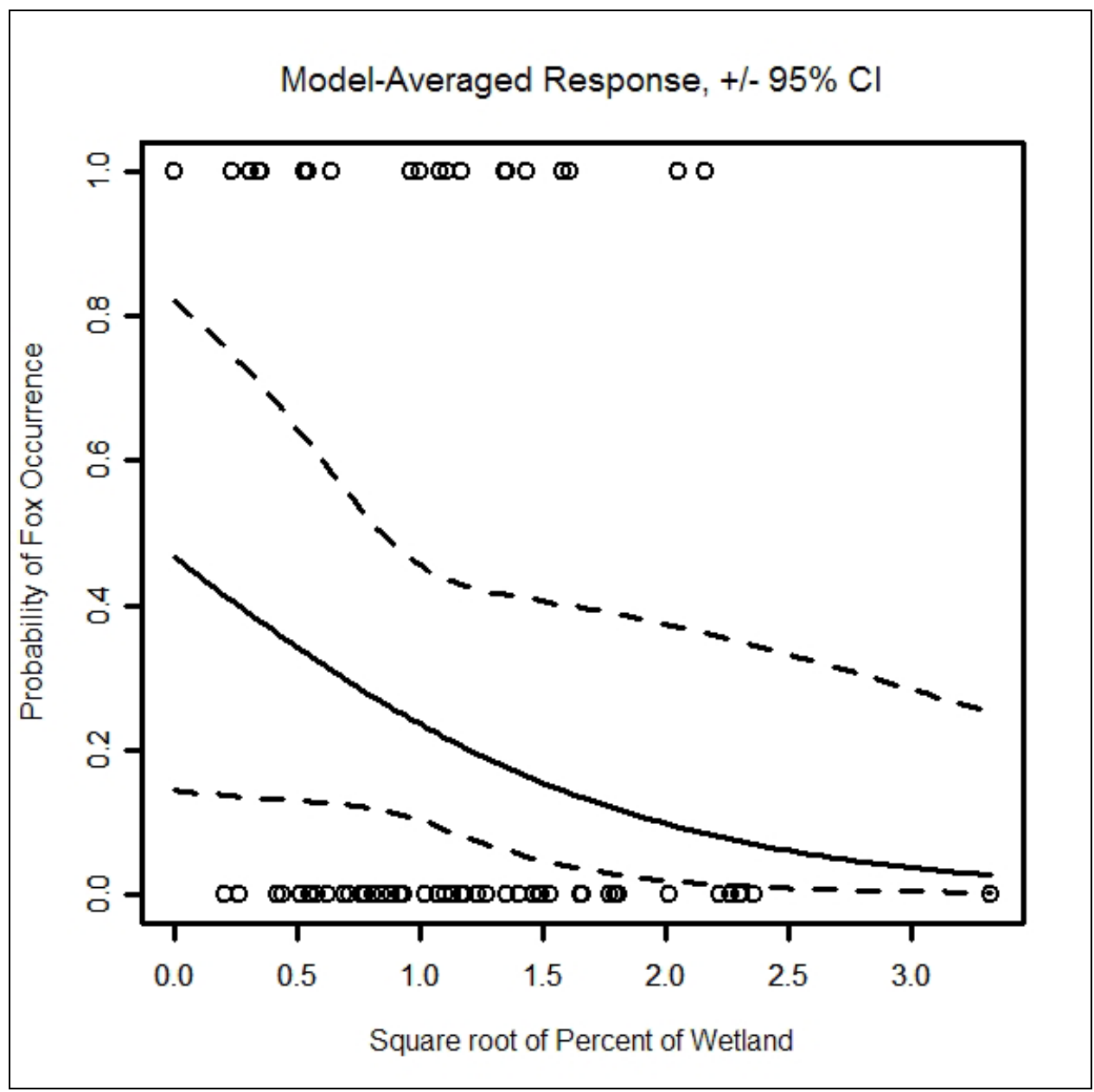

Figure 1.7. Solid line indicates the predicted probability of fox occurrence using modelaveraged parameter for 'Square root of Percent of Urban Wetland' from candidate set of logistic regression models ranked by $\mathrm{AIC}_{\mathrm{C}}$. The probability of fox occurrence was calculated holding all variables constant while allowing the square root of the percent of wetland to vary. Dashed lines indicate upper and lower 95\% confidence intervals. Open circles indicate original data points. 


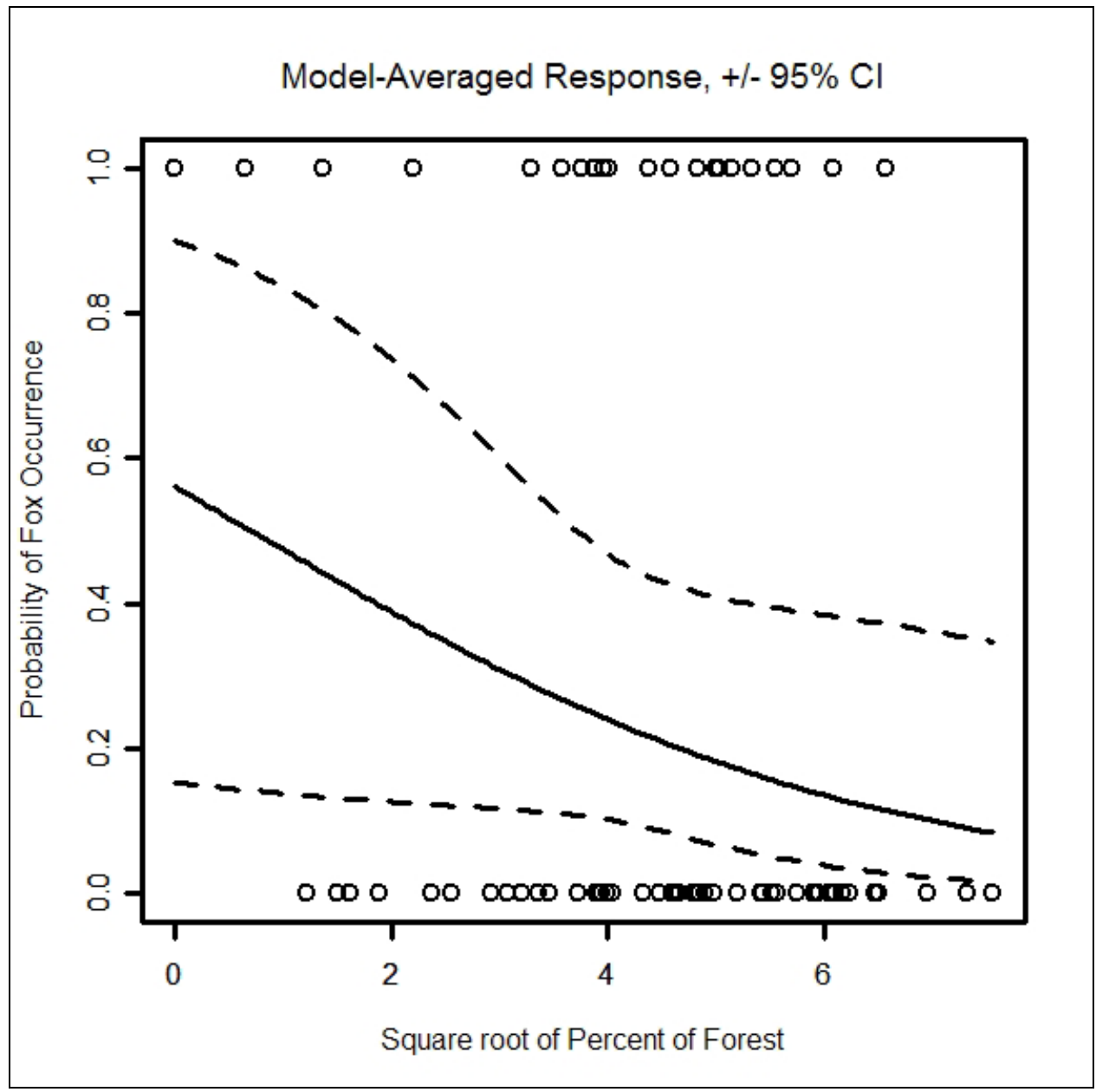

Figure 1.8. Solid line indicates the predicted probability of fox occurrence using modelaveraged parameter for 'Square root of Percent of Forest' from candidate set of models ranked by $\mathrm{AIC}_{\mathrm{C}}$. The probability of fox occurrence was calculated holding all variables constant while allowing the square root of the percent of forest to vary. Dashed lines indicate upper and lower 95\% confidence intervals. Open circles indicate original data points. 


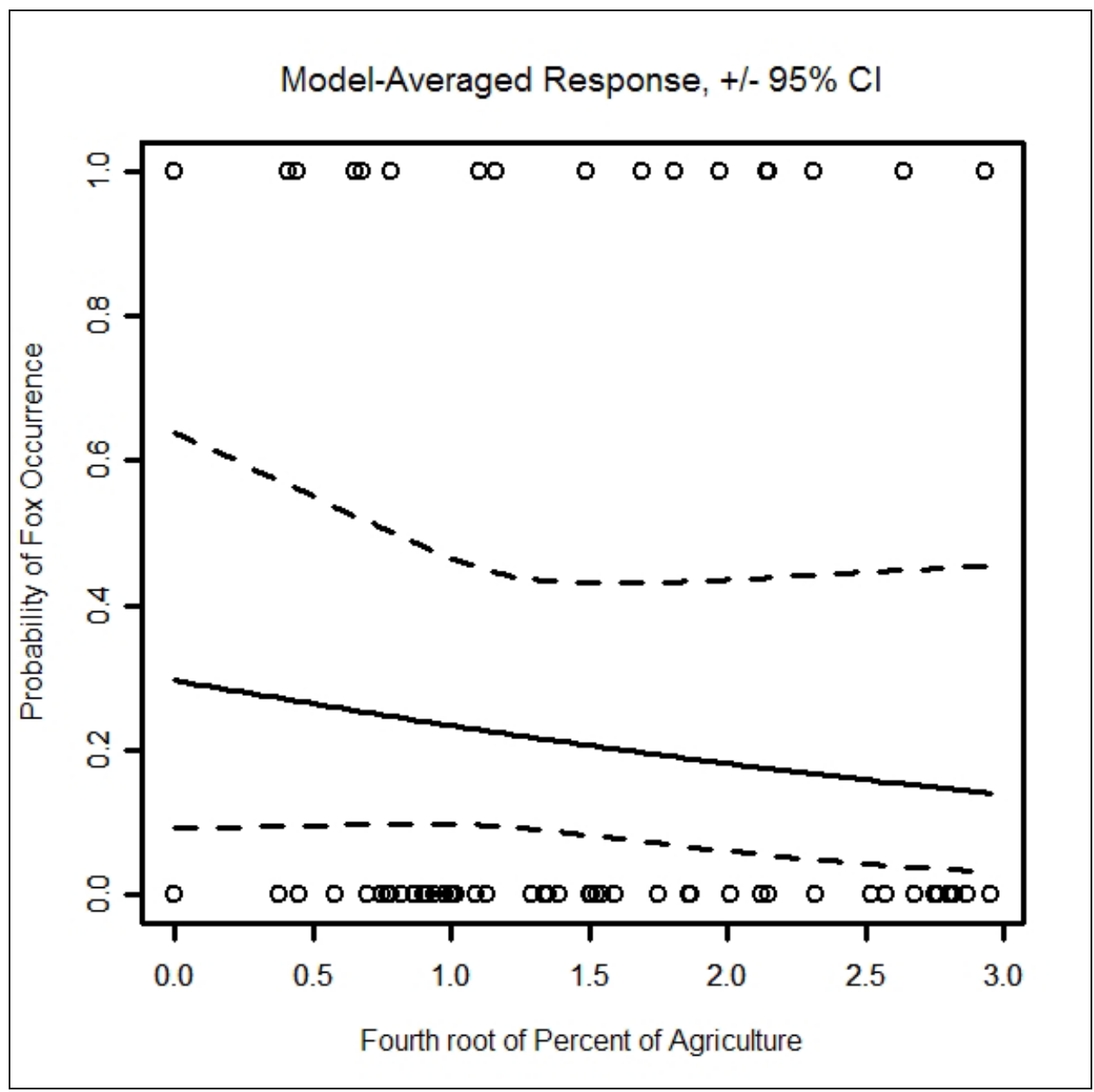

Figure 1.9. Solid line indicates the predicted probability of fox occurrence using modelaveraged parameter for 'Fourth root of Percent of Agriculture' from candidate set of models ranked by $\mathrm{AIC}_{\mathrm{C}}$. The probability of fox occurrence was calculated holding all variables constant while allowing the fourth root of the percent of agriculture to vary. Dashed lines indicate upper and lower 95\% confidence intervals. Open circles indicate original data points. 


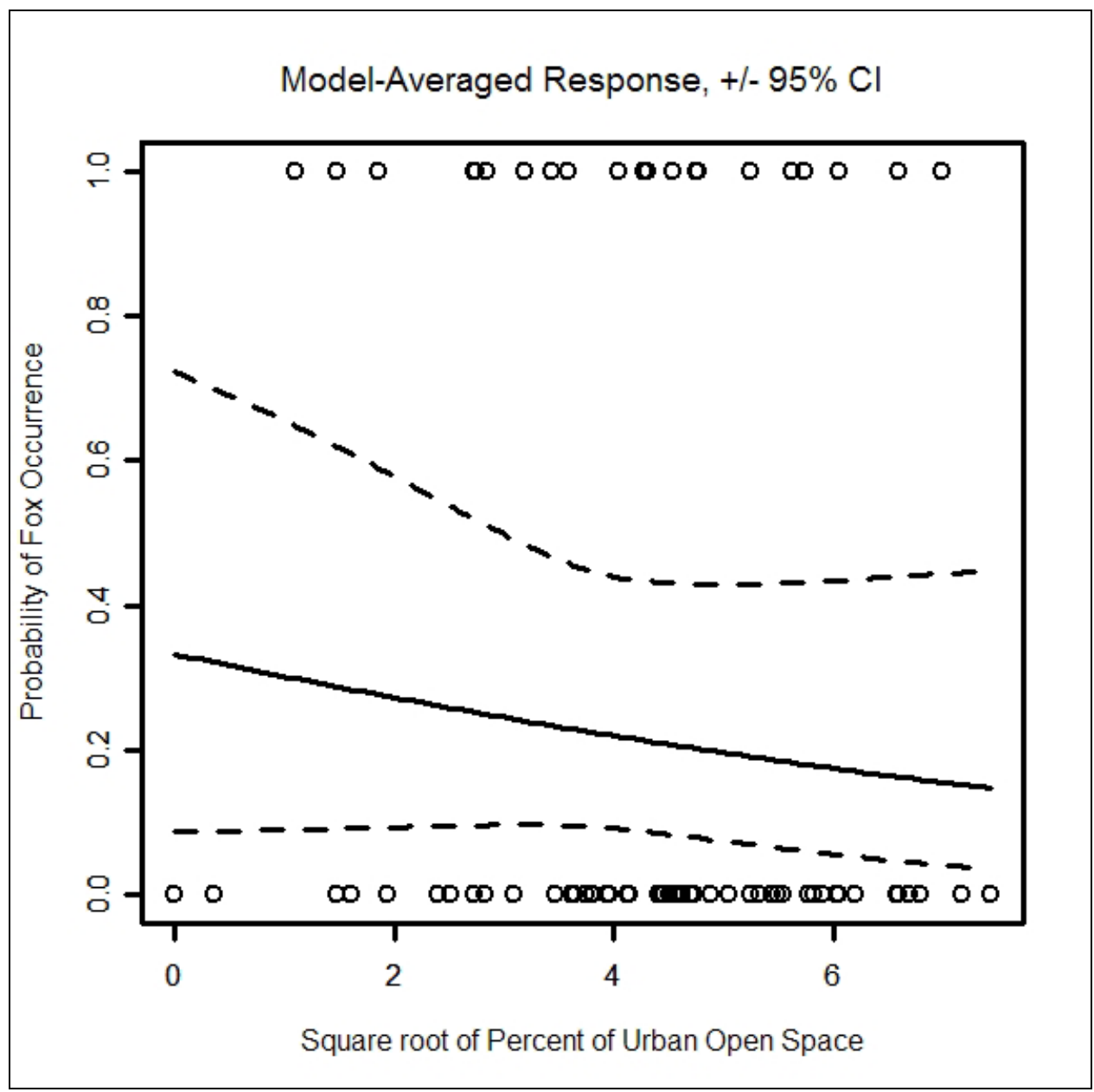

Figure 1.10. Solid line indicates the predicted probability of fox occurrence using modelaveraged parameter for 'Square root of Percent of Urban Open Space' from candidate set of models ranked by $\mathrm{AIC}_{\mathrm{C}}$. The probability of fox occurrence was calculated holding all variables constant while allowing the square root of the percent of urban open space to vary. Dashed lines indicate upper and lower 95\% confidence intervals. Open circles indicate original data points. 


\begin{tabular}{l|lllllllll}
\hline & \multicolumn{1}{|c}{ Occupancy $(\Psi)$} \\
$\mathrm{p}$ & 0.1 & 0.2 & 0.3 & 0.4 & 0.5 & 0.6 & 0.7 & 0.8 & 0.9 \\
\hline 0.1 & 14 & 15 & 16 & 17 & 18 & 20 & 23 & 26 & 34 \\
0.2 & 7 & 7 & 8 & 8 & 9 & 10 & 11 & 13 & 16 \\
0.3 & 5 & 5 & 5 & 5 & 6 & 6 & 7 & 8 & 10 \\
\hline 0.4 & 3 & 4 & 4 & 4 & 4 & 5 & 5 & 6 & 7 \\
0.5 & 3 & 3 & 3 & 3 & 3 & 3 & 4 & 4 & 5 \\
0.6 & 2 & 2 & 2 & 2 & 3 & 3 & 3 & 3 & 4 \\
\hline 0.7 & 2 & 2 & 2 & 2 & 2 & 2 & 2 & 3 & 3 \\
0.8 & 2 & 2 & 2 & 2 & 2 & 2 & 2 & 2 & 2 \\
0.9 & 2 & 2 & 2 & 2 & 2 & 2 & 2 & 2 & 2 \\
\hline
\end{tabular}

Table 1.11. Optimum number of surveys per site when sites are surveyed an equal number of times using estimates of occupancy and detectability. 'Occupancy $(\Psi)$ '= probability of a site being occupied, and detectability ' $p$ '= probability of detecting the species in site (MacKenzie and Royle 2005). 


\section{CHAPTER 2}

\section{MULTI-SCALE LAND COVER ASSOCIATIONS OF MESOPREDATORS IN AN URBANIZED LANDSCAPE}

\section{INTRODUCTION}

Urbanization is a prominent force that is reshaping landscapes across the world. The effects of urbanization occur at multiple spatial scales and result in fragmentation of natural land covers into small habitat patches and alterations to the landscape surrounding these habitat patches (Saunders et al. 1991). The resulting change to a human-dominated matrix can have substantial effects on biota inhabiting habitat fragments within urban areas. Habitat patches within an urbanized matrix may provide the only suitable habitat for much of the fauna inhabiting such areas, leading to changes in the wildlife community (Saunders et al. 1991). Dramatic changes in the landscape may favor generalist species, which due to dietary and behavioral plasticity and are better able to adapt and tolerate such changes (McKinney 2002). Urban carnivore communities are not immune to such changes, and are often composed of generalist species, which are presumably more 
tolerant of human disturbance and habitat loss (Swihart et al. 2003). Although mammalian mesopredators are common in many urbanized regions throughout North America, their urban ecology is still poorly understood. Mesopredators are difficult to study partially because of their secretive nature and wariness of humans (Sargeant et al. 1998, Gompper et al. 2006). Additionally, studying these animals in urban environments can be difficult because of limited access to privately owned land, security of equipment, heavy traffic, and limitations associated with operating within small natural habitat fragments.

Despite these limitations, however, there are many important reasons to investigate the role of mesopredators in the urban ecosystem. Urban mesopredators are hosts to various zoonoses such as rabies (Riley et al. 1998), canine distemper virus (Hoff et al. 1974, Nicholson and Hill 1984, Schubert et al. 1998, Gese et al. 2004), canine parvovirus (Gese et al. 2004, Riley et al. 2004), canine adenovirus (Gese et al. 2004), and parasitic infections such as mange (Gosselink et al. 2007). Mesopredators play an important role in shaping the urban wildlife community, particularly prey species (Erlinge et al. 1984, Crooks and Soule 1999, Dijak and Thompson 2000, Clarke and Pacin 2002). Finally, as urban sprawl continues and more natural area is lost or fragmented, it is important to understand the ecology and habitat use of urban mesopredators in order to better mitigate human-wildlife conflicts.

As generalist species (Swihart et al. 2003), mammalian mesopredators in urban areas may not perceive fragmented natural areas as habitat 'islands', but as useable habitat patches within a traversable urban matrix (Rosenblatt et al. 1999). The degree to which certain species interact with the landscape may be dependent upon body size, 
mobility, home range size, and dispersal capabilities (Rosenblatt et al. 1999, Gehring and Swihart 2003). Therefore, spatial scale should be incorporated into investigations of habitat associations of urban mesopredators. The importance of addressing spatial scale in ecological research has become increasingly evident (Hewitt 1998, Kotilar and Wiens 1990, George and Zack 2001, Cushman and McGarigal 2002, Kneitel and Chase 2004). Wildlife species, particularly those that are large and mobile, interact with their environment in a hierarchical manner (Johnson 1980, Senft et al. 1987, Gustine 2006), and in the setting of an urban environment are more likely to be associated with the urban matrix (Gehring and Swihart 2003).

Northeastern Illinois, including the Chicago metropolitan area, is an ideal landscape in which to study the habitat associations of urban mesopredators. The landscape consists of a highly developed urban matrix interspersed with urban open space (city parks, golf courses, cemeteries), remnant natural green space (forest preserves), and agriculture. The region supports a mesopredator community that includes species common to many urbanizing areas: coyotes (Canis latrans; Grinder and Krausman 2001), raccoons (Procyon lotor; Prange and Gehrt 2004), opossums (Didelphis virginiana; Prange and Gehrt 2004), domestic cats (Felis catus; Baker et al. 2005), foxes (gray [Urocyon cinereoargenteus; Riley 2006], and red [Vulpes vulpes; Gosselink et al. 2003]), and striped skunks (Mephitis mephitis; Prange and Gehrt 2004). 


\section{Land Cover Associations of Urban Mammalian Mesopredators}

Because of the high degree of urbanization in my study site, I predicted that at coyotes would be associated with urban development at large spatial scales. The spatial and energetic demands of a large mesopredator, such as the coyote, are likely not accommodated by small remnant patches of natural land cover associated with urbanized landscapes (Crooks 2002, Tigas et al. 2002). Within urban areas coyotes exploit humanderived foods (Quinn 1997a, Fedriani et al. 2001) as well as a diversity of prey items such as small mammals and birds (Morey et al. 2007). At a small scale, however, coyotes will likely be associated with natural land cover types that provide daytime resting and foraging opportunities (Quinn 1997b, Atwood et al. 2004). In Indiana natural land cover was underrepresented in coyote home ranges at a large scale $(95 \% \mathrm{kernel}$ home range contour) and predominant at a small scale (50\% kernel home range contour).

Foxes are a mobile species and, similar to coyotes, should be associated with urban development at large spatial scales. At small spatial scales I predicted that fox presence would be associated with natural land cover, which may provide foraging and daytime resting opportunities. Urban development has had a varied effect on fox populations throughout North America. In California and Illinois various fox species utilized urbanized areas (Cypher and Frost 1999, Gosselink et al. 2003, Riley 2006). In fact, compared to foxes living in undeveloped areas, those occupying residential areas are heavier and consume a more diverse diet including higher amounts of mammalian and avian prey items (Cypher and Frost 1999). The smaller size and decreased energetic demands of foxes may be better accommodated by small patches of natural land within 
urban matrices (Crooks 2002). Conversely, foxes in New Mexico and California avoided urban development (Harrison 1997, Caro et al. 2000). Discrepancies may be due to varying degrees and scopes of urbanization, landscape context, or the use of different spatial scales between studies.

Raccoons, opossums, skunks and domestic cats are less mobile than coyotes or foxes (Gehring and Swihart 2003) and in urban areas have smaller home ranges than populations inhabiting more natural or open areas (Gardner 1982, Kaufmann 1982, Barratt 1997, Prange and Gehrt 2007). Although raccoons, opossums, and skunks are habitat generalists (Gardner 1982, Godin 1982, Kaufmann 1982, Neiswenter and Dowler 2007) these three species will likely be associated with natural land cover at small scales, which provides denning and resting sites (Shirer and Fitch 1970, Hoffman and Gottschang 1977, Kaufmann 1982, Bixler and Gittleman 2000). At large spatial scales, however, I predicted that they would be associated with urban development, which provides diverse food resources that may supplement their diets (Hoffmann and Gottschang 1977, Prange and Gehrt 2004).

I predicted that domestic cats, compared to native mesopredators, would be associated with human development at small spatial scales. Cat densities are positively correlated with urban development (Lepczyk et al. 2003), likely due to the prevalence of free-ranging pet cats (Baker et al. 2005) and managed cat colonies (Clarke and Pacin 2002). Free-ranging domestic cats spend a majority of their time within the boundaries 
of human development, although they often enter natural habitats in proximity to humandominated land cover (Barratt 1997). At large spatial scales, therefore, I predicted that domestic cats would be positively associated with the presence of natural land covers, which might be used for hunting.

The objective of my study was to use presence data from a large-scale predator survey to describe possible differences in mesopredator response to land use at multiple spatial scales. I predicted that urban mesopredators would have different land cover associations at multiple spatial scales, dependent upon body size and mobility.

\section{STUDY SITE}

Northeastern Illinois is home to Chicago, the third largest metropolitan region in the United States. The Chicago metropolitan area spans six counties and encompasses approximately 887,838 ha. Collectively these six counties are home to a population of 8.4 million people, a third of which are living within the Chicago city limits (Openlands Project 2006). My study focused on Cook County, which is the second most populated county in the country, DuPage, Lake and McHenry counties, accounting for greater than 613,995 ha, and $85 \%$ of the total population of the Chicago metropolitan area (Openlands Project 2006). Urbanization and urban sprawl are apparent forces shaping the landscape around Chicago (Figure 2.1).

Following urban land cover, agriculture is the second most dominant land cover. Approximately $17 \%$ of the total area of the four counties is used for the production of crops, cattle and pigs (Illinois Agricultural Statistics Supplement 2004). Natural land managed by forest preserve and conservation districts is the third largest land cover and 
makes up approximately $9 \%$ of the total area of the four counties (Table 2.1; Openlands Project 2006). According to the Openlands Project (1999), most (52\%; Table 2.2) of the land cover in northeastern Illinois has been classified as 'built up', which includes urbanized and developed areas. Approximately 19\% of the land cover has been classified as 'at risk' (Table 2.2), which includes those areas under pressure to be developed within the next 10 to 30 years. Approximately $11 \%$ of the area is held as permanent open space (Table 2.2), which includes county holdings and the remainder is classified as 'low risk' (Table 2.2) including cemeteries, golf courses, private land and large tracts of government-owned land.

Major ecological communities within the six counties comprising the Chicago region include prairies, savannas, woodlands, and wetlands such as marshes, shrub swamps, sedge meadows, fens and bogs (Sullivan, 2000). The region has an average annual rainfall of $91 \mathrm{~cm}$ per year and average summer and winter temperatures of $21.7^{\circ} \mathrm{C}$ and $-3.9^{\circ} \mathrm{C}$, respectively (National Weather Service, 2006).

\section{METHODS}

Study Site Selection

This investigation was an evaluation of data collected during a large-scale sampling effort to detect gray foxes and, as such, site selection reflects this primary goal. ArcView 3.3 (Environmental Systems Research Institute, Redlands, California) was used to divide the entire study area into 64 grid cells, each encompassing approximately 9,400 ha. From the 64 grid cells, 32 were selected in a multi-step approach. Cells were first selected based upon priority levels, where a high priority cell was one containing either 
reported historic gray fox activity or a recent gray fox sighting. Of the 32 cells selected, 20 fell into this category. The 12 remaining cells were chosen by simple random selection. A multi-step approach was then used to select study sites within each of the 32 selected cells. Study site selection primarily focused on publicly owned forest preserves, golf courses, and cemeteries, which represented natural and semi-natural green space within the urban matrix. Public property was selected because of difficulties associated with gaining access to private property. Within each high priority cell, I selected a forest

preserve near the occurrence of gray fox activity and then randomly selected forest preserves until approximately $10 \%$ of the collective area of the cell had been selected. I then randomly selected 1 golf course and 1 cemetery in each cell. Study site selection in cells that were not classified as high priority occurred in much the same way, although in these cases there were no sites with reported.

\section{Field Surveys}

I used sand scent stations and camera scent stations in order to detect visitation to survey stations. Scent stations were operated from October through December in 2004, June through September in 2005, January through September in 2006, and March through September in 2007. I placed two scent stations per 120 ha of area at study sites, based upon the average annual home range size of gray fox in southern Illinois (Follman, 1973). The stations were spread opportunistically throughout the sites to avoid human disturbance. 
Methods for operating sand scent stations were adapted from Linhart and Knowlton (1975), and Roughton and Sweeny (1982). Sites were sampled using $1 \mathrm{~m}^{2}$ track stations baited with an attractant (e.g. gland lure, fatty acid disc). The substrate was a 1:32 mixture of masonry sand and mineral oil (Sargeant et al 1998). The stations were checked every other day, at which time they were smoothed and rebaited, until a minimum of four operative station-nights were accumulated. All identifiable tracks were documented and later recorded into a database as a presence for each respective species.

Infrared cameras were used to monitor scent stations in secure locations. Two types of cameras were used including infrared video systems and infrared digital trail cameras. The infrared video systems included an infrared video lens, a $17 \mathrm{~m}$ video power cable, a deep cycle marine battery and a time-lapse VCR housed in a waterproof case. The infrared video lens was placed approximately $1.5 \mathrm{~m}$ above the ground on a nearby tree and aimed at an attractant (e.g. scent lure, food lure). The remaining equipment was placed approximately $10 \mathrm{~m}$ away from the scent station and covered with local debris. The substrate of camera scent stations was typically left natural although camera equipment was placed at a small subset of sand scent stations in order to assess bias associated with either method. The video systems were allowed to run for two to three nights at which time the battery was replaced and the attractant refreshed. Scent stations equipped with infrared video systems were typically operated until four to six stationnights were accumulated. The tapes that were generated by these systems were viewed allowing me to document the species visiting the station, time of visits, duration of visits, and both inter- and intraspecific interactions. 
Several models of infrared digital trail cameras were used including: Leaf River IR-3BU (Leaf River, Taylorsville, MS), Bushnell Trail Scout (Bushnell, Overland Park, KS), Cuddeback NoFlash (Cuddeback, Park Falls, WI), and Moultrie Game Spy I40 (Moultrie, Alabaster, AL). All trail cameras consisted of self-contained units, which were placed approximately $0.3 \mathrm{~m}$ above the ground on a nearby tree and aimed at an attractant. Since these systems could run for an extended period of time without battery replacement, stations with infrared trail cameras ran undisturbed for approximately three to seven days before refreshing the lure. All species that were documented were recorded as a presence in the database.

\section{Multi-scale Landscape Characteristics}

A modified version of the Illinois GAP coverage (ILGAP; Illinois Natural History Survey, Champaign, Illinois) was used in which the original land cover categories were collapsed into 9 land cover classifications including: forest, agriculture, urban open space, high density urban, medium density urban, low density urban, wetland, surface water and barren exposed land (Table 2.3). Study site boundaries were derived from the ILGAP coverage. On occasion, scent stations were placed in a residential yard or commercial area where a logical study site boundary could not be delineated. In such cases an artificial boundary was created from a circular 120-ha buffer centered on the survey station, which reflected the annual home range size of gray foxes in southern 
Illinois (see Chapter 1), but was also approximately equal to an average urban home range estimate for all of the species combined. ArcView 3.3 was used to intersect the ILGAP data with digitized study site polygons, which yielded individual land cover clips for each of the 96 study sites.

These land cover clips were considered the smallest spatial scale of the study and is hereafter referred to as the study site scale (SS). SS scale was created to represent finescale land cover characteristics within the immediate area that the animal was using, which may influence habitat selection of mesopredators. For example, a species might be more likely to use a study site with an increased amount of natural habitat. Two additional spatial scales were created, resulting in a series of nested landscapes (Figure 2.2). The larger spatial scales represented course-scale landscape characteristics that may have influenced whether or not a species would be found within study sites. For example, a species might be more associated with natural habitat fragments (fine spatial scale) within a fragmented and diverse urbanized matrix (course scale). Conversely, a species might be associated with natural habitat fragments (fine scale) within a homogeneous agricultural matrix (course scale). The second spatial scale incorporated the area within the study site plus the area within a $1-\mathrm{km}$ buffer surrounding the study site; hereafter this scale is referred to as landscape 1 (L1). A 1-km buffer was used at the L1 scale in order to incorporate elements of the surrounding matrix that might be used by smaller less mobile mesopredators such as raccoons, opossums, and skunks. The third spatial scale incorporated the area within the study site plus the area within a 5-km buffer; hereafter this scale is referred to as landscape 2 (L2). A larger 5-km buffer was used at the L2 scale in order to incorporate matrix elements that may be used by larger or 
more mobile mesopredators such as coyotes and foxes. Landscape variables derived from the L1 and L2 scales described the composition of the landscape as well as landscape structure. Optimally, the same predictor variables would be derived at each spatial scale. However, due to the absence of certain land cover types at SS and L1 spatial scales this was not possible.

In order to mitigate the effects of spatial autocorrelation at L1 and L2 spatial scales, landscapes with $>30 \%$ overlap were merged at each respective level. This resulted in 72 unique L1 landscapes and 21 unique L2 landscapes. At each spatial scale, SS, L1 and L2 land cover clips were converted to raster format with a resolution of $30 \mathrm{~m}$ $\mathrm{x} 30 \mathrm{~m}$ corresponding to the resolution of the original ILGAP coverage.

Environmental Predictor Variables

Study Site Scale (SS)--I used FRAGSTATS 3.3 (University of Massachusetts, Amherst, MA) to derive environmental variables at all three spatial scales. At the SS spatial scale, environmental variables quantified the land cover composition of each study site. The percentages of eight different land cover types were used (Table 2.4): forest (PER_FOR), agriculture (PER_AG), wetland (PER_WET), surface water (PER_WAT), urban open space (PER_URBOP), low density urban (PER_LOW), medium density urban (PER_MED), and high density urban (PER_HIURB). I created three binary variables that classified study sites as urban, suburban or rural according to the matrix within a 1-km buffer that did not include the area of the study site (Prange and Gehrt 
2004; Table 2.4). Sites were classified as urban if $\geq 50 \%$ of the area surrounding the site was composed of high and medium density urban development; suburban if $\geq 25 \%$ of the surrounding matrix was composed of high or medium density urban development; and rural if the matrix contained a large amount of agriculture and consisted of $\leq 25 \%$ of high or medium density urban. Lastly, I included covariables to account for differences in sampling effort between sites (Table 2.4): Total area of site (TA_HA), number of stations operated at a site (no_stations), and total number of station nights accumulated at a site (no_stn_nights).

Landscape 1 Scale (L1)--At the L1 scale, environmental variables described both land cover composition and the general structure of individual landscapes. However, all land cover classes were not represented in each L1 landscape so environmental variables measuring structure were derived for the entire landscape, regardless of individual land cover classes (Table 2.5).

Environmental variables used to quantify the land cover composition of each L1 landscape included the percent of eight land cover types (Table 2.5): forest (PER_FOR), agriculture (PER_AG), wetland (PER_WET), surface water (PER_WAT), urban open space (PER_URBOP), low density urban (PER_LOW), medium density urban (PER_MED), and high density urban (PER_HIURB). A contagion index (CONTAG; Haines-Young and Copping 1996, O'Neill et al. 1988; Table 2.5) was used to quantify both structure and degree of fragmentation of L1 landscapes. High contagion values resulted from low levels of interspersion and dispersion of land cover types, whereas low contagion values resulted from high levels of interspersion and dispersion of land cover types. An area-weighted mean patch fractal dimension (FRAC_AM; O'Neill et al. 1988; 
Table 2.5) was derived as a measure of patch shape complexity within L1 landscapes. Small values indicated simple shapes whereas larger values indicate complex shapes. This index can be used as a measure of the overall anthropogenic influence upon the landscape (O’Neill et al. 1988). As humans manipulate the landscape they tend to create simple patch shapes such as those found in agricultural fields or those created by roads, whereas a more natural landscape has more complex patch shapes (i.e. shapes defined by mountains, changes in soil type, rivers, etc.). Shannon's diversity index (SDI; HainesYoung and Chopping 1996; Table 2.5) was used as a measure of landscape structure. This index reflected the evenness and diversity of land cover types within L1 landscapes. SDI increased as the number of different land cover types increased and/or the proportion of land cover types became more even. Finally, I included covariables to adjust for differences in sampling effort (Table 2.5).

Landscape 2 Scale (L2)-- At the L2 scale, environmental variables described both land cover composition and structure of individual landscapes. All land cover classes were represented in each L2 landscape so environmental variables measuring structure were derived for selected land cover classes as well as for the entire landscape (Table 2.6). I obtained variables which quantified the percent of eight different land cover types (PER_land cover; Table 2.6) within respective L2 landscapes including forest, agriculture, wetland, surface water, urban open space, low density urban, medium density urban, and high density urban. Additionally, land cover specific structure variables were derived for forest, agriculture, urban open space, low density urban, medium density urban, and high density urban land cover classes. Mean patch size (MPS_land cover; Table 2.6) was used as a basic measurement of landscape composition and structure. An 
area-weighted mean shape index (AWMSI_land cover; Haines-Young and Chopping 1996; Table 2.6) was used as a measure of class-specific patch shape complexity and edge effect as well as a class-specific measurement of human influence. Human dominated landscapes often contain simple shapes created by roads, urban development and agriculture. The AWMSI ranged from 1 to 2 and small values indicated compact patches with less edge, whereas high values indicated complex patches with a greater amount of edge. An area-weighted mean proximity index (PROXAM_land cover; Gustafson and Parker 1994; Table 2.6) and area-weighted mean Euclidian nearest neighbor distance (ENNAM_land cover; Table 2.6) were calculated within $500 \mathrm{~m}$ buffers around focal patches to assess the degree of isolation of land cover classes. A classspecific clumpiness index (CLUMPY_land cover; Table 2.6) was used to describe classspecific landscape structure. The clumpiness index ranged from -1 to 1 where low values indicated a disaggregated land cover class and maximum values indicated a high level of aggregation for a respective land cover class. An interspersion and juxtaposition index (IJI_land cover; Haines-Young and Chopping 1996; Table 2.6) was used as a measurement of class-specific landscape structure as well as fragmentation. The interspersion and juxtaposition index was used to indicate the degree to which respective land cover classes were intermixed will all other land cover classes, and ranged from 0 to 100\%. I used a patch cohesion index (COHESION_land cover; Table 2.6) to describe the connectedness of respective land cover classes within individual L2 landscapes. The patch cohesion index ranged from 0 to 100 , small values indicated decreased connectedness and large values indicated increased connectedness. Additionally, I used three metrics that were not class-specific, but measured general landscape structure which 
included: contagion index (CONTAG; Haines-Young and Copping 1996; O’Neill et al. 1988; Table 2.6), area-weighted mean patch fractal dimension (FRAC_AM; O'Neill 1998; Table 2.6) and Shannon's diversity index (SDI; Haines-Young and Chopping 1996; Table 2.6). Finally, I included three covariables (number of survey stations [no_stns]; number of station nights [no_stn_nights]; total landscape area [TA_HA]; Table 2.6) to adjust for differences in sampling effort between landscapes.

Data reduction techniques were used to decrease the number of environmental variables at the L2 spatial scale. I used MINITAB 14 to create groups of correlated environmental variables using a Ward's linkage method, an absolute correlation distance measure, and a similarity measure of 0.7 . This method resulted in 8 clusters of correlated environmental variables (Table 2.7). Within clusters, I calculated the average correlation between each variable and all other variables in the group and used the variable with the highest average correlation as the representative variable (Table 2.7 and 2.8).

\section{Species Data}

Individual survey stations within study sites were not considered to be independent so detections within individual study sites at each spatial scale were collapsed. The collapsed data yielded a single detection (1) or non-detection (0) value for respective species at SS, L1 and L2 spatial scales (Appendices A, B, C). Gray fox and red fox detections were combined into a fox category due to both low detection rates for both species and difficulties associated with discriminating between the two species from 
degraded sand track stations. The two species were likely exploiting similar resources in this urbanized environment, and results of the Illinois Archer Deer Hunter Survey (Bluett 2006) indicated that these two species may have been experiencing similar limiting factors. This approach assumes equal detectability of both gray and red foxes.

Analysis of Species Occurrence and Landscape Data

I examined the relationship between six urban mesopredators (raccoons, opossums, domestic cats, coyotes, foxes [red and gray], and striped skunks) and landscape composition and structure at SS, L1 and L2 spatial scales. This analysis was essentially a post-hoc evaluation of data collected during a study looking at the distribution of gray fox in northeastern Illinois (see Chapter 1). As such, I did not perform traditional hypothesis testing but evaluated more general patterns in mesopredator occurrence.

I used constrained ordination using CANOCO (ter Braak and Šmilauer 2002) to explore the relationship between a matrix of detection data for six urban mesopredators (response variables) and a matrix of environmental variables derived from remotely sensed data (environmental predictor variables) at three spatial scales. At each spatial scale, the gradient lengths were determined using a detrended canonical correspondence analysis (DCCA). The DCCA results indicated that a linear method would be appropriate for the data at all spatial scales (gradients $<3$ ). As a result, a partial redundancy analysis 
(pRDA) was used in which linear combinations of species data were predicted by linear combinations of environmental predictor variables. Monte Carlo permutation tests were used to assess the relationship between species data and environmental variables, thus removing constraints related to distributional assumptions.

Species matrices were constructed at SS, L1 and L2 spatial scales and consisted of presence/absence data for each species classification at 96 (Appendix A), 72 (Appendix B) and 21 (Appendix C) individual landscapes, respectively. Environmental matrices consisted of environmental predictor variables and covariables derived at each spatial scale: SS (Table 2.5), L1 (Table 2.6), L2 (Table 2.8). Covariables were included in analyses as a means by which to adjust for differences in sampling effort between landscapes. Within each pRDA I focused scaling on interspecies correlations and divided species scores by standard deviations. These steps resulted in species scores that were equal to the correlation of respective species with ordination axes, and thus increased the interpretability of ordination plots (ter Braak and Šmilauer 2002). Variable selection was accomplished using 1000 unrestricted permutations within a Monte Carlo permutation test. Variables with $p$-values $\leq 0.2$ were included, which allowed for the examination of general patterns between mesopredator presence and environmental predictor variables, rather than traditional significance testing.

I used variance partitioning to separate the total variance into that explained by environmental predictor variables; sampling effort covariables; environmental predictor variables and sampling effort covariables jointly; and that variance which remained unexplained (Lepš and Šmilauer 2003). This was accomplished using a series of pRDAs. I first determined the amount of variance explained solely by environmental variables 
$(\mathrm{E} \mid \mathrm{C})$, where environmental predictor variables were used as environmental variables and sampling effort covariables were used as covariables. Next, I determined the variance explained solely by sampling effort covariables $(\mathrm{C} \mid \mathrm{E})$, where sampling effort covariables were used as environmental variables and environmental predictor variables were used as covariables. In order to calculate the variance explained jointly $(\mathrm{E} \cap \mathrm{C})$ by both environmental predictor variables and sampling effort covariables, two steps were required. First, I determined the total amount of explained variance (TEV). To accomplish this I used a redundancy analysis in which environmental predictor variables and sampling effort covariables were used together as environmental variables. Second, I subtracted the variance explained solely by environmental predictor variables and the variance explained solely by sampling effort covariables from the total explained variance $(\mathrm{E} \cap \mathrm{C}=\mathrm{TEV}-\mathrm{E}|\mathrm{C}-\mathrm{C}| \mathrm{E})$. The final step of the variance partitioning process was to determine the amount of variance that remained unexplained (UV). This was accomplished by subtracting the total amount of explained variance (TEV) from 1 , the total amount of variance, $(\mathrm{UV}=1-\mathrm{TEV})$. All $R^{2}$ values obtained through the variance partitioning procedure were adjusted $\left(R^{2}\right.$ adj $)$ to account for inflated values due to the number of explanatory variables (Peres-Neto et al. 2006).

\section{RESULTS}

Field Surveys

I surveyed 96 sites within the study area, which resulted in 668 stations (Figure 2.3) monitored for 2746 station nights (Appendices A, B, C). Detections of mesopredators at SS, L1 and L2 spatial scales, respectively, included: raccoon $(86 \%$, 
$91.7 \%, 90.5 \%)$, opossum $(65 \%, 68.1 \%, 85.7 \%)$, coyote $(47 \%, 52.8 \%, 69.1 \%)$, domestic cat $(36 \%, 43.1 \%, 85.7 \%)$, fox (red and gray combined; $25 \%, 29.2 \%, 69.1 \%$ ), and striped skunk $(18 \%, 20.8 \%, 28.6 \%)$.

Analysis of Species Occurrence and Landscape Data

SS Spatial Scale--Environmental predictor variables utilized in the model included: PER_HIGH $($ F-ratio $=3.67, \mathrm{p}$-value $=0.002)$, PER_LOW $($ F-ratio $=2.33$, pvalue $=0.044)$, SUBURBAN $($ F-ratio $=2.09, p$-value $=0.045)$ and PER_WAT $($ F-ratio $=$ 1.49 , p-value $=0.187)$. The first axis was most strongly correlated with PER_HIGH (Table 2.9). The percent of high density urban land cover was weakly but significantly correlated with the percent of forested land cover within study sites $\left(R^{2}=-0.246, \mathrm{p}\right.$-value $=0.016, \mathrm{~N}=96$ ). The first ordination axis could be regarded as the gradient of forested land that is increasingly replaced by high density urban development. The second ordination axis was most strongly associated with the percent of low density urban land cover (Table 2.9). The percent of low density land cover within study sites was positively correlated with the percent of medium density urban development $\left(R^{2}=0.521\right.$, p-value $=0.000, \mathrm{~N}=96)$ and negatively correlated with the percent of forested land cover $\left(R^{2}=-0.356, \mathrm{p}\right.$-value $\left.=0.000, \mathrm{~N}=96\right)$. The second axis could therefore be interpreted as a gradient of forested land cover that is replaced by moderate urban development.

Both fox and cat presence were positively associated with first ordination axis and more weakly positively associated with the second ordination axis, whereas raccoon and opossum presence were negatively associated with the first ordination axis and positively associated with the second ordination axis (Figure 2.4). Raccoon and opossum presence 
were negatively associated with the amount of surface water (Figure 2.4). Coyote and skunk presence were both negatively associated with the second axis, although coyote presence was positively associated with the first axis whereas skunk presence was negatively associated with the first axis (Figure 2.4). Furthermore, coyote presence at the site level was positively associated with the percent of surface water (Figure 2.4).

Variance partitioning indicated that the environmental predictor variables explained approximately $4 \%$ of the variance in the species data; covariables used to quantify survey effort explained approximately $15.2 \%$; and the two sets of variables jointly explained $0.6 \%$ of the variance (Figure 2.5 ). In total, $19.8 \%$ of the variance was explained by predictor variables and 80.2\% remained unexplained (Figure 2.5).

L1 Spatial Scale--At the L1 spatial scale environmental predictor variables utilized in the model included PER_HIGH (F-ratio=4.10, p-value=0.001), PER_MED (Fratio $=4.98$, p-value $=0.001)$, PER_URBOP $($ F-ratio $=1.75$, p-value $=0.099)$, and PER_LOW $(\mathrm{F}-\mathrm{ratio}=1.47, \mathrm{p}$-value $=0.178)$. The first ordination axis was most strongly correlated with PER_HIGH (Table 2.10), which in turn was negatively correlated with the amount of forested land cover $\left(R^{2}=-0.465, \mathrm{p}\right.$-value $\left.=0.000, \mathrm{~N}=72\right)$. The first axis, therefore, may be interpreted as a gradient from increased forest to highly developed land cover. The second axis was most strongly correlated with PER_MED (Table 2.10), which was negatively correlated with both the amount of agricultural land cover $\left(R^{2}=-\right.$ $0.663, \mathrm{p}$-value $=0.000, \mathrm{~N}=72)$ as well as forested land cover $\left(R^{2}=-0.492, \mathrm{p}\right.$-value $=$ $0.000, \mathrm{~N}=72$ ). The second axis represented a gradient from more open, natural/seminatural landscapes comprised of forest and agriculture, replaced by a moderate degree of urbanized land cover. 
Coyote and fox presence were both positively associated with the first ordination axis, however, fox presence was also positively associated with the second ordination axis and negatively associated with urban open space (Figure 2.6). Raccoon, skunk, opossum, and cat presence were all negatively associated with the first axis, however, skunk, opossum, and cat presence were also positively associated with the second axis and positively associated with low density urban development (Figure 2.6).

Variance partitioning indicated that environmental predictor variables explained approximately $8 \%$ of the variance in the species data; covariables used to quantify survey effort explained approximately $17.1 \%$; and the two sets of variables jointly explained $11.1 \%$ of the variance (Figure 2.7). In total, $36.2 \%$ of the variance was explained by the ordination and $63.8 \%$ remained unexplained (Figure 2.7).

L2 Spatial Scale--At the L2 spatial scale environmental predictor variables allowed into the model included SDI $(\mathrm{F}-$ ratio $=2.99$, $\mathrm{p}$-value $=0.019)$ and ENNAM_URBOP $(\mathrm{F}-\mathrm{ratio}=1.89, \mathrm{p}$-value $=0.1029)$. The first ordination axis was most strongly correlated with SDI (negative correlation; Table 2.11), where small values of the first ordination axis indicated a diversity of land cover classes, simple shapes, increased amounts of urban open space and interspersed patches of fragmented forest. The second axis was most strongly correlated with ENNAM_URBOP (Table 2.11), where large axis values represented increased high density urban development with isolated urban open space and agriculture. Small values of the second ordination axis represented less high density development, and less isolated urban open space and agricultural patches. 
The presence of raccoons and opossums was negatively associated with the first and second ordination axes (Figure 2.8). Coyote, fox, and skunk presence were negatively associated with the first ordination axis and positively associated with the second ordination axis (Figure 2.8). Cat presence was positively associated with the first and second ordination axes (Figure 2.8).

Variance partitioning indicated that environmental predictor variables explained approximately $10.1 \%$ of the variance in the species data; covariables used to quantify survey effort explained approximately $10.5 \%$; and the two sets of variables jointly explained $12 \%$ of the variance (Figure 2.9). In total, $32.6 \%$ of the variance was explained by predictor variables and $67.4 \%$ remained unexplained (Figure 2.9).

\section{DISCUSSION}

\section{Land Cover Associations of Coyotes}

Presence of coyotes was associated with a high degree of urban development at all three spatial scales suggesting that coyotes may perceive the landscape to be more homogeneous than smaller mesopredators, due to their size and mobility (Gehring and Swihart 2003). At the largest spatial scale (L2) coyote presence was positively associated with diverse landscapes that were highly urbanized with interspersed and isolated urban open space, agriculture, and forest patches, and at the intermediate scale (L1), coyote presence was associated with highly urbanized landscapes with little forest, agriculture or urban open space. At the smallest spatial scale coyotes were found to utilize highly developed urban sites with increased forested land cover. 
Findings from other studies suggest that at large spatial scales coyotes may utilize diverse fragmented landscapes including increased amounts of development and agriculture (Oehler and Litvaitis 1996, Grinder and Krausmann 2001). Urban development can offer coyotes an abundance of mammalian prey (Quinn 1997a, Morey et al. 2007), as well as reliable anthropogenic food sources (Fedriani et al. 2001). Although the urban landscape can provide resources for mesopredators, the inclusion of natural and semi-natural land cover types at the largest spatial scale may indicate that coyotes utilize these land cover types to avoid human activity (Quinn 1997b, Grinder and Krausman 2001, Tigas et al. 2002, Riley et al. 2003, Atwood et al. 2004, George and Crooks 2006). These natural and semi-natural habitat patches may increase the connectivity of the landscape and aid in the movement of coyotes. At a small spatial scale, natural habitat patches may provide resting habitat within core use areas of coyote home ranges during daylight hours, and urban development may offer increased foraging opportunities by night. Indeed, carnivores in many urban areas demonstrate nocturnal activity patterns, which allow the opportunity to forage in developed areas (Quinn 1997b, Grinder and Krausman 2001, Riley et al. 2003, Atwood et al. 2004, George and Crooks 2006).

Coyote presence was positively associated with the amount of water that was available at a site. Water has been shown to be an important factor for other species of mesopredators (Sullivan 1956, Allen et al. 1985, Gehrt and Fritzell 1998). In the Chicago area it appears that coyotes exploit urban habitats by utilizing some natural land cover elements to avoid human activity within an urbanized matrix. 
As urbanization spreads across the landscape and coyotes continue to persist in urban environments, coyote-human interactions are sure to increase. One result of these interactions is a concern for both human and pet safety (Gompper 2002). In recent years the number of coyotes trapped as a result of nuisance complaints have increased (Gehrt 2006). Mitigation of coyote-human conflicts in urban areas is quickly becoming an issue that wildlife managers must confront.

Another issue of ecological concern is the impact of coyotes on sympatric species of mesopredators in the context of an urban landscape. Intraguild competition with large predators can influence populations of smaller predators (Crooks and Soule 1999, Linnel and Strand 2000, Switalski 2003). Coyotes have been shown to influence the land use, diet and survival of smaller mesopredators (Voigt and Earle 1983, Crooks and Soule 1999, Gosselink 2003, Lavin et al. 2003, Kamler and Gipson 2004, Moehrenschlager et al. 2007, Thompson and Gese 2007). However, coyote presence does not affect the presence of raccoons (Gehrt and Prange 2007), or skunks (Prange and Gehrt 2007) within the Chicago metropolitan area. However, there is limited evidence that suggests that coyotes may influence fox presence (see Chapter 1). The relationship between coyotes and opossums is unclear in the Chicago area, although coyotes have been shown to be a major source of mortality for opossums, particularly in the winter and spring (Gipson and Kamler 2001). The presence of coyotes in urban landscapes may have an influence on domestic cats as the diets of coyotes utilizing developed areas in Washington state included domestic cats as the primary mammalian prey item, comprising $13.1 \%$ of the annual diet of coyotes (Quinn 1997a). Coyotes in the Chicago area have been found to consume cats, although it appears to be rare (Gehrt 2006). 


\section{Land Cover Associations of Foxes}

Foxes were relatively rare in my study, and were found to be associated with urban development at all spatial scales. At the largest spatial scale (L2) foxes were associated with diverse landscapes that were highly developed and interspersed with isolated patches of forest, agriculture and urban open space. At an intermediate spatial scale (L1), foxes were found to be associated with high density urban development, which may be due to the availability of both natural prey items and anthropogenic resources (Quinn 1997a, Morey et al. 2007, Fedriani et al. 2001). Unlike coyotes, however, at the smallest spatial scale foxes were associated with high density urban development without the inclusion of natural habitat.

Foxes have been associated with urban development in Illinois (Lavin et al. 2003, Gosselink et al. 2003), California (Cypher and Frost 1999, Riley 2006), and New Mexico (Harrison 1997). Similar to coyotes, foxes may utilize natural and semi-natural areas within the urban matrix at large spatial scales to avoid human activity and foraging opportunities as they move through the landscape. At small spatial scales foxes may utilize highly urbanized areas to avoid interspecific competition with coyotes (Gosselink et al. 2003, Lavin et al. 2003). Foxes are small and residents may be more tolerant of their presence as compared to coyotes.

The detection of foxes (both gray and red) within the study site was relatively rare compared to other species of mesopredators. A statewide survey of archery hunters in Illinois indicated declining relative abundances of both red and gray foxes (Bluett 2006). Due to declines in fox populations in Illinois ecological issues that may arise from the use of urban areas by foxes may concern the conservation of these species. The use of urban 
areas can have can have a varied effect on fox populations ranging from detrimental (Harrison 1997) to beneficial (Cypher and Frost 1999). Foxes inhabiting an urban area in California were characterized by high exposure to disease and associated mortality (Riley et al. 2004). Furthermore, coyotes, which are common in urban settings, have been implicated as a source of fox mortality (Cypher and Spencer 1998, Farias et. al. 2005). In the Chicago metropolitan area, disease and coyote predation were both contributing factors to fox mortality (see Chapter 1). On the other hand, compared to foxes living in undeveloped areas, those occupying developed areas have been found to be heavier and consume a more diverse diet including higher amounts of mammalian and avian prey items (Harrison 1997, Cypher and Frost 1999).

Land Cover Associations of Raccoons and Opossums

At the largest spatial scale (L2), raccoons and opossums were positively associated with diverse landscapes with decreased high density urban development, increased interspersion of forest, and urban open space and agriculture that was less isolated. At intermediate and small spatial scales (L1 and SS), both species were positively associated with increased amounts of moderate and low levels of urban development, and increased forest but negatively associated with increased high density urban development.

Raccoons and opossums are commonly associated with deciduous woodlands (Kaufmann 1982, Gardner 1982), even within urban areas (Prange and Gehrt 2004, Bozek et al. 2007), likely due to the availability of resting and denning sites (Shirer and Fitch 1970, Kaufmann 1982). As both species are small and may be less mobile than 
coyotes or foxes, a highly developed matrix at a large spatial scale may not be as easily traversed. Land cover associations at the largest scale may be related to dispersal activities, which could be hindered in heavily urbanized landscapes. At smaller spatial scales moderate levels of urban development intermixed with forest may provide raccoons and opossums with denning and resting sites in close proximity to the abundance of natural prey items and anthropogenic resources that are available in urban areas. These results are supported by the reportedly smaller home range sizes of raccoons and opossums in urban areas compared to natural areas (Gardner 1982, Kaufmann 1982, Barratt 1997, Prange and Gehrt 2007) and suggest that in urban landscapes the biological needs of raccoons and opossums can be fulfilled within small areas (Rosatte et al. 1992).

Surprisingly, both raccoon and opossum presence was negatively associated with the amount of surface water available at study sites, as the habitat use of both species has been linked to the accessibility of water (Sullivan 1956, Gehrt and Fritzell 1998). Raccoons and opossums in urban environments may not be as dependent upon surface water due to anthropogenic water sources (e.g. fountains, pet water) found throughout urban areas (Harrison 1993).

It has been suggested that raccoons and opossums may be competitors (Ginger et al. 2003). The results of my study do not suggest such a relationship in the Chicago area. Although the course-scale nature of our investigation may not reveal temporal variations, differences in species densities or competition at fine-scales, one would expect that competition would lead to differentiation of landscape use. However, both species were 
associated with the landscape in similar ways at multiple spatial scales. If competition between raccoons and opossums is occurring, it may be decreased by the low winter survival of opossums (Gardner and Sunquist 2003), allowing both species to inhabit similar habitats across the landscape.

As urban sprawl continues, it is important to understand the possible implications of disease transmission through wildlife populations utilizing and living in proximity to human-dominated landscapes. Raccoons can reach high densities in urban areas (Riley et al. 1998, Prange et al. 2003, Schubert et al. 1998), and are carriers of many diseases including rabies (Riley et al. 1998), and canine distemper (Shubert et al. 1998). Disease can move through a dense wildlife population quickly not only infecting wildlife, but also pets, and humans in the case of zoonotic diseases. Furthermore, disease outbreaks may have more drastic effects on populations of less abundant wildlife species. In the Chicago metropolitan area, for example, mortality due to disease may be a contributing factor in the decline of gray fox populations (see Chapter 1).

\section{Land Cover Associations of Skunks}

At the largest (L2) spatial scale skunk presence was positively associated with diverse landscapes that were highly urbanized with interspersed and isolated agriculture, urban open space, and forest patches. At the intermediate spatial scale (L1), skunk presence was associated with moderate urban development and increased forested land cover. At the smallest spatial scale of my study skunk presence was positively associated with decreased urban development and increased forested land cover within study sites that were surrounded by suburban matrix. 
At a large spatial scale, natural and semi-natural patches within a highly urbanized landscape may increase the connectivity of the landscape, particularly for smaller species that may be less mobile. These patches may also provide resting locations and foraging opportunities during dispersal movements. Unlike raccoons and opossums, which were associated with a moderate degree of urbanization at the largest scale, skunks were associated with a high degree of urban development. This may indicate that skunks perceive the urban matrix as more homogeneous than raccoons or opossums. Conversely, this may be an artifact of the relatively low number of skunk detections during the study.

Similar to raccoons and opossums, skunks are habitat generalists (Wade-Smith and Verts 1982, Bixler and Gittleman 2000) and are able to exploit urban environments (Crooks 2002). However, skunk abundance has been shown to increase with the distance from urban edges (Crooks 2002). Results from the smallest scale of my study support these findings, as skunk presence was positively associated with sites that were composed primarily of forested land cover. Skunks may utilize the suburban matrix during nocturnal foraging activities but may not be tolerated in close proximity to human development as would be raccoons, opossums, or foxes. For this reason skunks may select resting and denning sites that are within more contiguous natural habitat fragments. 
Although skunks were the least detected species in the study, their role as disease reservoirs within an urban environment could be important. Striped skunks are the principle host of rabies in midwestern states (Gehrt 2005). Even though rabies is currently not present in the Illinois population (Gehrt 2005), the possibility of the disease entering the population is a threat to populations of mammalian wildlife as well as human health.

\section{Land Cover Associations of Domestic Cats}

At the largest spatial scale (L2), domestic cat presence was positively associated with increasingly urbanized, less diverse landscapes with decreased amounts of forest and urban open space. At the intermediate spatial scale (L1) cats were associated with urban development but also with increased forest cover. Similar to the largest spatial scale, at the small scale (SS) cats were associated with a high degree of urban development which may be due to a human tolerance of free-ranging pet and feral cats.

Increased cat densities are associated with increased urbanization (Lepczyk et al. 2003) likely due to their status as human companions. Pet cats are often allowed outside and feral cat colonies are often supported near human development by the establishment of feeding stations (Clarke and Pacin 2002). Free-ranging domestic cats in a developed region of Australia were found to spend a majority of their time within suburban boundaries, particularly during daylight hours, however, they utilized natural habitat surrounding suburban boundaries (Barratt 1997) for hunting during nighttime hours. 
Cat populations in the United States have doubled between 1970 and 1990, from 30 million to 60 million (Nassar and Mosier 1991). In the face of increasing populations of free-ranging domestic cats, impacts on wild prey and predator species must be assessed. Cats are considered a threat to native prey species (Clarke and Pacin 2002) and can compete with native predators (George 1974). It was estimated (Lepczyk et al. 2003) that cats killed between 16,000 to 47,000 birds during the breeding season in southeastern Michigan. In Australia, cats have been implicated in the extinction of small mammals (Burbidge and Manly 2002). Furthermore, in Bristol, UK, sink populations of bird species were created in urban areas due to cat predation (Baker et al. 2005). As urbanization increases, cat activity could have serious implications for prey species in urban areas.

\section{Assessment of Spatial Scale}

Results of the analysis suggest that spatial scale has an influence on the relationship of mesopredators and how they respond to their environment. At the smallest spatial scale (SS), four percent of the variation was explained by environmental variables alone, whereas at L1 and L2 spatial scales, the variation explained by environmental variables at least doubled ( $8 \%$ and $10 \%$, respectively). These results indicate that urban mesopredators may assess their environment at scales that are larger than remnant habitat patches within urbanized landscapes. However, the large amount of variance that remained unexplained at all spatial scales indicated that although land cover may influence patterns of mesopredator presence across the landscape, it does not appear 
to be a prominent force shaping the urban mesopredator community in northeastern Illinois. Other factors that may influence the distribution of mesopredators may include resource distribution, density-dependent factors, and varying degrees of human activity, among others.

\section{Limitations on Inference}

Several factors relating to study design and analysis could have influenced results. For instance, scent station surveys were used to assess land cover associations of a suite of urban mesopredators. In doing so, it was assumed that all species would be detected at a site given that they were present. In reality this assumption is often not met due to difference in behaviors of individual species. Furthermore, it was assumed that all mesopredators were equally likely to step in a sand track station or investigate the lure at camera stations. While conducting fieldwork it was apparent that this assumption might not be true, as raccoons seemed to be more curious and prone to investigate scent stations. A difference in detection rates between species could have biased results. Occupancy modeling (MacKenzie et al. 2006) is a technique that can be used to model detection probabilities that are less than 1. This analysis was not utilized, however, as currently occupancy models are largely limited to the assessment of a single species.

Within the study design, results may be biased due to sampling protocols. Typically forest preserves, cemeteries and golf courses were sampled although some residential yards were included in the samples. The association of some species of urban mesopredators with natural land cover at small spatial scales may be an artifact of this sampling scheme. Similarly, the association of foxes with urban land cover may be an 
artifact of sampling efforts. Informational fliers soliciting gray fox sightings were distributed to county forest preserve districts for posting in forest preserve kiosks. These postings generated reports of fox sightings not only within forest preserves but also in urban areas. Of the 24 study sites that had fox (gray fox and red fox combined) activity, $46 \%$ of those were sampled due to a gray fox report. Of the study sites where a fox was reported and documented, $73 \%$ were located in residential yards ranging from low to high density urban development. In total, these sites comprised approximately one-third of all sites with fox activity. This bias may have resulted in an overestimation of the importance of urban land cover relating to the presence of foxes.

It is possible that the largest spatial scale (L2) may be too large to infer associations for small mesopredators such as raccoons, opossums, skunks, and domestic cats. Reported raccoon home ranges often range from 4-100 ha, with the smallest home ranges occurring in urbanized areas (Kaufmann 1982). Similarly, reported opossum home ranges are small, often less than 40 ha. (Gardner 1982). Skunks in the Chicago area exhibited home range sizes that were less than 60 ha (Prange and Gehrt 2007), and cat home ranges in a suburban region of Australia were less than 30 ha (Barratt 1997). However, the average home range size of foxes in the Chicago area was 165 ha (Chapter 1), and home ranges of coyotes in the Chicago area ranged from 220-1230 ha (Prange and Gehrt 2007). Therefore, foxes and coyotes may be influenced by the landscape at larger scales than the other mesopredators in the study. Furthermore, due to issues 
related to multicollinearity between sites, landscapes at large spatial scales were combined if they overlapped by approximately $30 \%$. For this reason, it is unknown to what degree comparisons between scales can be made, however, there were some general trends that did arise.

\section{CONCLUSIONS}

Raccoons, opossums, coyotes, and domestic cats were the species most often detected during scent station surveys. My analysis showed that urban mesopredators may utilize land covers in different ways and that more mobile species may perceive a highly urbanized matrix to be more homogeneous than less mobile species. Spatial scale appeared to be an important element in assessing land cover associations of urban mesopredators.

\section{LITERATURE CITED}

Allen, C. H., R. L. Marchinton, and W. Mac Lentz. 1985. Movement, habitat use and denning of opossums in the Georgia Piedmont. American Midland Naturalist 113: 408-412.

Atwood, T. C., H. P. Weeks, and T. M. Gehring. 2004. Spatial ecology of coyotes along a suburban-to-rural gradient. Journal of Wildlife Management 68: 1000-1009.

Baker, P. J., A. J. Bentley, R. J. Ansell, and S. Harris. 2005. Impact of predation by domestic cats (Felis catus) in an urban area. Mammal Review 35: 302-312.

Barratt, D. G. 1997. Home range size, habitat utilization and movement patterns of suburban and farm cats (Felis catus). Ecography 20: 271-280.

Bixler, A., and J. L. Gittleman. 2000. Variation in home range and use of habitat in the striped skunk (Mephitis mephitis). Journal of Zoology, London 251: 525-533. 
Bluett, R. 2006. 2005 Illinois Archery Deer Hunter Survey. Wildlife Diversity Program Note 06-4. Illinois Department of Natural Resources, Springfield, Illinois, USA.

Bozek, C. K., S. Prange, and S. D. Gehrt. 2007. The influence of anthropogenic resources on multi-scale habitat selection by raccoons. Urban Ecosystems 10: 413-425.

Burbidge, A. A., and B. F. J. Manly. 2002. Mammal extinctions on Australian islands: causes and conservation implications. Journal of Biogeography 29: 465-473.

Caro, T. M., J. A. Shargel, and C. J. Stoner. 2000. Frequency of medium-sized mammal road kills in an agricultural landscape in California. American Midland Naturalist 144: 362-369.

Clarke, A. L., and T. Pacin. 2002. Domestic cat 'colonies' in natural areas: a growing exotic species threat. Natural Areas Journal 22: 154-159.

Crooks, K. R. 2002. Relative sensitivities of mammalian carnivores to habitat fragmentation. Conservation Biology 16: 488-502.

Crooks, K. R., and M. E. Soule. 1999. Mesopredator release and avifaunal extinctions in a fragmented system. Nature 400: 563-566.

Cushman, S. A., and K. McGarigal. 2002. Hierarchical, multi-scale decomposition of species-environment relationships. Landscape Ecology 17: 637-646.

Cypher, B. L., and N. Frost. 1999. Condition of San Joaquin kit foxes in urban and exurban habitats. Journal of Wildlife Management 63: 930-938.

Cypher, B. L., and K. A. Spencer. 1998. Competitive interactions between coyotes and San Joaquin kit foxes. Journal of Mammalogy 79: 204-214.

Dijak, W. D., and F. R. Thompson III. 2000. Landscape and edge effects on the distribution of mammalian predators in Missouri. Journal of Wildlife Management 64: 209-216.

Erlinge, S., G. Goransson, G. Hogstedt, G. Jansson, O. Liberg, J. Loman, I. N. Nilsson, T. Von Schantz, and M. Sylven. 1984. Can vertebrate predators regulate their prey? The American Naturalist 123: 125-133.

Farias, V., T. K. Fuller, R. K. Wayne, and R. M. Sauvajot. 2005. Survival and causespecific mortality of gray foxes (Urocyon cinereoargenteus) in southern California. Journal of Zoology, London 266: 249-254. 
Fedriani, J. M., T. K. Fuller, and R. M. Sauvajot. 2001. Does availability of anthropogenic food enhance densities of omnivorous animals? An example with coyotes in southern California. Ecography 24: 325-331.

Follman, E. H. 1973. Comparative ecology and behavior of red and gray foxes. Ph.D. dissertation. Southern Illinois University, Carbondale, Illinois, USA.

Gardner, A. L. 1982. Virginia Opossum. Chapter in Wild Mammals of North America: Biology, Management, and Economics, J. A. Chapman, and G. A. Feldhamer, eds. Pp. 3-36. John Hopkins University Press, Baltimore, Maryland, USA.

Gardner, A. L., and M. E. Sunquist. 2003. Opossums. Chapter in Wild Mammals of North America, G. Feldhamer, B. Thompson, and J. Chapman, eds. Second edition. Pp. 3-29. John Hopkins University Press, Baltimore, Maryland, USA.

Gehring, T. M., and R. K. Swihart. 2003. Body size, niche breadth, and ecologically scaled responses to habitat fragmentation: mammalian predators in an agricultural landscape. Biological Conservation 109: 283-295.

Gehrt, S. D. 2006. Urban coyote ecology and management: the Cook County, Illinois, coyote project. The Ohio State University Extension Bulletin 929, Columbus Ohio, USA.

Gehrt, S. D. 2005. Seasonal survival and cause-specific mortality of urban and rural striped skunks in the absence of rabies. Journal of Mammalogy 86: 1164-1170.

Gehrt, S, D., and S. Prange. 2007. Interference competition between coyotes and raccoons: a test of the mesopredator release hypothesis. Behavioral Ecology 18: 204-214.

Gehrt, S. D., and E. K. Fritzell. 1998. Resource distribution, female home range dispersion and male spatial interactions: group structure in a solitary carnivore. Animal Behaviour 55: 1211-1227.

George, W. G. 1974. Cats as predators and factors in winter shortages of raptor prey. The Wilson Bulletin 86: 384-396.

George, S. L., and K. R. Crooks. 2006. Recreation and large mammal activity in an urban nature reserve. Biological Conservation 133: 107-117.

George, T. L., and S. Zack. 2001. Spatial and temporal considerations in restoring habitat for wildife. Restoration Ecology 9: 272-279. 
Gese, E. M., S. M. Karki, M. L. Klavetter, E. R. Schauster, and A. M. Kitchen. 2004. Serologic survey for canine infectious diseases among sympatric swift foxes (Vulpes velox) and coyotes (Canis latrans) in southeastern Colorado. Journal of Wildlife Diseases 40: 741-748.

Ginger, S. M., E. C. Hellgren, M. A. Kasparian, L. P. Levesque, D. M. Engle, and D. M. Leslie, Jr. 2003. Niche shift by Virginia opossum following reduction of a putative competitor, the raccoon. Journal of Mammalogy 84: 1279-1291.

Gipson, P. S., and J. F. Kamler. 2001. Survival and home ranges of opossums in northeastern Kansas. Southwestern Naturalist 46: 178-182.

Godin, A. J. 1982. Striped and Hooded Skunks. Chapter in Wild Mammals of North America: Biology, Management, and Economics, Chapman, J. A., and G. A. Feldhamer, eds. Pp. 674-687. Johns Hopkins University Press, Baltimore, Maryland, USA.

Gompper, M. E. 2002. Top carnivores in the suburbs? Ecological and conservation issues raised by colonization of northeastern North America by coyotes. BioScience 52: 185-191.

Gompper, M. E., R. W. Kays, J. C. Ray, S. D. Lapoint, D. A. Bogan, and J. R. Cryan. 2006. A comparison of noninvasive techniques to survey carnivore communities in northeastern North America. Wildlife Society Bulletin 34: 1142-1151.

Gosselink, T. E., T. R. Van Deelen, R. E. Warner, and P. C. Mankin. 2007. Survival and cause-specific mortality of red foxes in agricultural and urban areas of Illinois. Journal of Wildlife Management 71: 1862-1873.

Gosselink, T. E., T. R. Van Deelen, R. E. Warner, and M. G. Joselyn. 2003. Temporal habitat partitioning and spatial use of coyotes and red foxes in east-central Illinois. Journal of Wildlife Management 67: 90-103.

Grinder, M. I., and P. R. Krausman. 2001. Home range, habitat use, and nocturnal activity of coyotes in an urban environment. Journal of Wildlife Management 65: 887-898.

Gustafson, E. J., and G. R. Parker. 1994. Using an index of habitat patch proximity for landscape design. Landscape and Urban Planning 29: 117-130.

Gustine, D. D., K. L. Parker, R. J. Lay, M. P. Gillingham, and D. C. Heard. 2006. Interpreting resource selection at different scales for woodland caribou in the winter. Journal of Wildlife Mangement 70: 1601-1614. 
Haines-Young, R., and M. Chopping. 1996. Quantifying landscape structure: a review of landscape indices and their application to forested landscapes. Progress in Physical Geography 20: 418-445.

Harrison, R. L. 1997. A comparison of gray fox ecology between residential and undeveloped rural landscapes. Journal of Wildlife Management 61: 112-122.

Harrison, R. L. 1993. A survey of anthropogenic ecological factors potentially affecting gray foxes (Urocyon cinereoargenteus) in a rural residential area. Southwestern Naturalist 38: 352-356.

Hewitt, J. E., S. F. Thrush, V. J. Cummings, and S. J. Turner. 1998. The effect of changing sampling scales on our ability to detect effects of large-scale processes on communities. Journal of Experimental Marine Biology and Ecology 227: 251-264.

Hoff, G. L., W. J. Bigler, S. J. Proctor, and L. P. Stallings. 1974. Epizootic of canine distemper virus infection among urban raccoons and gray foxes. Journal of Wildlife Diseases 10: 423-428.

Hoffmann, C. O., and J. L. Gottschang. 1977. Numbers, distribution, and movements of a raccoon population in a suburban residential community. Journal of Mammalogy 58: 623-636.

Illinois Agricultural Statistics Supplement. 2004. Illinois county statistics. Illinois Dept. of Agriculture and National Agriculture Statistics Service. 2 Oct. 2006. URL http:/www.agstats.state.il.us/ctyest/.

Johnson, D. H. 1980. The comparison of usage and availability measurements for evaluating resource preference. Ecology 61: 65-71.

Kamler, J. F., and P. S. Gipson. 2004. Survival and cause-specific mortality among furbearers in a protected area. American Midland Naturalist 151: 27-34.

Kaufmann, J. H. 1982. Raccoons and Allies. Chapter in Wild Mammals of North America: Biology, Management, and Economics, Chapman, J. A., and G. A. Feldhamer, eds. Pp 567-585. Johns Hopkins University Press, Baltimore, Maryland, USA.

Kneitel, J. M., and J. M. Chase. 2004. Trade-offs in community ecology: linking spatial scales and species coexistence. Ecology Letters 7: 69-80.

Kotliar, N. B., and J. A. Wiens. 1990. Multiple scales of patchiness and patch structure: a hierarchical framework for the study of heterogeneity. Oikos 59: 253-260. 
Lavin, S. R., T. R. Van Deelen, P. W. Brown, R. E. Warner, and S. H. Ambrose. 2003. Prey use by red foxes (Vulpes vulpes) in urban and rural areas of Illinois. Canadian Journal of Zoology 81: 1070-1082.

Lepczyk, C. A, A. G. Mertig, and J. Liu. 2003. Landowners and cat predation across rural-to-urban landscapes. Biological Conservation 115: 191-201.

Lepš, J., and P. Šmilauer. 2003. Multivariate Analysis of Ecological Data Using CANOCO. Cambridge University Press, Cambridge, England.

Linhart, S. B., and F. F. Knowlton. 1975. Determining the relative abundance of coyotes by scent station lines. Wildlife Society Bulletin 3: 119-124.

Linnel, J. D. C., and O. Strand. 2000. Interference interactions, co-existence and conservation of mammalian carnivores. Diversity and Distributions 6: 169-176.

McKinney, M. L. 2002. Urbanization, biodiversity, and conservation. BioScience 52: $883-890$

Moerenschlager, A., R. List, and D. W. Macdonald. 2007. Escaping intraguild predation: Mexican kit foxes survive while coyotes and golden eagles kill Canadian swift foxes. Journal of Mammalogy 88: 1029-1039.

Morey, P. S., E. M. Gese, and S. D. Gehrt. 2007. Spatial and temporal variation in the diet of coyotes in the Chicago metropolitan area. American Midland Naturalist 158: $147-161$.

Nassar, R., and J. Mosier. 1991. Projections of pet populations from census demographic data. Journal of the American Veterinary Medical Association 198: 1157-1159.

National Weather Service. 2006. Weather forecast office: Chicago, IL. National Oceanic and Atmospheric Administration. 2 Oct. 2006. URL http://www.crh.noaa.gov/lot/

Neiswenter, S. A., and R. C. Dowler. 2007. Habitat use of western spotted skunks and striped skunks in Texas. Journal of Wildlife Management 71: 582-586.

Nicholson, W. S., and E. P. Hill. 1984. Mortality in gray foxes from east-central Alabama. Journal of Wildlife Management 48: 1429-1432.

O’Neill, R. B., J. R. Krummel, R. H. Gardner, G. Sugihara, B. Jackson, D. L. DeAngelis, B. T. Milne, M. G. Turner, B. Zygmunt, S. W. Christensen, V. H. Dale, and R. L. Graham. 1988. Indices of landscape pattern. Landscape Ecology 1: 153-162. 
Oehler, J. D., and J. A. Litvaitis. 1996. The role of spatial scale in understanding responses of medium-sized carnivores to forest fragmentation. Canadian Journal of Zoology 74: 2070-2079.

Openlands Project. 2006. Forest preserve and conservation districts in northeastern Illinois: meeting the challenges of the $21^{\text {st }}$ century. Openlands Project, Chicago, Illinois, USA.

Openlands Project. 1999. Under pressure: land consumption in the Chicago region, 1998-2028. Openlands Project, Chicago, Illinois, USA.

Peres-Neto, P. R., P. Legendre, S. Dray, and D. Borcard. 2006. Variation partitioning of species data matrices: estimation and comparisons of fractions. Ecology 87: 2614-2625.

Prange, S., and S. D. Gehrt. 2007. Response of skunks to a simulated increase in coyote activity. Journal of Mammalogy 88: 1040-1049.

Prange, S., and S. D. Gehrt. 2004. Changes in mesopredator community structure in response to urbanization. Canadian Journal of Zoology 82: 1804-1817.

Prange, S., S. D. Gehrt, and E. P. Wiggers. 2003. Demographic factors contributing to high raccoon densities in urban landscapes. Journal of Wildlife Management 67: 324-333.

Quinn, T. 1997a. Coyote (Canis latrans) food habits in three urban habitat types of western Washington. Northwest Science 71: 1-5.

Quinn, T. 1997b. Coyote (Canis latrans) habitat selection in urban areas of western Washington via analysis of routine movements. Northwest Science 71: 289-297.

Riley, S. P. D. 2006. Spatial ecology of bobcats and gray foxes in urban and rural zones of a national park. Journal of Wildlife Management 70: 1425-1435.

Riley, S. P. D., J. Foley, and B. Chomel. 2004. Exposure to feline and canine pathogens in bobcats and gray foxes in urban and rural zones of a national park in California. Journal of Wildlife Diseases 40: 11-22.

Riley, S. P. D., R. M. Sauvajot, T. D. Fuller, E. C. York, D. A. Kamradt, C. Bromley, and R. K. Wayne. 2003. Effects of urbanization and habitat fragmentation on bobcats and coyotes in southern California. Conservation Biology 17: 566-576.

Riley, S. P. D., J. Hadidian, and D. A. Manski. 1998. Population density, survival, and rabies in raccoons in an urban national park. Canadian Journal of Zoology 76: 1153-1164. 
Rosatte, R. C., M. J. Power, and C. D. Macinnes. 1992. Density, dispersion, movements and habitat of skunks (Mephitis mephitis) and raccoons (Procyon lotor) in metropolitan Toronto. Chapter in Wildlife 2001: Populations, D. E. McCullough, and R. E. Barratt, eds. Pp. 932-944. Elsevier Science Publishers Ltd., Essex, United Kingdom.

Rosenblatt, D. L., E. J. Heske, S. L. Nelson, D. M. Barber, M. A. Miller, and B. MacAllister. 1999. Forest fragments in east-central Illinois: islands or habitat patches for mammals? American Midland Naturalist 141: 115-123.

Roughton, R. D., and M. W. Sweeny. 1982. Refinements in scent-station methodology for assessing trends in carnivore populations. Journal of Wildlife Management 46: 217-229.

Sargent, G. A., D. H. Johnson, and W. E. Berg. 1998. Interpreting carnivore scent station surveys. Journal of Wildlife Management 62: 1235-1245.

Saunders, D. A., R. J. Hobbs, and C. R. Margules. 1991. Biological consequences of ecosystem fragmentation: a review. Conservation Biology 5: 18-32.

Schirer, H. W., and H. S. Fitch. 1970. Comparison from radiotracking of movements and denning habits of the raccoon, striped skunk, and opossum in northeastern Kansas. Journal of Mammalogy 51: 491-503.

Schubert, C. A., I. K. Barker, R. C. Rosatte, and C. D. MacInnes. 1998. Effect of canine distemper on an urban raccoon population: an experiment. Ecological Applications 8: 379-387.

Senft, R. L., M. B. Coughenour, D. W. Bailey, L. R. Rittenhouse, O. E. Sala, and D. M. Swift. 1987. Large herbivore foraging ecology and ecological hierarchies. BioScience 37: 789-791.

Sullivan, E. G. 1956. Gray fox reproduction, denning, range, and weights in Alabama. Journal of Mammalogy 37:346-351.

Sullivan, J. 2000. An atlas of biodiversity. Chicago Region Biodiversity Council: 64 .

Swihart, R. K., T. M. Gehring, M. B. Kolozsvary, and T. E. Nupp. 2003. Responses of 'resistant' vertebrates to habitat loss and fragmentation: the importance of niche breadth and range boundaries. Diversity and Distributions 9: 1-18.

Switalski, T. A. 2003. Coyote foraging ecology and vigilance in response to gray wolf reintroduction in Yellowstone national park. Canadian Journal of Zoology 81: 985-993. 
ter Braak, C. J. F., and P. Šmilauer. 2002. CANOCO Reference Manual and CanoDraw for Windows User's Guide: Software for Canonical Community Ordination (version 4.5). Microcomputer Power, Ithaca, New York, USA.

Thompson, C. M., and E. M. Gese. 2007. Food webs and intraguild predation: community interactions of a native mesocarnivore. Ecology 88: 334-346.

Tigas, L. A., D. H. Van Vuren, and R. M. Sauvajot. 2002. Behavioral responses of bobcats and coyote to habitat fragmentation and corridors in an urban environment. Biological Conservation 108: 299-306.

Voigt, D. R., and B. D. Earle. 1983. Avoidance of coyotes by red fox families. Journal of Wildlife Management 47: 852-857.

Wade-Smith, J., and B. J. Verts. 1982. Mephitis mephitis. Mammalian Species 173: $1-7$. 


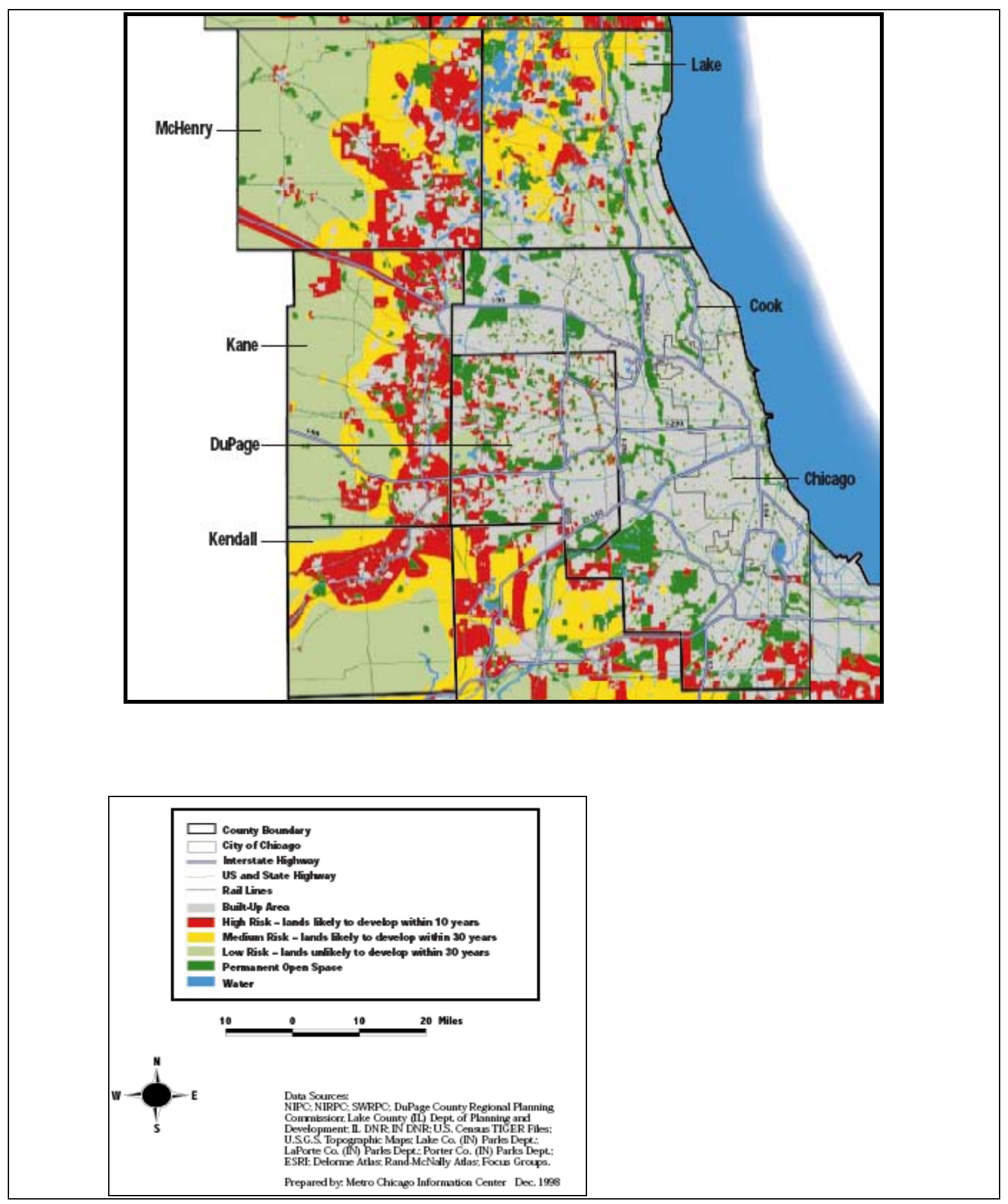

Figure 2.1. Land cover map of northeastern Illinois (Under Pressure Map, Openlands Project 1999). 


\begin{tabular}{lccccc}
\hline & & & & & \\
County & population & total area (ha) & preserved land (ha.) & \% of county & $\begin{array}{l}\text { hectares per } \\
1000 \text { residents }\end{array}$ \\
\hline Cook & 5303683 & 246796.8 & 27641.2 & $11.2 \%$ & 13 \\
DuPage & 929113 & 86982.7 & 10003.0 & $11.5 \%$ & 27 \\
Lake & 702682 & 121357.1 & 10194.0 & $8.4 \%$ & 36 \\
McHenry & 303990 & 158858.9 & 8101.8 & $5.1 \%$ & 66 \\
Totals & 7239468 & 613995.5 & 55940 & $9 \%$ & \\
\hline
\end{tabular}

Table 2.1. Amount of publicly owned land held as preserves and populations for each county (Openlands Project 2006).

\begin{tabular}{lcccc}
\hline County & \% Built Up & \% At Risk & \% Perm. Open Space & \% Low Risk \\
\hline Cook & 78.3 & 4.8 & 14.5 & 1.2 \\
DuPage & 67.3 & 12.0 & 14.7 & 5.3 \\
Lake & 39.6 & 32.6 & 11.66 & 11.5 \\
McHenry & 13.7 & 35.9 & 3.52 & 45.7 \\
\hline
\end{tabular}

Table 2.2. Status of land cover in northeastern Illinois (Openlands Project 1999). 'Built up' includes already developed land, 'At Risk' includes land at risk of being developed in 10-30 years, 'Perm. Open Space' includes county forest preserves and 'Low Risk' includes land uses such as golf courses and cemeteries. 


\begin{tabular}{|c|c|}
\hline Collapsed Classification & Original Illinois GAP Classification \\
\hline \multirow[t]{7}{*}{ Agriculture } & Corn \\
\hline & Soybeans \\
\hline & Winter Wheat \\
\hline & Other Small Grains and Hay \\
\hline & Winter Wheat/Soybeans \\
\hline & Other Agriculture \\
\hline & Rural Grassland \\
\hline \multirow[t]{8}{*}{ Forest } & Dry Upland \\
\hline & Dry-Mesic Upland \\
\hline & Mesic Upland \\
\hline & Partial Canopy/Savannah Upland \\
\hline & Coniferous \\
\hline & Mesic Floodplain Forest \\
\hline & Wet-Mesic Floodplain Forest \\
\hline & Wet Floodplain Forest \\
\hline Urban Open Space & Urban Open Space \\
\hline High Density Urban & High Density Urban Land \\
\hline Medium Density Urban & Medium Density Urban Land \\
\hline \multirow[t]{2}{*}{ Low Density Urban } & Low/Medium Density Urban Land \\
\hline & Low Density Urban \\
\hline \multirow[t]{5}{*}{ Wetland } & Shallow Marsh/Wet Meadow \\
\hline & Deep Marsh \\
\hline & Seasonally/Temporarily Flooded \\
\hline & Swamp \\
\hline & Shallow Water \\
\hline Surface Water & Surface Water \\
\hline Barren/Exposed Land & Barren and Exposed Land \\
\hline
\end{tabular}

Table 2.3. Original and reclassified land cover values derived from the Illinois GAP data. 


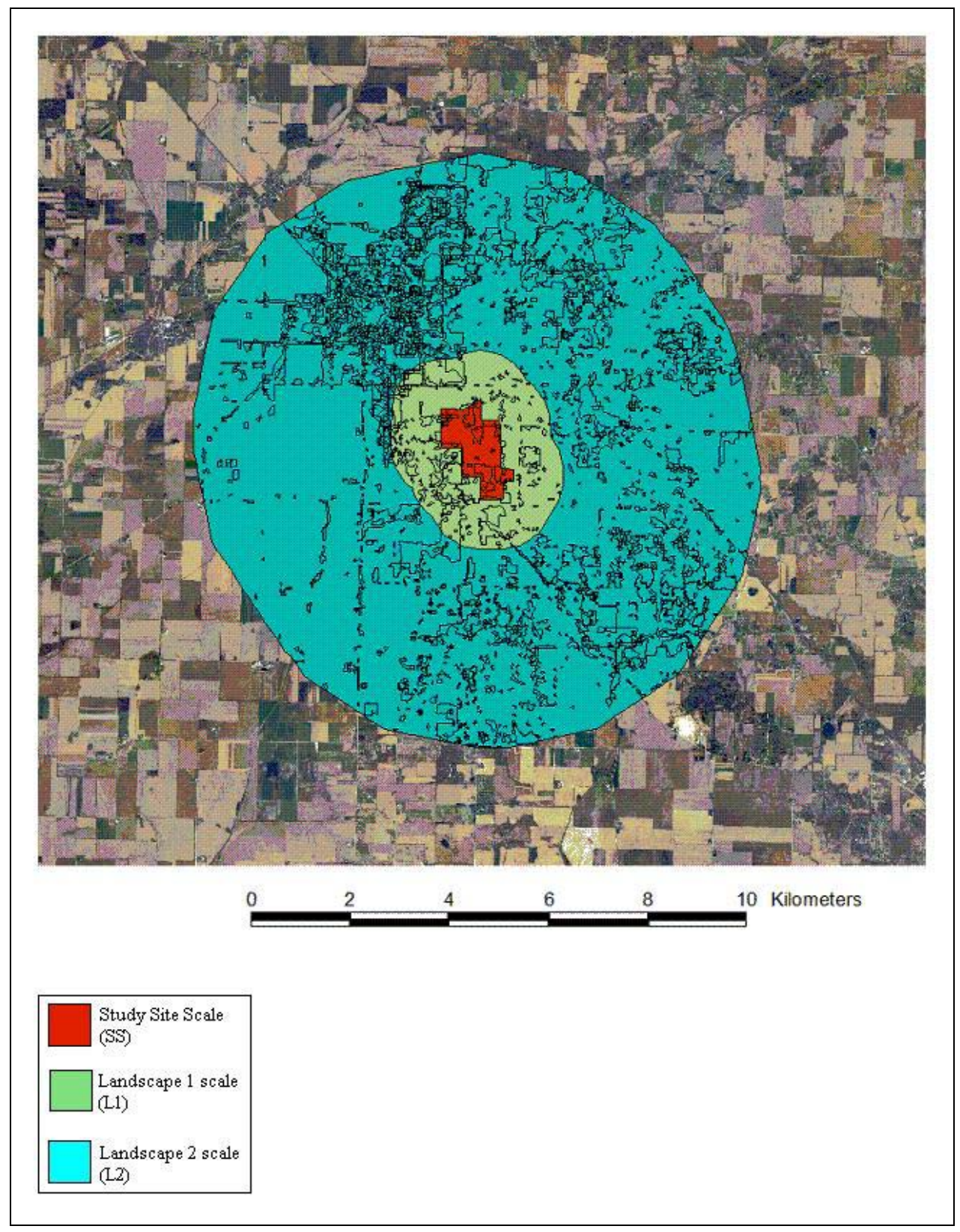

Figure 2.2. Example of three spatial scales used to assess land cover associations of mammalian mesopredators in the Chicago metropolitan area from 2005-2007. 'SS' indicates the smallest site-level scale, 'L1' indicated the intermediate landscape scale, which consisted of the study site plus a $1 \mathrm{~km}$ buffer, and 'L2' indicated the largest landscape scale which consisted of the study site plus a $5 \mathrm{~km}$ buffer. 


\begin{tabular}{|c|c|c|c|c|c|c|}
\hline ENV_VAR & Name & Description & Units & Mean \pm SD & Range & Application \\
\hline no_stations & $\begin{array}{l}\text { Number of survey } \\
\text { stations }\end{array}$ & Total number of survey stations operated within study sites. & count & $6.96 \pm 9.65$ & $1-52$ & $\begin{array}{l}\text { Covariable used to } \\
\text { adjust for differences } \\
\text { in survey effort. }\end{array}$ \\
\hline no_stn_nights & $\begin{array}{l}\text { Number of station } \\
\text { nights }\end{array}$ & $\begin{array}{l}\text { Total number of survey stations multiplied by the number of } \\
\text { operational nights within study sites. }\end{array}$ & stns $\mathrm{x}$ nights & $28.6 \pm 40.58$ & $1-210$ & $\begin{array}{l}\text { Covariable used to } \\
\text { adjust for differences } \\
\text { in survey effort. }\end{array}$ \\
\hline PER_AG & Percent agriculture & $\begin{array}{l}\text { Percent of agriculture land cover within respective study } \\
\text { sites. }\end{array}$ & $\%$ & $9.56 \pm 17.77$ & $0-82.36$ & $\begin{array}{l}\text { Study site } \\
\text { composition }\end{array}$ \\
\hline PER_FOR & Percent forest & Percent of forest land cover within respective study sites. & $\%$ & $44.03 \pm 29.15$ & $0-95.38$ & $\begin{array}{l}\text { Study site } \\
\text { composition }\end{array}$ \\
\hline PER_HIGH & $\begin{array}{l}\text { Percent high density } \\
\text { urban }\end{array}$ & $\begin{array}{l}\text { Percent of high density urban land cover within respective } \\
\text { study sites. }\end{array}$ & $\%$ & $2.12 \pm 9.06$ & $0-84.6$ & $\begin{array}{l}\text { Study site } \\
\text { composition }\end{array}$ \\
\hline PER_LOW & $\begin{array}{l}\text { Percent low density } \\
\text { urban }\end{array}$ & $\begin{array}{l}\text { Percent of low density urban land cover within respective } \\
\text { study sites. }\end{array}$ & $\%$ & $3.06 \pm 6.1$ & $0-42$ & $\begin{array}{l}\text { Study site } \\
\text { composition }\end{array}$ \\
\hline PER_MED & $\begin{array}{l}\text { Percent medium density } \\
\text { urban }\end{array}$ & $\begin{array}{l}\text { Percent of medium density urban land cover within respective } \\
\text { study sites. }\end{array}$ & $\%$ & $8.85 \pm 13.4$ & $0-73.39$ & $\begin{array}{l}\text { Study site } \\
\text { composition }\end{array}$ \\
\hline PER_URBOP & $\begin{array}{l}\text { Percent urban open } \\
\text { space }\end{array}$ & $\begin{array}{l}\text { Percent of urban open space land cover within respective } \\
\text { study sites. }\end{array}$ & $\%$ & $26.21 \pm 25.55$ & $0-84.93$ & $\begin{array}{l}\text { Study site } \\
\text { composition }\end{array}$ \\
\hline PER_WAT & Percent surface water & $\begin{array}{l}\text { Percent of surface water land cover within respective study } \\
\text { sites. }\end{array}$ & $\%$ & $3.29 \pm 5.61$ & $0-32.26$ & $\begin{array}{l}\text { Study site } \\
\text { composition }\end{array}$ \\
\hline PER_WET & Percent wetland & Percent of wetland land cover within respective study sites. & $\%$ & $2.83 \pm 5.67$ & $0-37.4$ & $\begin{array}{l}\text { Study site } \\
\text { composition }\end{array}$ \\
\hline RURAL & Rural matrix & $\begin{array}{l}\text { Binary variable indicates matrix within } 1 \mathrm{~km} \text { buffer of site } \\
\text { boundary consists of } \leq 25 \% \text { high and medium density urban } \\
\text { development. }\end{array}$ & none & - & - & $\begin{array}{l}\text { Composition of } \\
\text { surrounding matrix }\end{array}$ \\
\hline SUBURBAN & Suburban matrix & $\begin{array}{l}\text { Binary variable indicates matrix within } 1 \mathrm{~km} \text { buffer of site } \\
\text { boundary consists of } \geq 25 \% \text { high and medium density urban } \\
\text { development. }\end{array}$ & none & - & - & $\begin{array}{l}\text { Composition of } \\
\text { surrounding matrix }\end{array}$ \\
\hline TA_HA & $\begin{array}{l}\text { Total area measured in } \\
\text { hectares }\end{array}$ & Total area of study site. & hectares & $316.3 \pm 596.3$ & $\begin{array}{r}0.81- \\
4422.2\end{array}$ & $\begin{array}{l}\text { Covariable used to } \\
\text { adjust for differences } \\
\text { in survey effort. }\end{array}$ \\
\hline URBAN & Urban matrix & $\begin{array}{l}\text { Binary variable indicates matrix within } 1 \mathrm{~km} \text { buffer of site } \\
\text { boundary consists of } \geq 50 \% \text { high and medium density urban } \\
\text { development. }\end{array}$ & none & - & - & $\begin{array}{l}\text { Composition of } \\
\text { surrounding matrix }\end{array}$ \\
\hline
\end{tabular}

Table 2.4. Description of environmental predictor variables used in smallest (SS) spatial scale partial redundancy analysis to determine land cover associations of mammalian mesopredators in the Chicago metropolitan area from 2005-2007. 


\begin{tabular}{|c|c|c|c|c|c|c|}
\hline ENV_VAR & Name & Description & Units & Mean \pm SD & Range & Application \\
\hline CONTAG & Contagion index & $\begin{array}{l}\text { Reflects dispersion and interspersion of all land cover classes } \\
\text { in respective L1 landscapes. High contagion values result } \\
\text { from low levels of interspersion and dispersion, whereas low } \\
\text { contagion values result from high levels of interspersion and } \\
\text { dispersion. }\end{array}$ & $\%$ & $46.54 \pm 9.56$ & $31.17-74.11$ & $\begin{array}{l}\text { Measure of landscape } \\
\text { structure/fragmentation }\end{array}$ \\
\hline FRAC_AM & $\begin{array}{l}\text { Area-weighted mean } \\
\text { fractal dimension }\end{array}$ & $\begin{array}{l}\text { Index measures patch shape complexity of all land cover } \\
\text { classifications within respective L1 landscapes. Small values } \\
\text { indicate simple shapes whereas larger values indicate } \\
\text { complex shapes. This index has been shown to decrease as } \\
\text { landscapes become more dominated by anthropogenic land } \\
\text { uses such as ag. }\end{array}$ & none & $1.1982 \pm 0.0235$ & $1.14-1.26$ & $\begin{array}{l}\text { Overall measure of } \\
\text { human influence upon } \\
\text { landscape }\end{array}$ \\
\hline no_stn_nights & $\begin{array}{l}\text { Number of station } \\
\text { nights }\end{array}$ & $\begin{array}{l}\text { Total number of survey stations multiplied by the number of } \\
\text { operational nights within L1 landscapes. }\end{array}$ & $\begin{array}{l}\text { stns } x \\
\text { nights }\end{array}$ & $38.14 \pm 46.77$ & $2-210$ & $\begin{array}{l}\text { Covariable used to } \\
\text { adjust for differences in } \\
\text { survey effort. }\end{array}$ \\
\hline no_stns & $\begin{array}{l}\text { Number of survey } \\
\text { stations }\end{array}$ & $\begin{array}{l}\text { Total number of survey stations operated within respective } \\
\text { L1 landscapes. }\end{array}$ & count & $9.28 \pm 10.78$ & $1-52$ & $\begin{array}{l}\text { Covariable used to } \\
\text { adjust for differences in } \\
\text { survey effort. }\end{array}$ \\
\hline PER_AG & Percent agriculture & $\begin{array}{l}\text { Percent of agriculture land cover within respective L1 } \\
\text { landscapes. }\end{array}$ & $\%$ & $14.21 \pm 21.71$ & $0-75.58$ & Landscape composition \\
\hline PER_FOR & Percent forest & Percent of forest land cover within respective L1 landscapes. & $\%$ & $22.42 \pm 13.24$ & $0-57.11$ & Landscape composition \\
\hline PER_HIGH & $\begin{array}{l}\text { Percent high density } \\
\text { urban }\end{array}$ & $\begin{array}{l}\text { Percent of high density urban land cover within respective L1 } \\
\text { landscapes. }\end{array}$ & $\%$ & $8.72 \pm 11$ & $0-59.64$ & Landscape composition \\
\hline PER_LOW & $\begin{array}{l}\text { Percent low density } \\
\text { urban }\end{array}$ & $\begin{array}{l}\text { Percent of low density urban land cover within respective L1 } \\
\text { landscapes. }\end{array}$ & $\%$ & $6.244 \pm 5.476$ & $0.1-22.71$ & Landscape composition \\
\hline PER_MED & $\begin{array}{l}\text { Percent medium } \\
\text { density urban }\end{array}$ & $\begin{array}{l}\text { Percent of medium density urban land cover within respective } \\
\text { L1 landscapes. }\end{array}$ & $\%$ & $22.16 \pm 15.5$ & $0-66.16$ & Landscape composition \\
\hline
\end{tabular}

Table 2.5. Description of environmental predictor variables used in intermediate (L1) spatial scale partial redundancy analysis to determine land cover associations of mammalian mesopredators in the Chicago metropolitan area from 2005-2007.

Table 2.5 continued... 
Table 2.5 (continued)...

\begin{tabular}{|c|c|c|c|c|c|c|}
\hline ENV VAR & Name & Description & Units & Mean \pm SD & Range & Application \\
\hline$\overline{\text { PER_URBOP }}$ & $\begin{array}{l}\text { Percent urban open } \\
\text { space }\end{array}$ & $\begin{array}{l}\text { Percent of urban open space land cover within respective L1 } \\
\text { landscapes. }\end{array}$ & $\%$ & $21.39 \pm 13.73$ & $0-55.25$ & Landscape composition \\
\hline PER_WATER & Percent surface water & $\begin{array}{l}\text { Percent of surface water land cover within respective L1 } \\
\text { landscapes. }\end{array}$ & $\%$ & $2.739 \pm 2.907$ & $0.07-17.14$ & Landscape composition \\
\hline PER_WET & Percent wetland & $\begin{array}{l}\text { Percent of wetland land cover within respective L1 } \\
\text { landscapes. }\end{array}$ & $\%$ & $1.686 \pm 1.849$ & $0-11.04$ & Landscape composition \\
\hline SDI & $\begin{array}{l}\text { Shannon's diversity } \\
\text { index }\end{array}$ & $\begin{array}{l}\text { Reflects amount and evenness of all land cover classifications } \\
\text { within respective L1 landscapes. The value of this index } \\
\text { increase as the number of different land cover classes } \\
\text { increases and/or the proportion of land cover classes becomes } \\
\text { more even. }\end{array}$ & none & $1.4676 \pm 0.2756$ & $0.73-1.88$ & $\begin{array}{l}\text { Measure of landscape } \\
\text { structure }\end{array}$ \\
\hline TA_HA & $\begin{array}{l}\text { Total area measured } \\
\text { in hectares }\end{array}$ & Total area of L1 landscape. & hectares & $1611 \pm 1340$ & $390-7913$ & $\begin{array}{l}\text { Covariable used to } \\
\text { adjust for differences in } \\
\text { survey effort. }\end{array}$ \\
\hline
\end{tabular}




\begin{tabular}{|c|c|c|c|c|c|}
\hline ENV_VAR & Name & Land cover classes & Units & Description & Applicability \\
\hline PER_land cover & $\begin{array}{l}\text { Percent of land cover } \\
\text { class }\end{array}$ & $\begin{array}{l}\text { FOR; AG; WET; WAT; } \\
\text { URBOP; LOW; MED; HIGH }\end{array}$ & $\%$ & $\begin{array}{l}\text { Percent of respective land cover classes in individual } \\
\text { L2 landscapes. }\end{array}$ & Landscape composition \\
\hline MPS_land cover & $\begin{array}{l}\text { Mean patch size of } \\
\text { land cover class }\end{array}$ & $\begin{array}{l}\text { FOR; AG; URBOP; LOW; } \\
\text { MED; HIGH }\end{array}$ & ha & $\begin{array}{l}\text { Sum of respective land cover class patch sizes divided } \\
\text { by the number of patches in respective land cover } \\
\text { class. }\end{array}$ & $\begin{array}{l}\text { Landscape } \\
\text { composition/structure }\end{array}$ \\
\hline AWMSI_land cover & $\begin{array}{l}\text { Area-weighted mean } \\
\text { shape index of } \\
\text { patches within a land } \\
\text { cover class }\end{array}$ & $\begin{array}{l}\text { FOR; AG; URBOP; LOW; } \\
\text { MED; HIGH }\end{array}$ & none & $\begin{array}{l}\text { Reflects shape complexity of patches within } \\
\text { respective habitat classes. This metric equals } 1 \text { when } \\
\text { the land cover class is maximally compact and } \\
\text { increases as shape complexity increases. }\end{array}$ & $\begin{array}{l}\text { Measure of landscape } \\
\text { structure/human influence } \\
\text { on land cover classes } \\
\text { within the landscape }\end{array}$ \\
\hline PROXAM_land cover & $\begin{array}{l}\text { Area-weighted mean } \\
\text { proximity index of } \\
\text { patches within a land } \\
\text { cover class }\end{array}$ & $\begin{array}{l}\text { FOR; AG; URBOP; LOW; } \\
\text { MED; HIGH }\end{array}$ & none & $\begin{array}{l}\text { Reflects both size and proximity of patches of the } \\
\text { same land cover class within a } 500 \mathrm{~m} \text { search radius } \\
\text { around a focal patch. The proximity index increases } \\
\text { as the amount of the focal habitat class increases } \\
\text { within the } 500 \mathrm{~m} \text { search radius. }\end{array}$ & $\begin{array}{l}\text { Measure of isolation of } \\
\text { land cover classes }\end{array}$ \\
\hline ENNAM_land cover & $\begin{array}{l}\text { Area-weighted mean } \\
\text { nearest neighbor of } \\
\text { patches within a land } \\
\text { cover class }\end{array}$ & $\begin{array}{l}\text { FOR; AG; URBOP; LOW; } \\
\text { MED; HIGH }\end{array}$ & meters & $\begin{array}{l}\text { Measures mean distance between a focal patch and } \\
\text { the nearest neighbor of the same land cover class } \\
\text { within a } 500 \mathrm{~m} \text { search radius. }\end{array}$ & Measure of isolation \\
\hline CLUMPY_land cover & $\begin{array}{l}\text { Clumpiness index of } \\
\text { land cover }\end{array}$ & $\begin{array}{l}\text { FOR; AG; URBOP; LOW; } \\
\text { MED; HIGH }\end{array}$ & none & $\begin{array}{l}\text { Reflects aggregation of respective land cover types } \\
\text { within focal landscapes. This metric equals }-1 \text { when } \\
\text { the habitat type is maximally spread out, } 0 \text { when } \\
\text { distributed randomly and } 1 \text { when maximally clumped. }\end{array}$ & $\begin{array}{l}\text { Measure of landscape } \\
\text { structure }\end{array}$ \\
\hline IJI_land cover & $\begin{array}{l}\text { Interspersion and } \\
\text { juxtaposition index } \\
\text { of land cover }\end{array}$ & $\begin{array}{l}\text { FOR; AG; URBOP; LOW; } \\
\text { MED; HIGH }\end{array}$ & $\%$ & $\begin{array}{l}\text { Reflects intermixing of a respective land cover class } \\
\text { with all other land cover classes within a focal } \\
\text { landscape. The maximum value }(100 \%) \text { indicates } \\
\text { maximum interspersion and juxtaposition of patches } \\
\text { of a focal land cover type to all other land cover } \\
\text { categories. Larger values indicate greater } \\
\text { fragmentation of a land cover class. }\end{array}$ & $\begin{array}{l}\text { Measure of landscape } \\
\text { structure/fragmentation of } \\
\text { land cover classes }\end{array}$ \\
\hline
\end{tabular}

Table 2.6. Description of all environmental predictor variables used in largest (L2) spatial scale partial redundancy analysis to determine land cover associations of mammalian mesopredators in the Chicago metropolitan area from 2005-2007. 'Land cover classes' indicates all land cover classes for which a respective metric was derived.

Table 2.6 continued... 
Table 2.6 (continued)...

\begin{tabular}{|c|c|c|c|c|c|}
\hline ENV_VAR & Name & Land cover classes & Units & Description & Applicability \\
\hline COHESION_land cover & $\begin{array}{l}\text { Patch cohesion index } \\
\text { of land cover }\end{array}$ & $\begin{array}{l}\text { x FOR; AG; URBOP; LOW; } \\
\text { MED; HIGH }\end{array}$ & none & $\begin{array}{l}\text { Reflects connectedness of respective land cover } \\
\text { classes. Cohesion approaches } 0 \text { when a land cover } \\
\text { class is subdivided and not connected, but increases } \\
\text { when a land cover class becomes more aggregated } \\
\text { and connected. }\end{array}$ & $\begin{array}{l}\text { Measure of landscape } \\
\text { structure and } \\
\text { fragmentation of land } \\
\text { cover classes }\end{array}$ \\
\hline SDI & $\begin{array}{l}\text { Shannon's diversity } \\
\text { index }\end{array}$ & $\begin{array}{l}\text { All land cover classes } \\
\text { combined }\end{array}$ & none & $\begin{array}{l}\text { Reflects amount and evenness of all land cover } \\
\text { classes within a focal landscape. The value of this } \\
\text { index increases as the number of different land cover } \\
\text { classes increase and/or the proportion of land cover } \\
\text { classes becomes more even. }\end{array}$ & $\begin{array}{l}\text { Measure of landscape } \\
\text { structure }\end{array}$ \\
\hline FRAC_AM & $\begin{array}{l}\text { Area-weighted mean } \\
\text { patch fractal } \\
\text { dimension }\end{array}$ & $\begin{array}{l}\text { All land cover classes } \\
\text { combined }\end{array}$ & none & $\begin{array}{l}\text { Index of complexity of patch shapes of all land cover } \\
\text { classifications within individual landscapes. Small } \\
\text { values indicate simple shapes whereas larger values } \\
\text { indicate complex shapes. This index has been shown } \\
\text { to decrease as landscapes become more dominated by } \\
\text { anthropogenic land uses such as ag which typically } \\
\text { show patterns of less complex shapes. }\end{array}$ & $\begin{array}{l}\text { Overall measure of human } \\
\text { influence on the landscape }\end{array}$ \\
\hline CONTAG & Contagion index & $\begin{array}{l}\text { All land cover classes } \\
\text { combined }\end{array}$ & $\%$ & $\begin{array}{l}\text { Reflects dispersion and interspersion of all habitat } \\
\text { classes in a focal landscape. High values of contagion } \\
\text { result from low levels of interspersion and dispersion, } \\
\text { whereas low values of contagion result from high } \\
\text { levels of interspersion and dispersion. }\end{array}$ & $\begin{array}{l}\text { Measure of landscape } \\
\text { structure/fragmentation }\end{array}$ \\
\hline
\end{tabular}




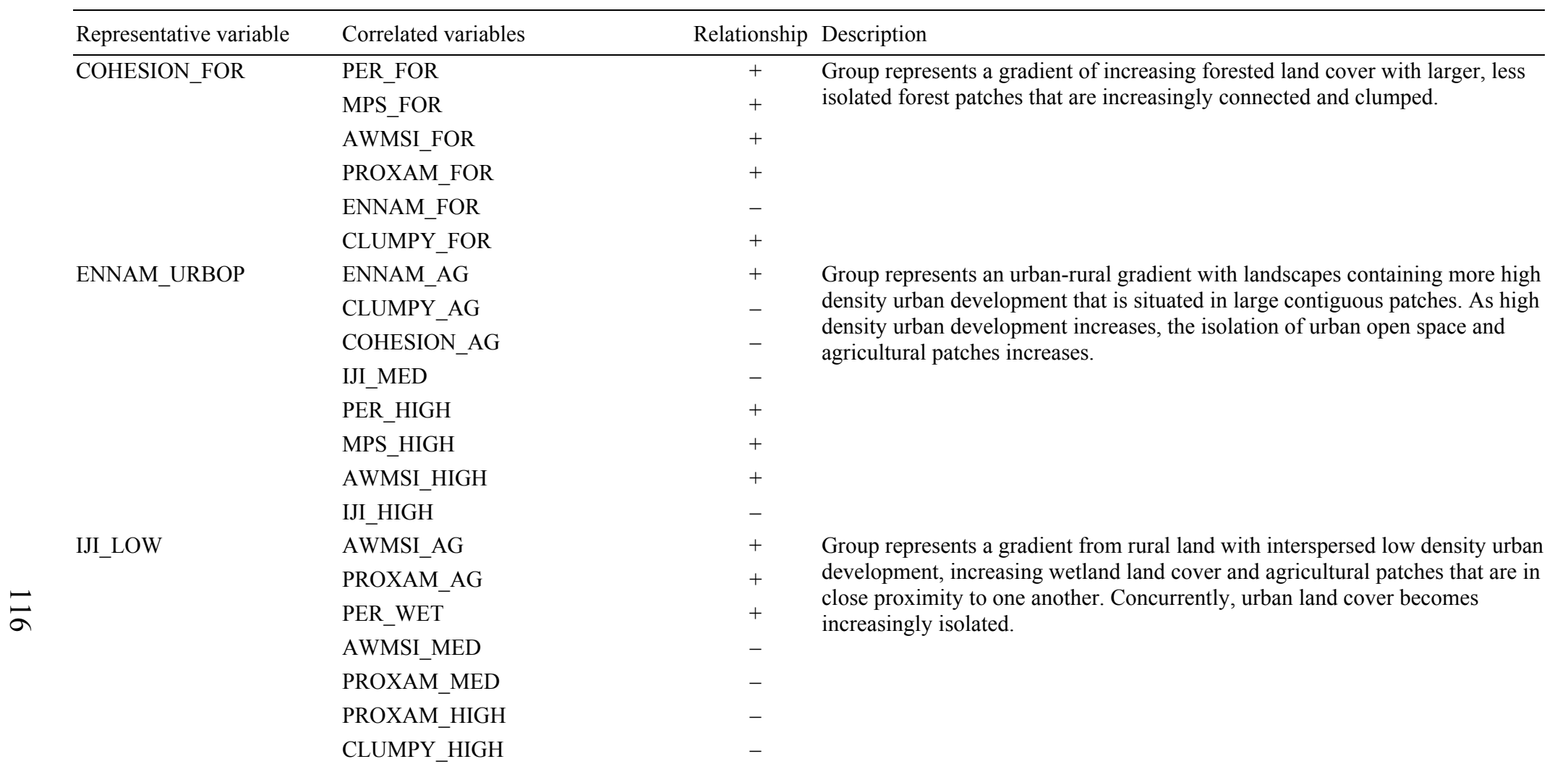

Table 2.7. Results of data reduction step at largest (L2) spatial scale, in which environmental predictor variables were grouped according to correlation coefficients. 'Relationship' indicates the direction of the correlation relative to the representative variable. 'Description' indicates general characteristics of each group of variables.

Table 2.7 continued... 
Table 2.7 (continued)...

\begin{tabular}{|c|c|c|c|}
\hline Representative variable & Correlated variables & Relationship & Description \\
\hline \multirow[t]{6}{*}{ MPS_LOW } & PER_LOW & + & \multirow{6}{*}{$\begin{array}{l}\text { Group represents a gradient of increasing low density urban development } \\
\text { where landscapes exhibit larger, less isolated low density urban patches that are } \\
\text { increasingly connected and clumped. }\end{array}$} \\
\hline & AWMSI_LOW & + & \\
\hline & PROXAM_LOW & + & \\
\hline & ENNAM_LOW & - & \\
\hline & CLUMPY_LOW & + & \\
\hline & COHESION_LOW & + & \\
\hline \multirow[t]{5}{*}{ MPS_MED } & IJI_AG & - & \multirow{5}{*}{$\begin{array}{l}\text { Group represents a suburban-rural gradient as medium density urban } \\
\text { development patches increase in size and are increasingly clumped. The } \\
\text { interspersion of agricultural patches decreases along the the interspersion and } \\
\text { connectedness of urban open space. }\end{array}$} \\
\hline & PER_WATER & + & \\
\hline & IJI_URBOP & - & \\
\hline & COHESION_URBOP & - & \\
\hline & CLUMPY_MED & + & \\
\hline \multirow[t]{8}{*}{ PER_AG } & MPS_AG & + & \multirow{8}{*}{$\begin{array}{l}\text { Group represents a gradient from rural to urban with landscapes exhibiting an } \\
\text { increasing amount of agriculture as well as increasing patch sizes of both } \\
\text { agriculture and urban open space. Concurrently, landscapes contain less } \\
\text { medium and high density urban land cover that is increasingly isolated. }\end{array}$} \\
\hline & MPS_URBOP & + & \\
\hline & CLUMPY_URBOP & + & \\
\hline & PER_MED & - & \\
\hline & ENNAM_MED & + & \\
\hline & COHESION_MED & - & \\
\hline & ENNAM_HIGH & + & \\
\hline & COHESION_HIGH & - & \\
\hline PROXAM_URBOP & AWMSI_URBOP & + & $\begin{array}{l}\text { Group represents a gradient in which landscapes exhibit urban open space } \\
\text { patches with increasingly complex shapes in close proximity to other urban } \\
\text { open space patches. }\end{array}$ \\
\hline \multirow[t]{4}{*}{ SDI } & IJI_FOR & + & \multirow{4}{*}{$\begin{array}{l}\text { Group represents a gradient of fragmentation with increasing land cover class } \\
\text { diversity as well and increasing evenness of land cover classes. The more } \\
\text { fragmented landscapes contain increasing amounts of urban open space as well } \\
\text { as isolated and interspersed forest patches. }\end{array}$} \\
\hline & PER_URBOP & + & \\
\hline & FRAC_AM & - & \\
\hline & CONTAG & - & \\
\hline
\end{tabular}




\begin{tabular}{|c|c|c|c|c|c|c|}
\hline ENV_VAR & Name & Description & Units & Mean \pm SD & Range & Application \\
\hline COHES_FOR & $\begin{array}{l}\text { Patch cohesion index } \\
\text { of forest }\end{array}$ & $\begin{array}{l}\text { Reflects connectedness of forest patches within } \\
\text { respective L } 2 \text { landscapes. Cohesion approaches } 0 \text { as } \\
\text { forest is subdivided and less connected. Cohesion } \\
\text { increases as forest becomes more aggregated and } \\
\text { connected. }\end{array}$ & none & $92.21 \pm 6.44$ & $71.97-97.79$ & $\begin{array}{l}\text { Measure of landscape } \\
\text { structure and } \\
\text { fragmentation of forested } \\
\text { land }\end{array}$ \\
\hline
\end{tabular}

ENNAM_URBOP Area-weighted mean Within respective L2 landscapes, measures mean nearest neighbor for distance between focal urban open space patches and urban open space nearest neighbor urban open space patches within $500 \mathrm{~m}$ land cover search radii.

IJI_LOW Interspersion and Reflects intermixing of low density urban land cover juxtaposition index with all other land cover classes. The maximum value of low density urban indicates maximum interspersion and juxtaposition of

MPS LOW Mean patch size of Sum of areas of low density urban patches within low density urban respective L2 landscapes divided by the number of low patches

meters $\quad 68.92 \pm 9.53 \quad 60.78-94.79$ Measure of isolation of urban open space patches low density urban land cover to all other land cover classes and indicates greater fragmentation of low density urban land cover. density urban patches.
$\%$

$56.49 \pm 9.19$

.

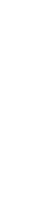
Sum of areas of med density urban patches within respective L2 landscapes divided by the number of med $\begin{array}{ll}\text { med density urban } & \text { respective L2 landscapes } \\ \text { patches } & \text { density urban patches. }\end{array}$
MPS_MED

Table 2.8. Description of final set of environmental predictor variables, after data reduction steps, used in largest (L2) spatial scale partial redundancy analysis to determine land cover associations of mammalian mesopredators in the Chicago metropolitan area from 2005-2007. 'Land cover classes' indicates all land cover classes for which a respective metric was derived.

Table 2.8 continued... 
Table 2.8 (continued)...

\begin{tabular}{|c|c|c|c|c|c|c|}
\hline ENV_VAR & Name & Description & Units & Mean \pm SD & Range & Application \\
\hline no_stn_nights & $\begin{array}{l}\text { Number of station } \\
\text { nights }\end{array}$ & $\begin{array}{l}\text { Total number of survey stations multiplied by the } \\
\text { number of operational nights within respective L } 2 \\
\text { landscapes. }\end{array}$ & $\begin{array}{l}\text { stns } x \\
\text { nights }\end{array}$ & $130.8 \pm 202.3$ & $4-708$ & $\begin{array}{l}\text { Covariable used to adjust } \\
\text { for differences in survey } \\
\text { effort }\end{array}$ \\
\hline no_stns & $\begin{array}{l}\text { Number of survey } \\
\text { stations }\end{array}$ & $\begin{array}{l}\text { Total number of survey stations operated within } \\
\text { respective L2 landscapes. }\end{array}$ & count & $31.8 \pm 49.3$ & $1-182$ & $\begin{array}{l}\text { Covariable used to adjust } \\
\text { for differences in survey } \\
\text { effort }\end{array}$ \\
\hline PER_AG & $\begin{array}{l}\text { Percent of ag land } \\
\text { cover }\end{array}$ & Percent of agriculture in individual L2 landscapes. & $\%$ & $25.52 \pm 30.93$ & $0.03-85.29$ & Landscape structure \\
\hline PROXAM_URBOP & $\begin{array}{l}\text { Area-weighted mean } \\
\text { proximity index of } \\
\text { urban open space }\end{array}$ & $\begin{array}{l}\text { Within respective L2 landscapes, reflects both mean size } \\
\text { and proximity of patches of urban open space within } \\
500 \mathrm{~m} \text { radii around focal patches. The proximity index } \\
\text { increases as the amount of the urban open space } \\
\text { increases. }\end{array}$ & none & $566 \pm 1048$ & $13.2-4104$ & $\begin{array}{l}\text { Measure of isolation of } \\
\text { patches of urban open } \\
\text { space }\end{array}$ \\
\hline SDI & $\begin{array}{l}\text { Shannon's diversity } \\
\text { index }\end{array}$ & $\begin{array}{l}\text { Reflects amount and evenness of all land cover } \\
\text { classifications within respective L } 2 \text { landscapes. The } \\
\text { value of this index increase as the number of different } \\
\text { land cover classes increases and/or the proportion of } \\
\text { land cover classes becomes more even. }\end{array}$ & none & $1.47 \pm 0.39$ & $0.65-1.92$ & $\begin{array}{l}\text { Measure of landscape } \\
\text { structure }\end{array}$ \\
\hline TLA_HA & $\begin{array}{l}\text { Total area measured } \\
\text { in hectares }\end{array}$ & $\begin{array}{l}\text { Total area of respective L2 landscapes including all } \\
\text { habitat classifications. }\end{array}$ & hectares & $25021 \pm 25902$ & $9008-121205$ & $\begin{array}{l}5 \text { Covariable used to adjust } \\
\text { for differences in survey } \\
\text { effort }\end{array}$ \\
\hline
\end{tabular}




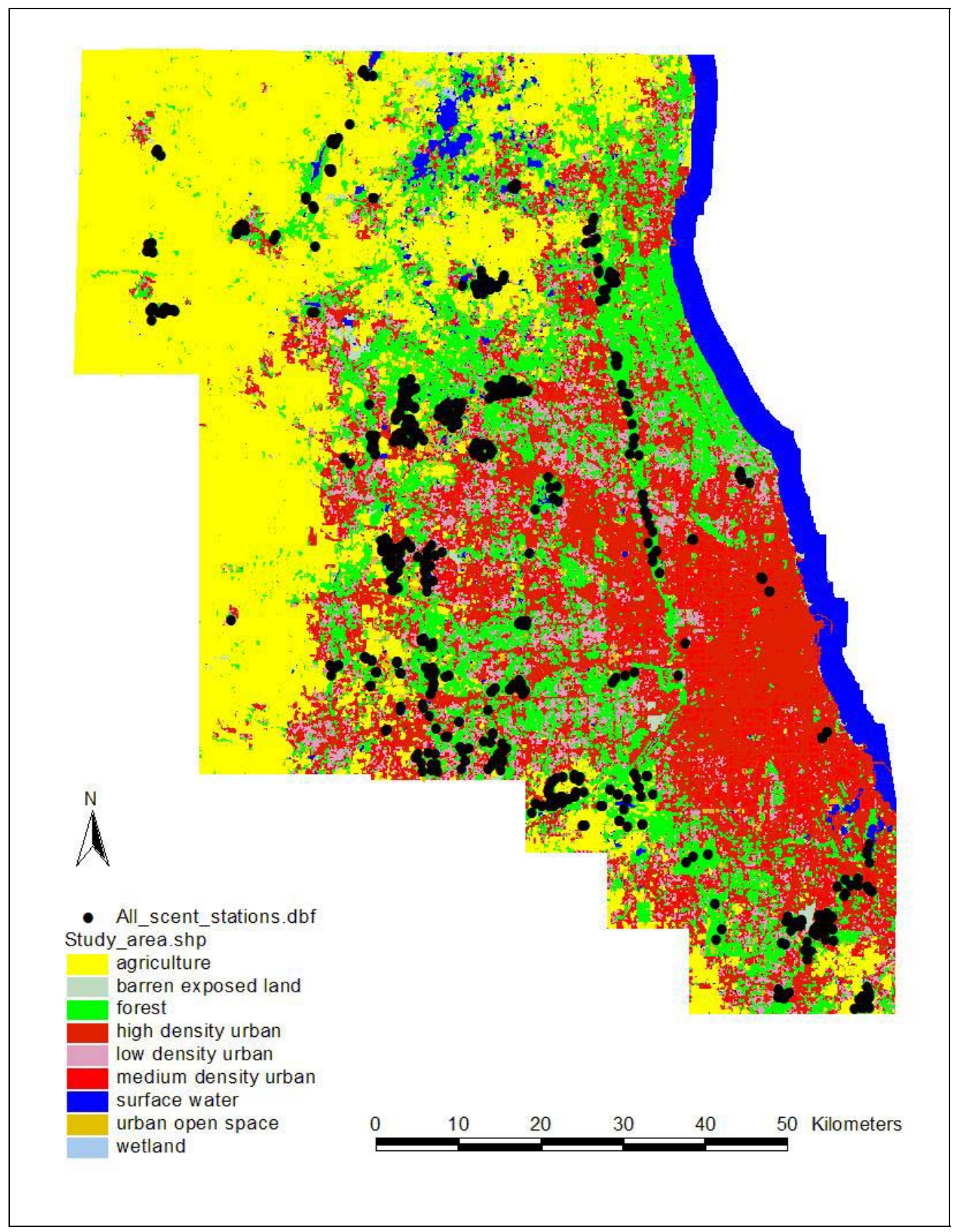

Figure 2.3. Distribution of scent station surveys conducted from 2005-2007 in northeastern Illinois. Black dots indicate scent station placement across the landscape. 


\begin{tabular}{lllll}
\hline ENV_VAR & Axis 1 & Axis 2 & Axis 3 & Axis 4 \\
\hline SUBURBAN & -0.2733 & -0.5149 & 0.7362 & 0.3439 \\
PER_WAT & 0.3853 & -0.5266 & 0.0629 & -0.7551 \\
PER_LOW & 0.3145 & 0.7045 & 0.6226 & -0.1313 \\
PER_HIGH & 0.8051 & -0.2227 & -0.0545 & 0.547 \\
\hline
\end{tabular}

Table 2.9. Correlation matrix from smallest (SS) spatial scale partial redundancy analysis for environmental predictor variables and ordination axes. Description and coding of environmental variables can be found in Table 2.5. 


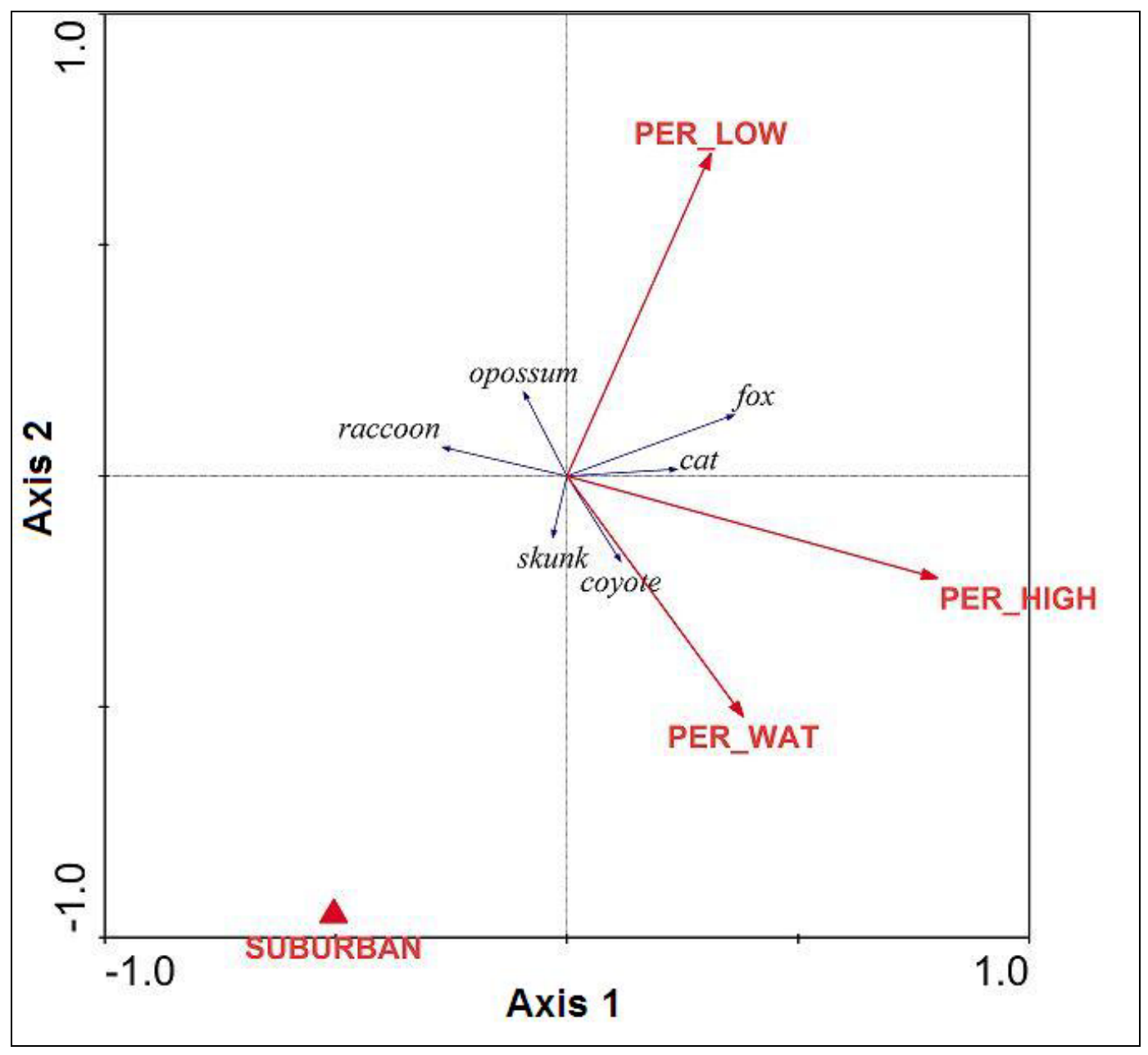

Figure 2.4. Ordination biplot of first and second axes of pRDA at smallest (SS) spatial scale describing association of mammalian mesopredators with environmental predictor variables in the Chicago metropolitan area from 2005-2007. Angles between respective species arrows and other species or environmental arrows indicate the correlation value. The length of arrows indicates the correlation strength with the ordination axes. Explanation of coding of environmental variables can be found in Table 2.5. 


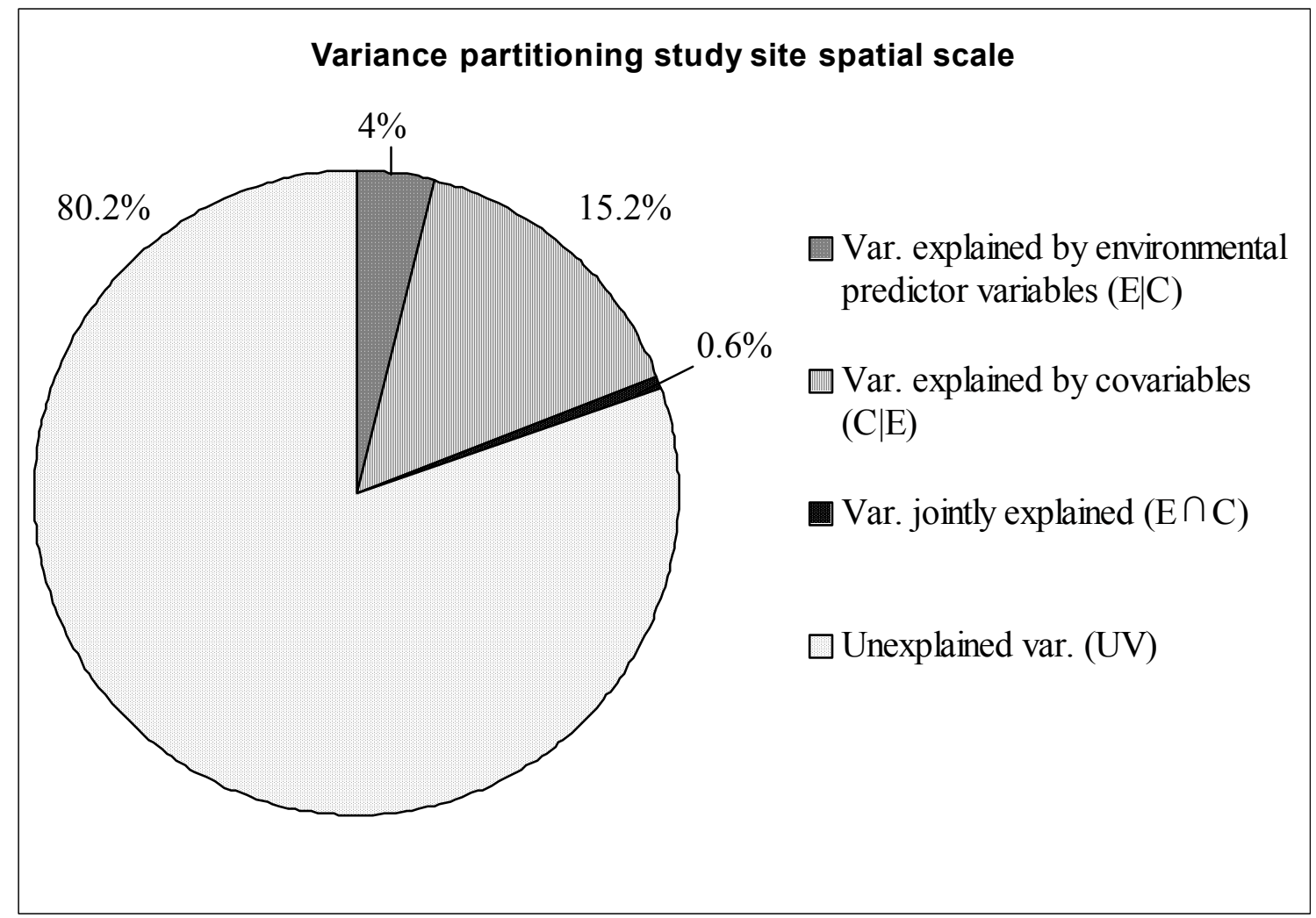

Figure 2.5. Variance partitioning results of partial redundancy analysis at smallest (SS) spatial scale. Reported variance fractions are adjusted $R^{2}$ values. 


\begin{tabular}{lcccc}
\hline ENV_VAR & Axis 1 & Axis 2 & Axis 3 & Axis 4 \\
\hline PER_URBO & -0.1921 & -0.3629 & -0.9118 & -0.0115 \\
PER_LOW & -0.5117 & 0.6064 & -0.2393 & -0.5597 \\
PER_MED & -0.2791 & 0.7905 & -0.203 & 0.5059 \\
PER_HIGH & 0.6651 & 0.5758 & -0.1477 & 0.4519 \\
\hline
\end{tabular}

Table 2.10. Correlation matrix from intermediate (L1) spatial scale partial redundancy analysis for environmental predictor variables and ordination axes. Description and coding of environmental variables can be found in Table 2.6. 


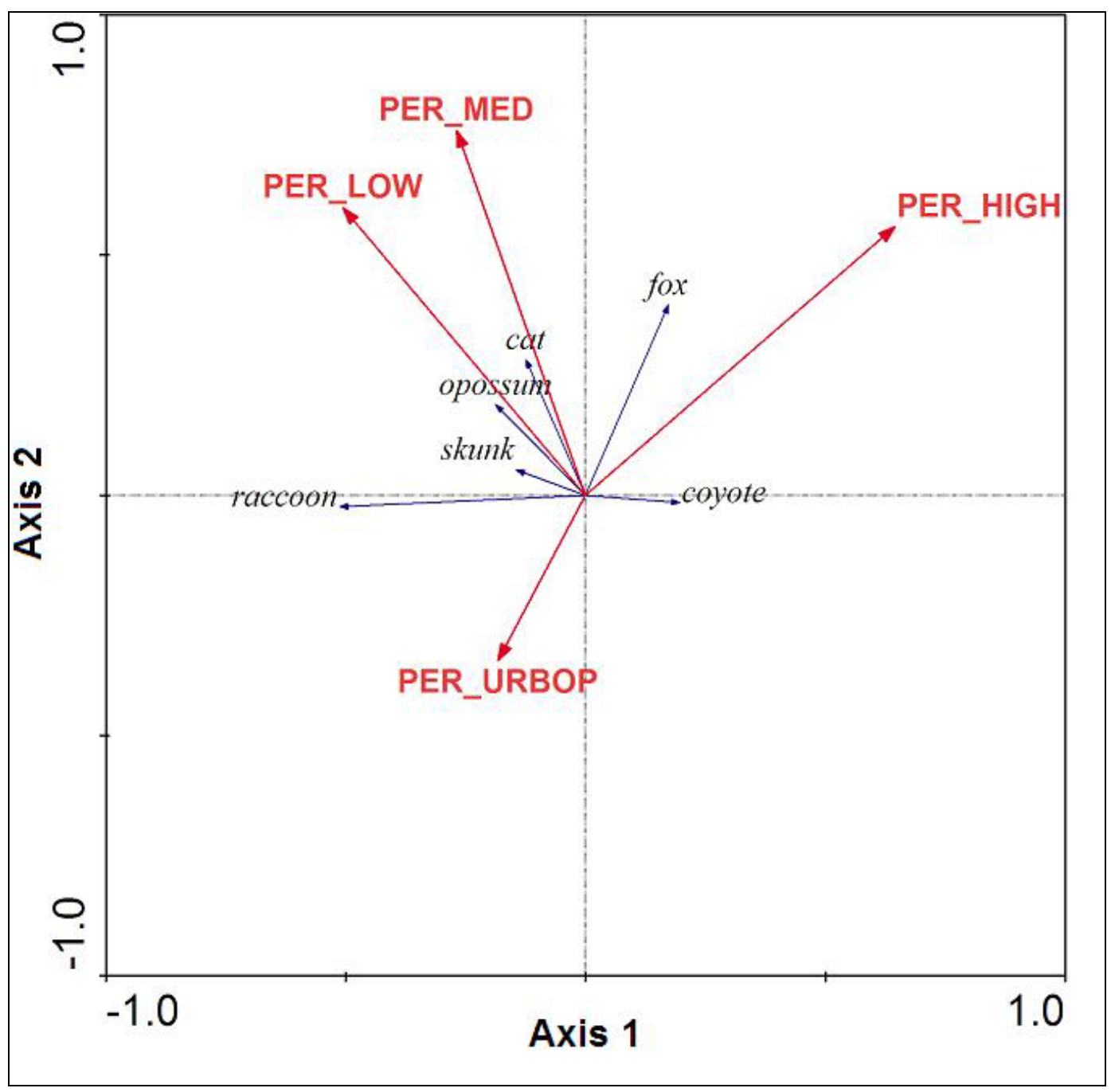

Figure 2.6. Ordination biplot of first and second axes of partial redundancy analysis at intermediate (L1) spatial scale describing the association of mammalian mesopredators with environmental predictor variables in the Chicago metropolitan area from 2005-2007. Angles between respective species arrows and other species or environmental arrows indicate the correlation value. The length of arrows indicates the correlation strength with the ordination axes. Explanation of coding of environmental variables can be found in Table 2.6. 


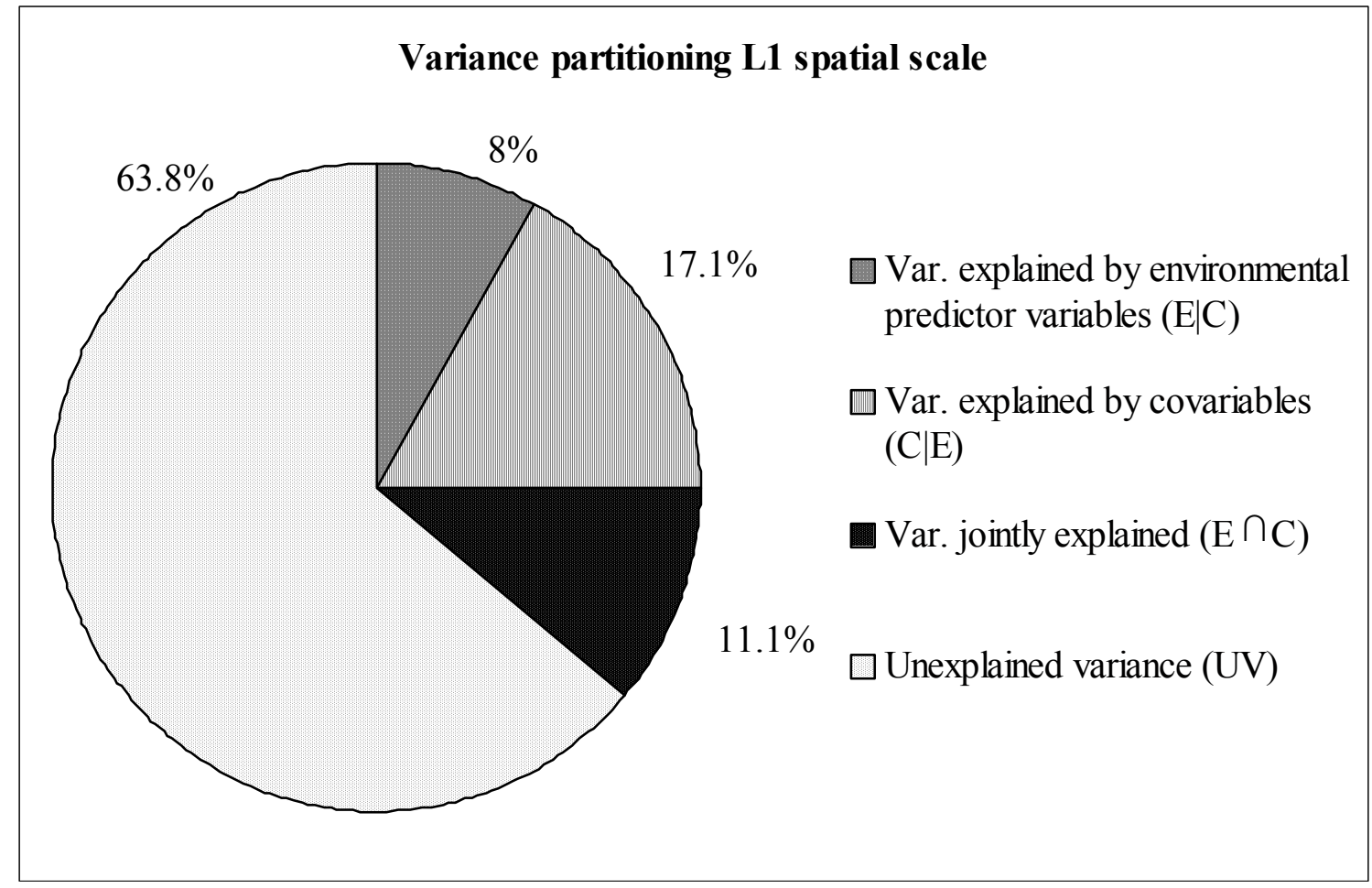

Figure 2.7. Results of variance partitioning procedure for partial redundancy analysis at intermediate (L1) spatial scale. Reported variance fractions are adjusted $R^{2}$ values. 


\begin{tabular}{lcc}
\hline ENV_VAR & Axis 1 & Axis 2 \\
\hline SDI & -0.9906 & 0.1368 \\
ENNAM_URBOP & 0.0851 & 0.9964 \\
\hline
\end{tabular}

Table 2.11. Correlation matrix from largest (L2) spatial scale partial redundancy analysis for environmental predictor variables and ordination axes. Description and coding of environmental variables can be found in Table 2.8 . 


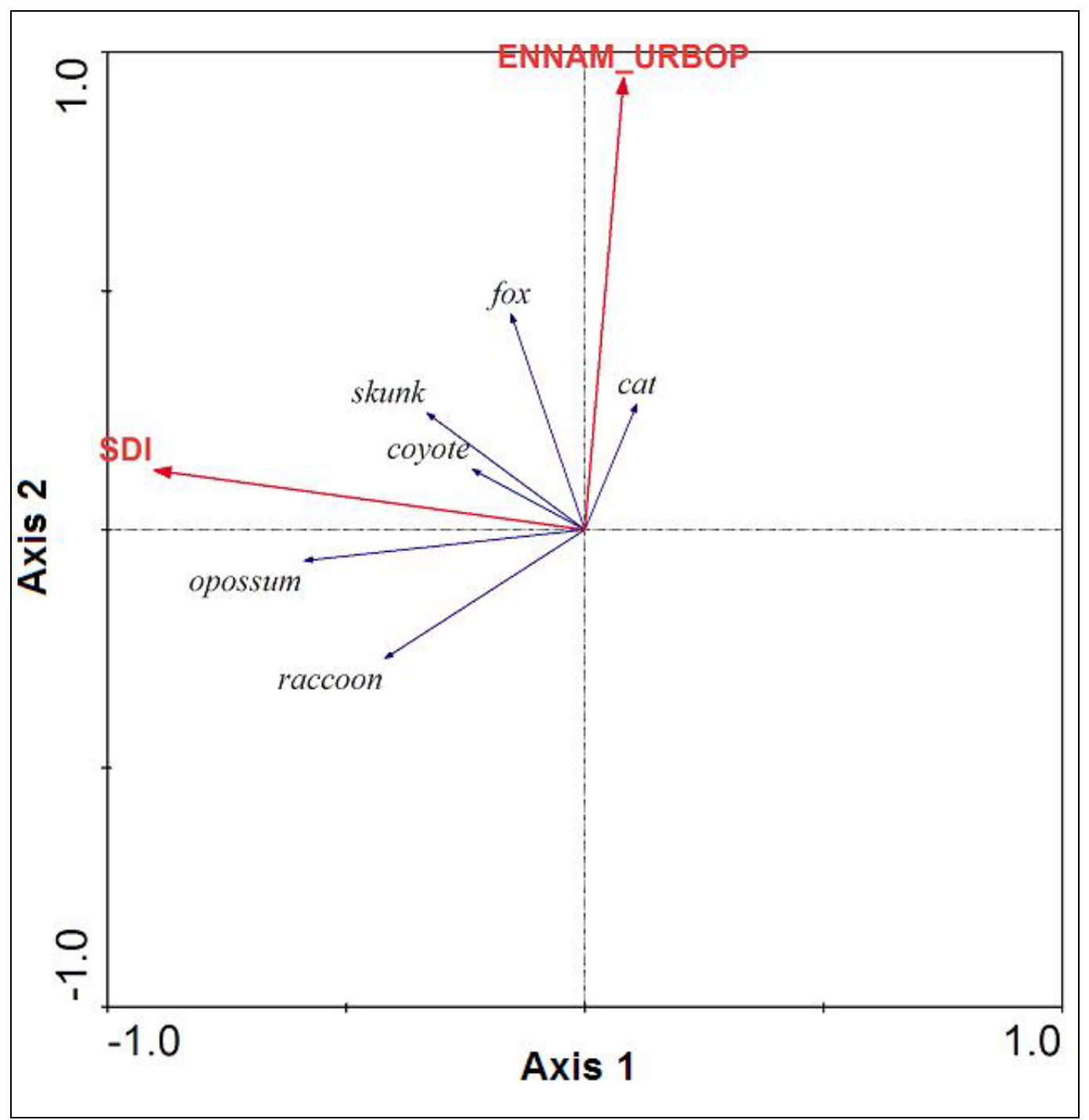

Figure 2.8. Ordination biplot of first and second axes of partial redundancy analysis at largest (L2) spatial scale describing association between mammalian mesopredators and environmental predictor variables in the Chicago metropolitan area from 2005-2007. Angles between respective species arrows and other species or environmental arrows indicate the correlation value. The length of arrows indicates the correlation strength with the ordination axes. Explanation of coding of environmental variables can be found in Table 2.8. 


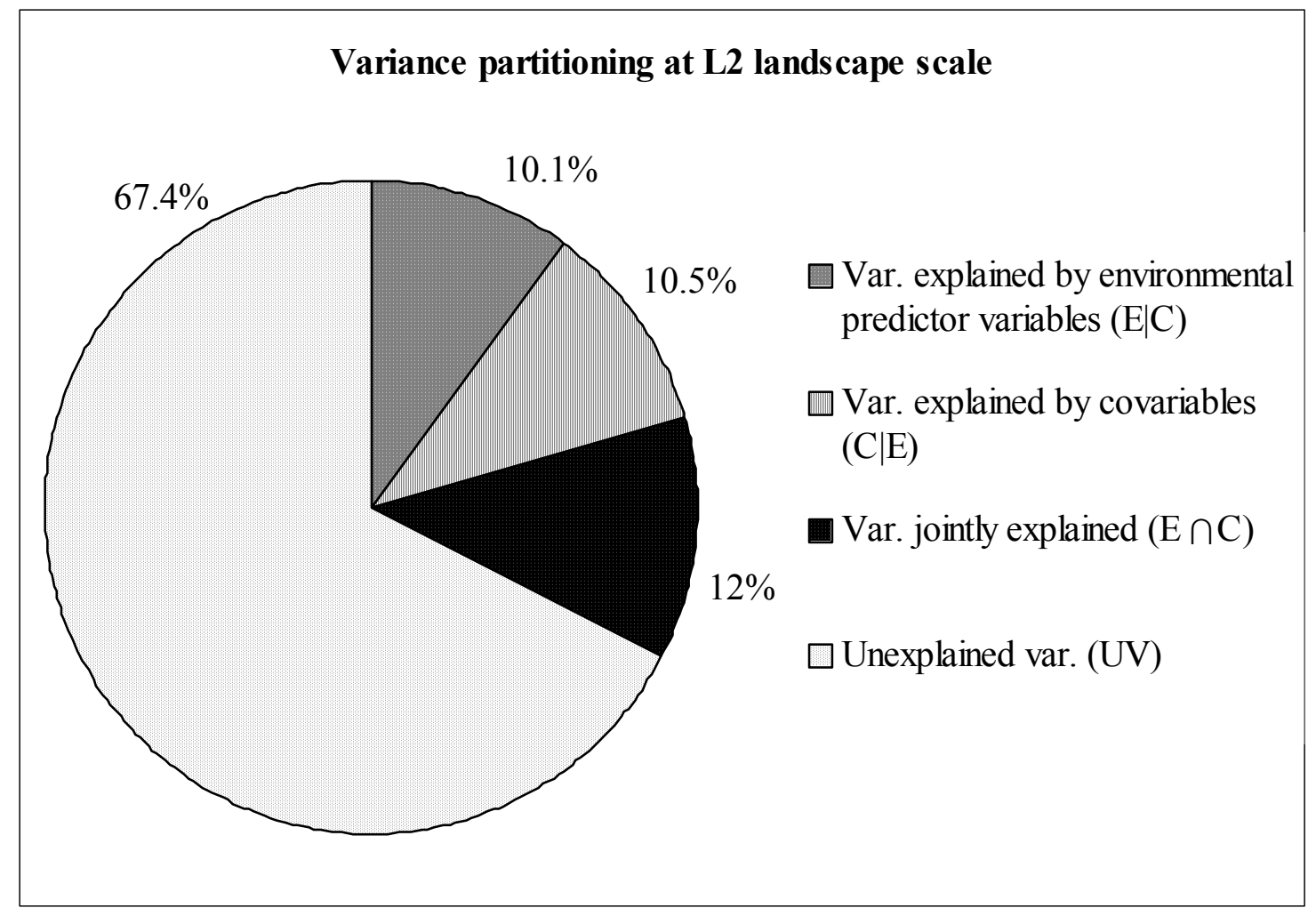

Figure 2.9. Results of variance partitioning procedure for partial redundancy analysis at the largest (L2) spatial scale. Reported variance fractions are adjusted $R^{2}$ values. 


\section{BIBLIOGRAPHY}

Allen, C. H., R. L. Marchinton, and W. Mac Lentz. 1985. Movement, habitat use and denning of opossums in the Georgia Piedmont. American Midland Naturalist 113: 408-412.

Atwood, T. C., H. P. Weeks, and T. M. Gehring. 2004. Spatial ecology of coyotes along a suburban-to-rural gradient. Journal of Wildlife Management 68: 1000-1009.

Baker, P. J., A. J. Bentley, R. J. Ansell, and S. Harris. 2005. Impact of predation by domestic cats (Felis catus) in an urban area. Mammal Review 35: 302-312.

Barratt, D. G. 1997. Home range size, habitat utilization and movement patterns of suburban and farm cats (Felis catus). Ecography 20: 271-280.

Bixler, A., and J. L. Gittleman. 2000. Variation in home range and use of habitat in the striped skunk (Mephitis mephitis). Journal of Zoology, London 251: 525-533.

Bluett, R. 2006. 2005 Illinois Archery Deer Hunter Survey. Wildlife Diversity Program Note 06-4. Illinois Department of Natural Resources, Springfield, Illinois, USA.

Bozek, C. K., S. Prange, and S. D. Gehrt. 2007. The influence of anthropogenic resources on multi-scale habitat selection by raccoons. Urban Ecosystems 10: 413-425.

Burbidge, A. A., and B. F. J. Manly. 2002. Mammal extinctions on Australian islands: causes and conservation implications. Journal of Biogeography 29: 465-473.

Burnham, K. P., and D. R. Anderson. 2002. Model Selection and Multimodel Inference: A Practical Information-Theoretic Approach. Second edition. Springer, New York, New York, USA.

Caro, T. M., J. A. Shargel, and C. J. Stoner. 2000. Frequency of medium-sized mammal road kills in an agricultural landscape in California. American Midland Naturalist 144: 362-369. 
Chamberlain, M. J., and B. D. Leopold. 2005. Overlap and space use among bobcats (Lynx rufus), coyotes (Canis latrans) and gray foxes (Urocyon cinereoargenteus). American Midland Naturalist 153: 171-179.

Chamberlain, M. J., and B. D. Leopold. 2000. Spatial use patterns, seasonal habitat selection, and interactions among adult gray foxes in Mississippi. Journal of Wildlife Management 64: 742-751.

Clarke, A. L., and T. Pacin. 2002. Domestic cat 'colonies' in natural areas: a growing exotic species threat. Natural Areas Journal 22: 154-159.

Crooks, K. R. 2002. Relative sensitivities of mammalian carnivores to habitat fragmentation. Conservation Biology 16: 488-502.

Crooks, K. R., and M. E. Soule. 1999. Mesopredator release and avifaunal extinctions in a fragmented system. Nature 400: 563-566.

Cushman, S. A., and K. McGarigal. 2002. Hierarchical, multi-scale decomposition of species-environment relationships. Landscape Ecology 17: 637-646.

Cypher, B. L. 2003. Foxes. Chapter in Wild Mammals of North America, G. Feldhamer, B. Thompson, and J. Chapman, eds. Pp. 511-546. Second edition. John Hopkins University Press, Baltimore, Maryland, USA.

Cypher, B. L. 1993. Food item use by three sympatric canids in southern Illinois. Transactions of the Illinois State Academy of Science 86: 139-144.

Cypher, B. L., and N. Frost. 1999. Condition of San Joaquin kit foxes in urban and exurban habitats. Journal of Wildlife Management 63: 930-938.

Cypher, B. L., and K. A. Spencer. 1998. Competitive interactions between coyotes and San Joaquin kit foxes. Journal of Mammalogy 79: 204-214.

Davidson, W. R., V. F. Nettles, L. E. Hayes, E. W. Howerth, and C. E. Couvillion. 1992. Diseases diagnosed in gray foxes (Urocyon cinereoargenteus) from the southeastern United States. Journal of Wildlife Diseases 28: 28-33.

Dijak, W. D., and F. R. Thompson III. 2000. Landscape and edge effects on the distribution of mammalian predators in Missouri. Journal of Wildlife Management 64: 209-216.

Erlinge, S., G. Goransson, G. Hogstedt, G. Jansson, O. Liberg, J. Loman, I. N. Nilsson, T. Von Schantz, and M. Sylven. 1984. Can vertebrate predators regulate their prey? The American Naturalist 123: 125-133. 
Farias, V., T. K. Fuller, R. K.Wayne, and R. M. Sauvajot. 2005. Survival and causespecific mortality of gray foxes (Urocyon cinereoargenteus) in southern California. Journal of Zoology, London 266: 249-254.

Fedriani, J. M., T. K. Fuller, and R. M. Sauvajot. 2001. Does availability of anthropogenic food enhance densities of omnivorous animals? An example with coyotes in southern California. Ecography 24: 325-331.

Fedriani, J. M., T. K. Fuller, R. M. Sauvajot, and E. C. York. 2000. Competition and intraguild predation among three sympatric carnivores. Oecologia 125: 258-270.

Follman, E. H. 1973. Comparative ecology and behavior of red and gray foxes. Ph.D. dissertation. Southern Illinois University, Carbondale, Illinois, USA.

Fritzell, E. K. 1987. Gray Fox and Island Gray Fox. Chapter in Wild Furbearer Management and Conservation in North America, M. Novak, J. A. Baker, M. E. Obbard, and B. Malloch, eds. Pp. 408-420. Ministry of Natural Resources, Concord, Ontario, Canada.

Fritzell, E. K., and K. J. Haroldson. 1982. Urocyon cinereoargenteus. Mammalian Species 189: 1-8.

Gardner, A. L. 1982. Virginia Opossum. Chapter in Wild Mammals of North America: Biology, Management, and Economics, J. A. Chapman, and G. A. Feldhamer, eds. Pp. 3-36. John Hopkins University Press, Baltimore, Maryland, USA.

Gardner, A. L., and M. E. Sunquist. 2003. Opossums. Chapter in Wild Mammals of North America, G. Feldhamer, B. Thompson, and J. Chapman, eds. Second edition. Pp. 3-29. John Hopkins University Press, Baltimore, Maryland, USA.

Gehring, T. M., and R. K. Swihart. 2003. Body size, niche breadth, and ecologically scaled responses to habitat fragmentation: mammalian predators in an agricultural landscape. Biological Conservation 109: 283-295.

Gehrt, S. D. 2006. Urban coyote ecology and management: the Cook County, Illinois, coyote project. The Ohio State University Extension Bulletin 929, Columbus, Ohio, USA.

Gehrt, S. D. 2005. Seasonal survival and cause-specific mortality of urban and rural striped skunks in the absence of rabies. Journal of Mammalogy 86: 1164-1170.

Gehrt, S, D., and S. Prange. 2007. Interference competition between coyotes and raccoons: a test of the mesopredator release hypothesis. Behavioral Ecology 18: 204-214. 
Gehrt, S. D., and E. K. Fritzell. 1998. Resource distribution, female home range dispersion and male spatial interactions: group structure in a solitary carnivore. Animal Behaviour 55: 1211-1227.

George, W. G. 1974. Cats as predators and factors in winter shortages of raptor prey. The Wilson Bulletin 86: 384-396.

George, S. L., and K. R. Crooks. 2006. Recreation and large mammal activity in an urban nature reserve. Biological Conservation: 133 107-117.

George, T. L., and S. Zack. 2001. Spatial and temporal considerations in restoring habitat for wildife. Restoration Ecology 9: 272-279.

Gese, E. M., S. M. Karki, M. L. Klavetter, E. R. Schauster, and A. M. Kitchen. 2004. Serologic survey for canine infectious diseases among sympatric swift foxes (Vulpes velox) and coyotes (Canis latrans) in southeastern Colorado. Journal of Wildlife Diseases 40: 741-748.

Ginger, S. M., E. C. Hellgren, M. A. Kasparian, L. P. Levesque, D. M. Engle, and D. M. Leslie, Jr. 2003. Niche shift by Virginia opossum following reduction of a putative competitor, the raccoon. Journal of Mammalogy 84: 1279-1291.

Gipson, P. S., and J. F. Kamler. 2001. Survival and home ranges of opossums in northeastern Kansas. Southwestern Naturalist 46: 178-182.

Godin, A. J. 1982. Striped and Hooded Skunks. Chapter in Wild Mammals of North America: Biology, Management, and Economics, Chapman, J. A., and G. A. Feldhamer, eds. Pp. 674-687. Johns Hopkins University Press, Baltimore, Maryland, USA.

Gompper, M. E. 2002. Top carnivores in the suburbs? Ecological and conservation issues raised by colonization of northeastern North America by coyotes. BioScience 52: 185-191.

Gompper, M. E., R. W. Kays, J. C. Ray, S. D. Lapoint, D. A. Bogan, and J. R. Cryan. 2007. A comparison of noninvasive techniques to survey carnivore communities in northeastern North America. Wildlife Society Bulletin 34: $1142-1151$.

Gosselink, T. E., T. R. Van Deelen, R. E. Warner, and P. C. Mankin. 2007. Survival and cause-specific mortality of red foxes in agricultural and urban areas of Illinois. Journal of Wildlife Management 71: 1862-1873. 
Gosselink, T. E., T. R. Van Deelen, R. E. Warner, and M. G. Joselyn. 2003. Temporal habitat partitioning and spatial use of coyotes and red foxes in east-central Illinois. Journal of Wildlife Management 67: 90-103.

Graser, W. H. 2008. Density, demographic patterns, population structure and pathogen exposure of raccoons in the Chicago metropolitan area. M. S. thesis. The Ohio State University, Columbus, Ohio, USA.

Grinder, M. I., and P. R. Krausman. 2001. Home range, habitat use, and nocturnal activity of coyotes in an urban environment. Journal of Wildlife Management 65: 887-898.

Gustafson, E. J., and G. R. Parker. 1994. Using an index of habitat patch proximity for landscape design. Landscape and Urban Planning 29: 117-130.

Gustine, D. D., K. L. Parker, R. J. Lay, M. P. Gillingham, and D. C. Heard. 2006. Interpreting resource selection at different scales for woodland caribou in the winter. Journal of Wildlife Management 70: 1601-1614.

Haines-Young, R., and M. Chopping. 1996. Quantifying landscape structure: a review of landscape indices and their application to forested landscapes. Progress in Physical Geography 20: 418-445.

Harrison, R. L. 1997. A comparison of gray fox ecology between residential and undeveloped rural landscapes. Journal of Wildlife Management 61: 112-122.

Harrison, R. L. 1993. A survey of anthropogenic ecological factors potentially affecting gray foxes (Urocyon cinereoargenteus) in a rural residential area. Southwestern Naturalist 38: 352-356.

Harrison, D. J., J. A. Bissonette, and J. A. Sherburne. 1989. Spatial relationships between coyotes and red foxes in eastern Maine. Journal of Wildlife Management 53: 181-185.

Hewitt, J. E., S. F. Thrush, V. J. Cummings, and S. J. Turner. 1998. The effect of changing sampling scales on our ability to detect effects of large-scale processes on communities. Journal of Experimental Marine Biology and Ecology 227: 251-264.

Hockman, J. G., and J. A. Chapman. 1983. Comparative feeding habits of red foxes (Vulpes vulpes) and gray foxes (Urocyon cinereoargenteus) in Maryland. American Midland Naturalist 110: 276-285. 
Hoff, G. L., W. J. Bigler, S. J. Proctor, and L. P. Stallings. 1974. Epizootic of canine distemper virus infection among urban raccoons and gray foxes. Journal of Wildlife Diseases 10: 423-428.

Hoffmann, C. O., and J. L. Gottschang. 1977. Numbers, distribution, and movements of a raccoon population in a suburban residential community. Journal of Mammalogy 58: 623-636.

Illinois Agricultural Statistics Supplement. 2004. Illinois county statistics. Illinois Dept. of Agriculture and National Agriculture Statistics Service. 2 Oct. 2006. URL http://www.agstats.state.il.us/ctyest/.

Johnson, D. H. 1980. The comparison of usage and availability measurements for evaluating resource preference. Ecology 61: 65-71.

Kamler, J. F., and P. S. Gipson. 2004. Survival and cause-specific mortality among furbearers in a protected area. American Midland Naturalist 151: 27-34.

Kaufmann, J. H. 1982. Raccoons and Allies. Chapter in Wild Mammals of North America: Biology, Management and Economics, Chapman, J. A., and G. A. Feldhamer, eds. Pp 567-585. Johns Hopkins University Press, Baltimore, Maryland, USA.

Kneitel, J. M., and J. M. Chase. 2004. Trade-offs in community ecology: linking spatial scales and species coexistence. Ecology Letters 7: 69-80.

Kotliar, N. B., and J. A. Wiens. 1990. Multiple scales of patchiness and patch structure: a hierarchical framework for the study of heterogeneity. Oikos 59: 253-260.

Lavin, S. R., T. R. Van Deelen, P. W. Brown, R. E. Warner, and S. H. Ambrose. 2003. Prey use by red foxes (Vulpes vulpes) in urban and rural areas of Illinois. Canadian Journal of Zoology 81: 1070-1082.

Lepczyk, C. A, A. G. Mertig, and J. Liu. 2003. Landowners and cat predation across rural-to-urban landscapes. Biological Conservation 115: 191-201.

Lepš, J., and P. Šmilauer. 2003. Multivariate Analysis of Ecological Data Using CANOCO. Cambridge University Press, Cambridge, England.

Linhart, S. B., and F. F. Knowlton. 1975. Determining the relative abundance of coyotes by scent station lines. Wildlife Society Bulletin 3: 119-124.

Linnel, J. D. C., and O. Strand. 2000. Interference interactions, co-existence and conservation of mammalian carnivores. Diversity and Distributions 6: 169-176 
MacKenzie, D. I., J. D. Nichols, J. A. Royle, K. H. Pollock, L. L. Bailey, and J. E. Hines. 2006. Occupancy Estimation and Modeling: Inferring Patterns and Dynamics of Species Occurrence. Elsevier Inc., San Diego, California, USA.

MacKenzie, D. I., and J. A. Royle. 2005. Designing occupancy studies: general advice and allocating survey effort. Journal of Applied Ecology 42: 1105-1114.

McKinney, M. L. 2002. Urbanization, biodiversity, and conservation. BioScience 52: 883-890.

Moerenschlager, A., R. List, and D. W. Macdonald. 2007. Escaping intraguild predation: Mexican kit foxes survive while coyotes and golden eagles kill Canadian swift foxes. Journal of Mammalogy 88: 1029-1039.

Morey, P. S., E. M. Gese, and S. D. Gehrt. 2007. Spatial and temporal variation in the diet of coyotes in the Chicago metropolitan area. American Midland Naturalist 158: $147-161$.

Nams, V. O. 1990. Locate II User’s Guide. Pacer, Truro, Nova Scotia.

Nassar, R., and J. Mosier. 1991. Projections of pet populations from census demographic data. Journal of the American Veterinary Medical Association 198: 1157-1159.

National Weather Service. 2006. Weather forecast office: Chicago, IL. National Oceanic and Atmospheric Administration. 2 Oct. 2006. URL http://www.crh.noaa.gov/lot/.

Neale, C. C., and B. N. Sacks. 2001. Food habits and space use of gray foxes in relation to sympatric coyotes and bobcats. Canadian Journal of Zoology 79: 1794-1800.

Neiswenter, S. A., and R. C. Dowler. 2007. Habitat use of western spotted skunks and striped skunks in Texas. Journal of Wildlife Management 71: 582-586.

Nelson, J. L., B. L. Cypher, C. D. Bjurlin, and S. Creel. 2007. Effects of habitat on competition between kit foxes and coyotes. Journal of Wildlife Management 71: 1467-1475.

Nicholson, W. S., and E. P. Hill. 1984. Mortality in gray foxes from east-central Alabama. Journal of Wildlife Management 48: 1429-1432.

O’Neill, R. B., J. R. Krummel, R. H. Gardner, G. Sugihara, B. Jackson, D. L. DeAngelis, B. T. Milne, M. G. Turner, B. Zygmunt, S. W. Christensen, V. H. Dale, and R. L. Graham. 1988. Indices of landscape pattern. Landscape Ecology 1: 153-162. 
Oehler, J. D., and J. A. Litvaitis. 1996. The role of spatial scale in understanding responses of medium-sized carnivores to forest fragmentation. Canadian Journal of Zoology 74: 2070-2079.

Openlands Project. 2006. Forest preserve and conservation districts in northeastern Illinois: meeting the challenges of the $21^{\text {st }}$ century. Openlands Project, Chicago, Illinois, USA.

Openlands Project. 1999. Under pressure: land consumption in the Chicago region, 1998-2028. Openlands Project, Chicago Illinois, USA.

Patterson, B. R., and F. Messier. 2001. Social organization and space use of coyotes in eastern Canada relative to prey distribution and abundance. Journal of Mammalogy 82: 463-477.

Peres-Neto, P. R., P. Legendre, S. Dray, and D. Borcard. 2006. Variation partitioning of species data matrices: estimation and comparisons of fractions. Ecology 87: 2614-2625.

Pollock, K. H., S. R. Winterstein, C. M. Bunck, and P. D. Curtis. 1989. Survival analysis in telemetry studies: the staggered entry design. Journal of Wildlife Management 53: 7-15.

Prange, S., and S. D. Gehrt. 2007. Response of skunks to a simulated increase in coyote activity. Journal of Mammalogy 88: 1040-1049.

Prange, S., and S. D. Gehrt. 2004. Changes in mesopredator community structure in response to urbanization. Canadian Journal of Zoology 82: 1804-1817.

Prange, S., S. D. Gehrt, and E. P. Wiggers. 2003. Demographic factors contributing to high raccoon densities in urban landscapes. Journal of Wildlife Management 67: 324-333.

Quinn, T. 1997a. Coyote (Canis latrans) food habits in three urban habitat types of western Washington. Northwest Science 71: 1-5.

Quinn, T. 1997b. Coyote (Canis latrans) habitat selection in urban areas of western Washington via analysis of routine movements. Northwest Science 71: 289-297.

R Development Core Team. 2008. R: A language and environment for statistical computing. R Foundation for Statistical Computing, Vienna, Austria, URL http://www.R-project.org.

Riley, S. P. D. 2006. Spatial ecology of bobcats and gray foxes in urban and rural zones of a national park. Journal of Wildlife Management 70: 1425-1435. 
Riley, S. P. D., J. Foley, and B. Chomel. 2004. Exposure to feline and canine pathogens in bobcats and gray foxes in urban and rural zones of a national park in California. Journal of Wildlife Diseases 40: 11-22.

Riley, S. P. D., R. M. Sauvajot, T. D. Fuller, E. C. York, D. A. Kamradt, C. Bromley, and R. K. Wayne. 2003. Effects of urbanization and habitat fragmentation on bobcats and coyotes in southern California. Conservation Biology 17: 566-576.

Riley, S. P. D., J. Hadidian, and D. A. Manski. 1998. Population density, survival, and rabies in raccoons in an urban national park. Canadian Journal of Zoology 76: $1153-1164$.

Rosatte, R. C., M. J. Power, and C. D. Macinnes. 1992. Density, dispersion, movements and habitat of skunks (Mephitis mephitis) and raccoons (Procyon lotor) in metropolitan Toronto. Chapter in Wildlife 2001: Populations, D. E. McCullough, and R. E. Barratt, eds. Pp. 932-944. Elsevier Science Publishers Ltd., Essex, United Kingdom.

Rosenblatt, D. L., E. J. Heske, S. L. Nelson, D. M. Barber, M. A. Miller, and B. MacAllister. 1999. Forest fragments in east-central Illinois: islands or habitat patches for mammals? American Midland Naturalist 141: 115-123.

Roughton, R. D., and M. W. Sweeny. 1982. Refinements in scent-station methodology for assessing trends in carnivore populations. Journal of Wildlife Management 46: $217-229$.

Sargent, G. A., D. H. Johnson, and W. E. Berg. 1998. Interpreting carnivore scent station surveys. Journal of Wildlife Management 62: 1235-1245.

Sargeant, A. B., S. H. Allen, and J. O. Hastings. 1987. Spatial relations between sympatric coyotes and red foxes in North Dakota. Journal of Wildlife Management 51: 285-293.

Saunders, D. A., R. J. Hobbs, and C. R. Margules. 1991. Biological consequences of ecosystem fragmentation: a review. Conservation Biology 5: 18-32.

Schirer, H. W., and H. S. Fitch. 1970. Comparison from radiotracking of movements and denning habits of the raccoon, striped skunk, and opossum in northeastern Kansas. Journal of Mammalogy 51: 491-503.

Schubert, C. A., I. K. Barker, R. C. Rosatte, and C. D. MacInnes. 1998. Effect of canine distemper on an urban raccoon population: an experiment. Ecological Applications 8: 379-387. 
Senft, R. L., M. B. Coughenour, D. W. Bailey, L. R. Rittenhouse, O. E. Sala, and D. M. Swift. 1987. Large herbivore foraging ecology and ecological hierarchies. BioScience 37: 789-791.

Sheldon, W. G. 1949. Reproductive behavior of foxes in New York state. Journal of Mammalogy 30: 236-246.

Smith, W. S., R. O. Peterson, and D. B. Houston. 2003. Yellowstone after wolves. BioScience 53: 330-340.

Sullivan, J. 2000. An atlas of biodiversity. Chicago Region Biodiversity Council: 64.

Sullivan, E. G. 1956. Gray fox reproduction, denning, range, and weights in Alabama. Journal of Mammalogy 37:346-351.

Swihart, R. K., T. M. Gehring, M. B. Kolozsvary, and T. E. Nupp. 2003. Responses of 'resistant' vertebrates to habitat loss and fragmentation: the importance of niche breadth and range boundaries. Diversity and Distributions 9: 1-18.

Switalski, T. A. 2003. Coyote foraging ecology and vigilance in response to gray wolf reintroduction in Yellowstone national park. Canadian Journal of Zoology 81: 985-993.

ter Braak, C. J. F., and P. Šmilauer. 2002. CANOCO Reference Manual and CanoDraw for Windows User's Guide: Software for Canonical Community Ordination (version 4.5). Microcomputer Power, Ithaca, New York, USA.

Thompson, C. M., and E. M. Gese. 2007. Food webs and intraguild predation: community interactions of a native mesocarnivore. Ecology 88: 334-346.

Tigas, L. A., D. H. Van Vuren, and R. M. Sauvajot. 2002. Behavioral responses of bobcats and coyote to habitat fragmentation and corridors in an urban environment. Biological Conservation 108: 299-306.

Voigt, D. R., and B. D. Earle. 1983. Avoidance of coyotes by red fox families. Journal of Wildlife Management 47: 852-857.

Wade-Smith, J., and B. J. Verts. 1982. Mephitis mephitis. Mammalian Species 173: $1-7$.

Weston, J. L., and I. L. Brisbin. 2003. Demographics of a protected population of gray foxes (Urocyon cinereoargenteus) in South Carolina. Journal of Mammalogy 84: 996-1005. 
White, G. C., and K. P. Burnham. 1999. Program MARK: survival estimation from populations of marked animals. Bird Study 46 Supplement: 120-138.

Wood, J. E. 1958. Age structure and productivity of a gray fox population. Journal of Mammalogy 39: 74-86. 
APPENDIX A. RESULTS OF SCENT STATION SURVEYS FROM 96 STUDY SITES 


\begin{tabular}{|c|c|c|c|c|c|c|c|c|c|}
\hline Study site & TA_HA & no_stns & no_stn_nts & raccoon & opossum & coyote & cat & fox & skunk \\
\hline Auroraven_grd & 26 & 2 & 8 & 1 & 0 & 0 & 0 & 0 & 0 \\
\hline Batavia_grd & 60 & 1 & 4 & 1 & 0 & 0 & 0 & 0 & 0 \\
\hline Bemis_grd & 525 & 4 & 12 & 1 & 0 & 0 & 0 & 0 & 0 \\
\hline Blackwell_grd & 275 & 7 & 32 & 1 & 1 & 1 & 1 & 0 & 1 \\
\hline Bmx_grd & 3 & 4 & 4 & 0 & 0 & 0 & 0 & 1 & 0 \\
\hline Bogerbog_grd & 26 & 1 & 3 & 1 & 0 & 1 & 0 & 0 & 0 \\
\hline Boonecrk_grd & 197 & 4 & 12 & 1 & 0 & 0 & 0 & 0 & 0 \\
\hline Bullvlygc_grd & 98 & 2 & 6 & 0 & 1 & 0 & 0 & 0 & 0 \\
\hline Burnham_grd & 245 & 4 & 18 & 1 & 0 & 1 & 1 & 0 & 0 \\
\hline Busse_grd & 1469 & 6 & 18 & 1 & 1 & 1 & 0 & 0 & 0 \\
\hline Churchill_grd & 119 & 15 & 57 & 1 & 1 & 1 & 1 & 1 & 0 \\
\hline Colakegc_grd & 104 & 2 & 8 & 1 & 0 & 1 & 0 & 0 & 0 \\
\hline Coral_grd & 136 & 9 & 36 & 1 & 1 & 0 & 0 & 1 & 0 \\
\hline Crabtree_grd & 672 & 48 & 210 & 1 & 1 & 1 & 0 & 1 & 1 \\
\hline Daleward_grd & 31 & 5 & 84 & 1 & 1 & 0 & 1 & 1 & 0 \\
\hline Deergrv_grd & 742 & 27 & 121 & 1 & 1 & 1 & 1 & 0 & 1 \\
\hline Desriver_grd & 1247 & 10 & 30 & 1 & 1 & 1 & 0 & 0 & 0 \\
\hline Egermann_grd & 36 & 1 & 5 & 1 & 1 & 0 & 0 & 0 & 0 \\
\hline Elburn_grd & 60 & 1 & 4 & 1 & 1 & 0 & 1 & 0 & 0 \\
\hline Elgin_grd & 60 & 1 & 1 & 0 & 0 & 0 & 0 & 1 & 0 \\
\hline Elizlake_grd & 165 & 4 & 42 & 1 & 1 & 1 & 0 & 0 & 0 \\
\hline Fermi_grd & 2276 & 21 & 73 & 1 & 1 & 1 & 0 & 0 & 1 \\
\hline Forestpk_grd & 60 & 1 & 13 & 1 & 1 & 0 & 1 & 0 & 0 \\
\hline Glacial1_grd & 108 & 12 & 37 & 1 & 1 & 1 & 0 & 1 & 0 \\
\hline Glacial2_grd & 60 & 1 & 2 & 1 & 1 & 1 & 0 & 0 & 0 \\
\hline Glenwood_grd & 282 & 4 & 12 & 1 & 0 & 0 & 0 & 0 & 1 \\
\hline Goodrich_grd & 6 & 1 & 5 & 1 & 1 & 0 & 0 & 0 & 0 \\
\hline Greenevly_grd & 609 & 12 & 60 & 1 & 1 & 1 & 1 & 0 & 1 \\
\hline Harrison_grd & 32 & 4 & 12 & 1 & 0 & 0 & 0 & 0 & 0 \\
\hline Hawk_grd & 326 & 5 & 25 & 1 & 1 & 1 & 1 & 0 & 0 \\
\hline Herrick_grd & 49 & 2 & 8 & 0 & 0 & 1 & 0 & 0 & 1 \\
\hline Hickory_grd & 13 & 2 & 16 & 1 & 1 & 1 & 1 & 0 & 0 \\
\hline Highland_grd & 744 & 13 & 64 & 1 & 1 & 1 & 1 & 0 & 0 \\
\hline
\end{tabular}

Appendix A. Summary of the results of carnivore surveys at 96 study sites including the total area of the study site (TA_HA), total number of stations (no_stns), total number of station nights (no_stn_nts), and the species that were detected (1) or not detected (0) at a site, number of stations, number of station nights, area (ha) and species detected at each of the 96 study sites. 
Appendix A (continued)...

\begin{tabular}{|c|c|c|c|c|c|c|c|c|c|}
\hline Study site & TA_HA & no_stns & no_stn_nts & raccoon & opossum & coyote & cat & fox & skunk \\
\hline Hitchcock_grd & 8 & 1 & 5 & 1 & 1 & 0 & 0 & 0 & 0 \\
\hline Hmwdcem_grd & 44 & 4 & 12 & 1 & 1 & 1 & 0 & 1 & 1 \\
\hline Homedep_grd & 60 & 3 & 4 & 0 & 0 & 1 & 1 & 1 & 0 \\
\hline Idlewild_grd & 58 & 2 & 12 & 1 & 0 & 0 & 1 & 1 & 0 \\
\hline Indepgrv_grd & 484 & 7 & 14 & 1 & 1 & 0 & 0 & 0 & 0 \\
\hline Izkwltn_grd & 155 & 9 & 56 & 1 & 1 & 1 & 1 & 1 & 0 \\
\hline Lakewood_grd & 821 & 22 & 59 & 1 & 1 & 1 & 1 & 0 & 0 \\
\hline Lesarend_grd & 43 & 1 & 4 & 1 & 0 & 0 & 0 & 0 & 0 \\
\hline Macarthur_grd & 208 & 4 & 8 & 1 & 1 & 0 & 0 & 0 & 0 \\
\hline Marengo_grd & 127 & 7 & 21 & 1 & 0 & 0 & 1 & 0 & 0 \\
\hline Maris_grd & 11 & 1 & 7 & 1 & 0 & 0 & 1 & 0 & 0 \\
\hline Mcdow1_grd & 181 & 3 & 12 & 1 & 1 & 1 & 0 & 0 & 0 \\
\hline Mcdow2_grd & 5 & 1 & 4 & 1 & 0 & 0 & 0 & 0 & 0 \\
\hline Mcgraw_grd & 289 & 17 & 62 & 1 & 1 & 1 & 1 & 1 & 0 \\
\hline Mortarb_grd & 751 & 22 & 78 & 1 & 1 & 1 & 0 & 1 & 1 \\
\hline Mtverncem_grd & 31 & 2 & 6 & 1 & 0 & 1 & 0 & 0 & 0 \\
\hline Napcem_grd & 13 & 2 & 8 & 1 & 1 & 0 & 0 & 0 & 0 \\
\hline Oakwood_grd & 73 & 8 & 19 & 1 & 1 & 1 & 1 & 1 & 0 \\
\hline Oldsch1_grd & 180 & 7 & 14 & 1 & 1 & 1 & 0 & 0 & 0 \\
\hline Oldsch2_grd & 10 & 2 & 4 & 1 & 0 & 0 & 0 & 0 & 0 \\
\hline Pepacem_grd & 7 & 1 & 5 & 1 & 1 & 0 & 0 & 0 & 0 \\
\hline Pioneerpk_grd & 7 & 1 & 5 & 0 & 1 & 0 & 0 & 0 & 0 \\
\hline Plumcrk_grd & 460 & 14 & 56 & 1 & 1 & 1 & 1 & 1 & 0 \\
\hline Pratt1_grd & 1528 & 29 & 134 & 1 & 1 & 1 & 1 & 1 & 1 \\
\hline Pratt2_grd & 15 & 1 & 5 & 0 & 0 & 1 & 1 & 0 & 1 \\
\hline Randys_grd & 60 & 1 & 2 & 1 & 0 & 0 & 0 & 0 & 0 \\
\hline Renwood_grd & 42 & 8 & 34 & 1 & 1 & 0 & 1 & 0 & 0 \\
\hline Riveroaks_grd & 84 & 3 & 12 & 1 & 1 & 0 & 0 & 1 & 0 \\
\hline Riverside_grd & 60 & 1 & 5 & 1 & 1 & 0 & 1 & 1 & 0 \\
\hline Rushcrk_grd & 163 & 3 & 9 & 0 & 0 & 0 & 0 & 0 & 0 \\
\hline Ryerson_grd & 201 & 4 & 16 & 1 & 0 & 0 & 0 & 0 & 0 \\
\hline Sagawau_grd & 4422 & 27 & 93 & 1 & 1 & 1 & 0 & 0 & 0 \\
\hline Sandrdg_grd & 249 & 4 & 20 & 1 & 1 & 1 & 1 & 0 & 0 \\
\hline Sauktr_grd & 258 & 5 & 15 & 1 & 0 & 1 & 0 & 0 & 0 \\
\hline Schill1_grd & 109 & 2 & 6 & 0 & 1 & 0 & 0 & 0 & 0 \\
\hline Schill2_grd & 234 & 4 & 12 & 1 & 0 & 0 & 0 & 0 & 0 \\
\hline Schill3_grd & 693 & 5 & 15 & 1 & 1 & 1 & 0 & 0 & 0 \\
\hline Skokie_grd & 240 & 5 & 40 & 1 & 1 & 0 & 1 & 1 & 1 \\
\hline
\end{tabular}

Appendix A continued... 
Appendix A (continued)...

\begin{tabular}{lccccccccc}
\hline Study site & TA_HA & no_stns & no_stn_nts & raccoon & opossum & coyote & cat & fox & skunk \\
\hline Springbrk_grd & 723 & 10 & 40 & 1 & 0 & 1 & 0 & 0 & 1 \\
Springlk_grd & 1746 & 52 & 195 & 1 & 1 & 1 & 1 & 0 & 0 \\
Stmarys_grd & 6 & 2 & 6 & 0 & 0 & 0 & 0 & 0 & 0 \\
Thorncrk_grd & 801 & 26 & 116 & 1 & 1 & 1 & 1 & 1 & 1 \\
Tinley1_grd & 1333 & 3 & 9 & 1 & 0 & 0 & 0 & 0 & 0 \\
Tinley2_grd & 76 & 1 & 3 & 1 & 0 & 0 & 0 & 0 & 0 \\
Tinley3_grd & 347 & 2 & 6 & 0 & 1 & 0 & 0 & 0 & 0 \\
Tylercrk_grd & 31 & 1 & 15 & 1 & 1 & 1 & 0 & 0 & 0 \\
Unionrdg_grd & 6 & 2 & 11 & 1 & 1 & 0 & 1 & 0 & 0 \\
Unknown_grd & 10 & 1 & 5 & 1 & 1 & 0 & 0 & 0 & 0 \\
Walis_grd & 60 & 1 & 7 & 0 & 1 & 0 & 1 & 1 & 0 \\
Warren3_grd & 9 & 2 & 8 & 1 & 1 & 0 & 0 & 0 & 0 \\
Waterfall_grd & 913 & 35 & 136 & 1 & 1 & 1 & 1 & 1 & 1 \\
Wauccem_grd & 3 & 1 & 2 & 0 & 0 & 0 & 0 & 0 & 0 \\
Wdupage_grd & 195 & 7 & 26 & 1 & 1 & 1 & 1 & 0 & 0 \\
Webranch_grd & 370 & 8 & 39 & 1 & 1 & 1 & 1 & 0 & 1 \\
Webrriv1_grd & 1 & 1 & 5 & 1 & 1 & 0 & 1 & 0 & 0 \\
Webrriv2_grd & 5 & 1 & 5 & 1 & 0 & 1 & 0 & 0 & 0 \\
Webrriv3_grd & 9 & 1 & 5 & 1 & 1 & 1 & 0 & 0 & 0 \\
Wedgewood_grd & 116 & 2 & 6 & 1 & 1 & 0 & 0 & 1 & 1 \\
Wentworth_grd & 77 & 3 & 15 & 1 & 1 & 0 & 0 & 0 & 0 \\
Westcem_grd & 12 & 3 & 12 & 1 & 1 & 0 & 0 & 0 & 0 \\
Wilmont_grd & 37 & 1 & 2 & 1 & 0 & 0 & 0 & 0 & 0 \\
Woodridge_grd & 133 & 3 & 9 & 1 & 0 & 0 & 0 & 0 & 0 \\
Woodstock_grd & 109 & 20 & 128 & 1 & 1 & 1 & 1 & 1 & 0 \\
& TOTAL & 668 & 2746 & $86.5 \%$ & $64.6 \%$ & $46.9 \%$ & $36.5 \%$ & $25 \%$ & $17.7 \%$ \\
\hline
\end{tabular}


APPENDIX B. RESULTS OF SCENT STATION SURVEYS FROM 72 UNIQUE LANDSCAPES COMPOSED OF THE STUDY SITE PLUS 1-KM BUFFER AROUND THE STUDY SITE 


\begin{tabular}{|c|c|c|c|c|c|c|c|c|c|}
\hline L1 landscapes & TA_HA & no_stations & no_stn_nights & raccoon & opossum & coyote & cat & fox & skunk \\
\hline Auroraven_grd & 538.92 & 2 & 8 & 1 & 0 & 0 & 0 & 0 & 0 \\
\hline Batavia_grd & 1191.6 & 5 & 20 & 1 & 1 & 0 & 0 & 0 & 0 \\
\hline Bemis grd & 2024.82 & 4 & 12 & 1 & 0 & 0 & 0 & 0 & 0 \\
\hline Blackwell_grd & 2923.47 & 14 & 60 & 1 & 1 & 1 & 1 & 0 & 1 \\
\hline Bmx_grd & 390.42 & 4 & 4 & 0 & 0 & 0 & 0 & 1 & 0 \\
\hline Bogerbog_grd & 542.97 & 1 & 3 & 1 & 0 & 1 & 0 & 0 & 0 \\
\hline Boonecrk_grd & 1206.81 & 4 & 12 & 1 & 0 & 0 & 0 & 0 & 0 \\
\hline Bullvlygc_grd & 1035.99 & 2 & 6 & 0 & 1 & 0 & 0 & 0 & 0 \\
\hline Burnham_grd & 1218.87 & 4 & 18 & 1 & 0 & 1 & 1 & 0 & 0 \\
\hline Busse_grd & 3416.85 & 6 & 18 & 1 & 1 & 1 & 0 & 0 & 0 \\
\hline Churchill_grd & 938.88 & 15 & 57 & 1 & 1 & 1 & 1 & 1 & 0 \\
\hline Coral_grd & 1581.12 & 15 & 127 & 1 & 1 & 0 & 1 & 1 & 0 \\
\hline Countrygc_grd & 958.5 & 2 & 8 & 1 & 0 & 1 & 0 & 0 & 0 \\
\hline Crabtree_grd & 2088.27 & 48 & 210 & 1 & 1 & 1 & 0 & 1 & 1 \\
\hline Deergrv_grd & 2558.88 & 27 & 121 & 1 & 1 & 1 & 1 & 0 & 1 \\
\hline Desriver_grd & 4144.23 & 10 & 30 & 1 & 1 & 1 & 0 & 0 & 0 \\
\hline Elburn_grd & 648.9 & 1 & 4 & 1 & 1 & 0 & 1 & 0 & 0 \\
\hline Elgin_grd & 852.57 & 2 & 16 & 1 & 1 & 1 & 0 & 1 & 0 \\
\hline Elizlake_grd & 1037.97 & 4 & 42 & 1 & 1 & 1 & 0 & 0 & 0 \\
\hline Fermi_grd & 4510.26 & 21 & 73 & 1 & 1 & 1 & 0 & 0 & 1 \\
\hline Forestpk_grd & 648.9 & 1 & 13 & 1 & 1 & 0 & 1 & 0 & 0 \\
\hline Glacial1_grd & 828.36 & 12 & 37 & 1 & 1 & 1 & 0 & 1 & 0 \\
\hline Glacial2_grd & 675.27 & 1 & 2 & 1 & 1 & 1 & 0 & 0 & 0 \\
\hline Glenwood_grd & 1415.61 & 4 & 12 & 1 & 0 & 0 & 0 & 0 & 1 \\
\hline Greenvly_grd & 2857.32 & 16 & 86 & 1 & 1 & 1 & 1 & 0 & 1 \\
\hline Harrison_grd & 575.1 & 4 & 12 & 1 & 0 & 0 & 0 & 0 & 0 \\
\hline Highland_grd & 2187.54 & 13 & 64 & 1 & 1 & 1 & 1 & 0 & 0 \\
\hline Hitchcock_grd & 474.84 & 1 & 5 & 1 & 1 & 0 & 0 & 0 & 0 \\
\hline Homedep_grd & 648.9 & 3 & 4 & 0 & 0 & 1 & 1 & 1 & 0 \\
\hline Idlewild_grd & 667.08 & 2 & 12 & 1 & 0 & 0 & 1 & 1 & 0 \\
\hline Indgrove_grd & 1861.92 & 7 & 14 & 1 & 1 & 0 & 0 & 0 & 0 \\
\hline Izkwltn_grd & 1354.05 & 13 & 68 & 1 & 1 & 1 & 1 & 1 & 1 \\
\hline Lakewd grd & 2996.28 & 23 & 61 & 1 & 1 & 1 & 1 & 0 & 0 \\
\hline
\end{tabular}

Appendix B. Summary of the results of carnivore surveys at 72 unique landscapes including the total area of the study site (TA_HA), total number of stations (no_stns), total number of station nights (no_stn_nts), and the species that were detected (1) or not detected ( 0$)$ at a site, number of stations, number of station nights, area (ha) and species detected at each of the 96 study sites. 
Appendix B (continued)...

\begin{tabular}{|c|c|c|c|c|c|c|c|c|c|}
\hline L1 landscapes & TA_HA nc & 10_stations & no_stn_nights & raccoon & opossum & coyote & cat & fox & skunk \\
\hline Macarthur_grd & 1166.76 & 4 & 8 & 1 & 1 & 0 & 0 & 0 & 0 \\
\hline Marengo_grd & 919.8 & 7 & 21 & 1 & 0 & 0 & 1 & 0 & 0 \\
\hline Maris_grd & 474.93 & 1 & 7 & 1 & 0 & 0 & 1 & 0 & 0 \\
\hline Mcdow2_grd & 739.62 & 3 & 12 & 1 & 1 & 0 & 0 & 0 & 0 \\
\hline Mcgraw_grd & 1346.94 & 17 & 62 & 1 & 1 & 1 & 1 & 1 & 0 \\
\hline Mortarb_grd & 2518.56 & 22 & 78 & 1 & 1 & 1 & 0 & 1 & 1 \\
\hline Mtverncem_grd & 620.01 & 2 & 6 & 1 & 0 & 1 & 0 & 0 & 0 \\
\hline Oakwood_grd & 739.26 & 8 & 19 & 1 & 1 & 1 & 1 & 1 & 0 \\
\hline Oldschl_grd & 1817.46 & 10 & 20 & 1 & 1 & 1 & 0 & 0 & 0 \\
\hline Pepacem_grd & 417.15 & 1 & 5 & 1 & 1 & 0 & 0 & 0 & 0 \\
\hline Plumcrk_grd & 1807.74 & 14 & 56 & 1 & 1 & 1 & 1 & 1 & 0 \\
\hline Pratts_grd & 5658.03 & 35 & 164 & 1 & 1 & 1 & 1 & 1 & 1 \\
\hline Randys_grd & 648.9 & 1 & 2 & 1 & 0 & 0 & 0 & 0 & 0 \\
\hline Renwood_grd & 606.42 & 8 & 34 & 1 & 1 & 0 & 1 & 0 & 0 \\
\hline Riverside_grd & 648.9 & 1 & 5 & 1 & 1 & 0 & 1 & 1 & 0 \\
\hline Rushcrk_grd & 1069.74 & 3 & 9 & 0 & 0 & 0 & 0 & 0 & 0 \\
\hline Ryerson_grd & 1145.43 & 4 & 16 & 1 & 0 & 0 & 0 & 0 & 0 \\
\hline Sagawau_grd & 7912.98 & 27 & 93 & 1 & 1 & 1 & 0 & 0 & 0 \\
\hline Sandrdg_grd & 1668.78 & 7 & 32 & 1 & 1 & 1 & 1 & 1 & 0 \\
\hline Sauktrl_grd & 1250.46 & 5 & 15 & 1 & 0 & 1 & 0 & 0 & 0 \\
\hline Schill1_grd & 1956.24 & 6 & 18 & 1 & 1 & 0 & 0 & 0 & 0 \\
\hline Schill3_grd & 2314.98 & 5 & 15 & 1 & 1 & 1 & 0 & 0 & 0 \\
\hline Skok_grd & 1249.74 & 5 & 40 & 1 & 1 & 0 & 1 & 1 & 1 \\
\hline Springbrk_grd & 2224.53 & 10 & 40 & 1 & 0 & 1 & 0 & 0 & 1 \\
\hline Springlk_grd & 4492.17 & 52 & 195 & 1 & 1 & 1 & 1 & 0 & 0 \\
\hline Stmarys_grd & 426.78 & 2 & 6 & 0 & 0 & 0 & 0 & 0 & 0 \\
\hline Thorncrk_grd & 2354.04 & 26 & 116 & 1 & 1 & 1 & 1 & 1 & 1 \\
\hline Tinley1_grd & 3202.11 & 3 & 9 & 1 & 0 & 0 & 0 & 0 & 0 \\
\hline Tinley2_grd & 742.59 & 1 & 3 & 1 & 0 & 0 & 0 & 0 & 0 \\
\hline Tinley3_grd & 1397.16 & 2 & 6 & 0 & 1 & 0 & 0 & 0 & 0 \\
\hline Unionrdg_grd & 436.41 & 2 & 11 & 1 & 1 & 0 & 1 & 0 & 0 \\
\hline Waterfall_grd & 3468.42 & 35 & 136 & 1 & 1 & 1 & 1 & 1 & 1 \\
\hline Wbrariv_grd & 1173.42 & 5 & 25 & 1 & 1 & 1 & 1 & 0 & 0 \\
\hline Webranch_grd & 1584.54 & 8 & 39 & 1 & 1 & 1 & 1 & 0 & 1 \\
\hline Wedgewood_grd & 874.62 & 2 & 6 & 1 & 1 & 0 & 0 & 1 & 1 \\
\hline Wedupage_grd & 1219.14 & 7 & 26 & 1 & 1 & 1 & 1 & 0 & 0 \\
\hline Wentworth_grd & 828.72 & 3 & 15 & 1 & 1 & 0 & 0 & 0 & 0 \\
\hline Woodridge_grd & 991.17 & 3 & 9 & 1 & 0 & 0 & 0 & 0 & 0 \\
\hline \multirow[t]{2}{*}{ Woodstock_grd } & 855.54 & 20 & 128 & 1 & 1 & 1 & 1 & 1 & 0 \\
\hline & TOTAL & 668 & 2746 & $91.7 \%$ & $68.1 \%$ & $52.8 \%$ & $43.1 \%$ & $29.2 \%$ & $20.8 \%$ \\
\hline
\end{tabular}


APPENDIX C. RESULTS OF SCENT STATION SURVEYS FROM 21 UNIQUE LANDSCAPES COMPOSED OF THE STUDY SITE PLUS 5-KM BUFFER AROUND THE STUDY SITE 


\begin{tabular}{lccccccccc}
\hline NAME & TLA_HA & no_stations & no_stn_nights & raccoon & opossum & cat & coyote & fox & skunk \\
\hline 5kbemis_grd & 23120.10 & 6 & 30 & 1 & 1 & 1 & 0 & 1 & 0 \\
5kbusse_grd & 21589.83 & 7 & 25 & 1 & 1 & 1 & 1 & 0 & 0 \\
5kchurch_grd & 10288.62 & 15 & 57 & 1 & 1 & 1 & 1 & 1 & 0 \\
5kcoral_grd & 12598.02 & 15 & 127 & 1 & 1 & 1 & 0 & 1 & 0 \\
5kdesriv_grd & 44474.85 & 27 & 90 & 1 & 1 & 1 & 1 & 0 & 0 \\
5kelburn_grd & 9280.08 & 1 & 4 & 1 & 1 & 1 & 0 & 0 & 0 \\
5kelgin_grd & 51868.80 & 160 & 670 & 1 & 1 & 1 & 1 & 1 & 1 \\
5kglacial_grd & 46683.72 & 50 & 248 & 1 & 1 & 1 & 1 & 1 & 0 \\
5khomedep_grd & 10723.59 & 7 & 8 & 0 & 0 & 1 & 1 & 1 & 0 \\
5klakewd_grd & 16312.86 & 23 & 61 & 1 & 1 & 1 & 1 & 0 & 0 \\
5kmarengo_grd & 10211.94 & 7 & 21 & 1 & 0 & 1 & 0 & 0 & 0 \\
5koakwood_grd & 9518.04 & 8 & 19 & 1 & 1 & 1 & 1 & 1 & 0 \\
5koldsch_grd & 22317.57 & 21 & 42 & 1 & 1 & 0 & 1 & 0 & 0 \\
5kplumcrk_grd & 11103.03 & 14 & 56 & 1 & 1 & 1 & 1 & 1 & 0 \\
5kpratt_grd & 25708.95 & 43 & 203 & 1 & 1 & 1 & 1 & 1 & 1 \\
5krenwood_grd & 9008.37 & 8 & 34 & 1 & 1 & 1 & 0 & 0 & 0 \\
5krushcr_grd & 10674.90 & 3 & 9 & 0 & 0 & 0 & 0 & 0 & 0 \\
5kskokie_grd & 11429.28 & 5 & 40 & 1 & 1 & 1 & 0 & 1 & 1 \\
5kthorn_grd & 37294.11 & 64 & 288 & 1 & 1 & 1 & 1 & 1 & 1 \\
5kwater_grd & 121205.25 & 182 & 708 & 1 & 1 & 1 & 1 & 1 & 1 \\
5kwedgwd_grd & 10028.79 & 2 & 6 & 1 & 1 & 0 & 0 & 1 & 1 \\
& TOTAL & 668 & 2746 & $90.5 \%$ & $85.7 \%$ & $85.7 \%$ & $61.9 \%$ & $61.9 \%$ & $28.6 \%$ \\
\hline
\end{tabular}

Appendix C. Summary of the results of carnivore surveys at 21 unique landscapes including the total area of the study site (TA_HA), total number of stations (no_stns), total number of station nights (no_stn_nts), and the species that were detected (1) or not detected ( 0 ) at a site, number of stations, number of station nights, area (ha) and species detected at each of the 96 study sites. 